\title{
MODERNIZAÇÃO DA AGRICULTURA: ANÁLISE DE SEIS CULTURAS NO BRASIL
}

\author{
BERNARDO M. T. DE S. PACHECO DE CARVALHO
}

Orientador: Prof. RODOLFO HOFFMANN

Dissertação apresentada à Escola Superior de Agricultura "Luiz de Queiroz", da Universidade de São Paulo, para obtenção do título de Mestre em Economia Agrária.

PIRACICABA

Estado de São Paulo - Brasil

Junho - 1982 
.ii.

A minha Familia

de Portugal

$e$ do Brasil 
- Escola Superior de Agricultura "Luiz de Queiroz" e ao Departamento de Economia e Sociologia Rural que me possibilitaram a realizaçāo do curso de Pós Graduação em Economia Agrária.

- Ao Conselho Nacional de Pesquisa, Ciência e Tecnologia (CNPq) que permitiu uma maior dedicaçāo na con diçāo de bolsista dessa entidade.

- Ao Prof. Rodolfo Hoffmann pela constante e criteriosa orientaçāo.

- Aos Professores Geraldo Sant'Atar de Camargo Barros e Cicely Moitinho do Amaral pelas críticas e sugestöes apontadas no texto original.

- A todos os Professores e Funcionários do Departamento de Economia e Sociologia Rural, que direta ou indiretamente colaboraram na realizaçāo deste trabalho.

- A todos os amigos e colegas do Departamen-to de Economia e Sociologia Rural da ESALQ que, direta ou indiretamente, contribuiram para a execução desta pesqui̇ia. 
.iv.

INDICE

página

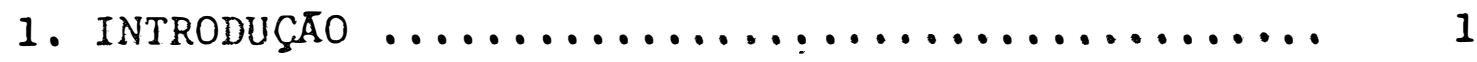

1.1. Objetivos ....................... 3

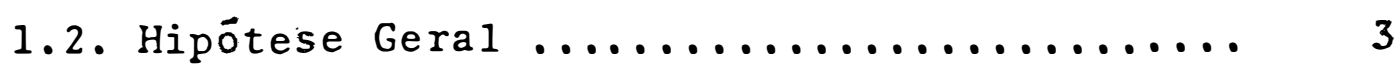

1.3. Hipóteses Específicas .............. 3

2. REVISAOO BIBLIOGRAFICA $\ldots \ldots \ldots \ldots \ldots \ldots \ldots \ldots \ldots, 5$

2.1. "Dualismo" ..................... 8

2.2. Aspectos da Teoria da Modernização Amplamen te Reconhecidos .................... 12

2.3. Modernização e Diferentes Características dos Produtos Agrícolas ............... 17

2.3.1. Produto Exportável ............. 20

2.3.2. Industrialização do Produto Agrícola 23

2.3.3. Produtos de Alimentação Básica ..... 23

2.3.4. Concentração e Distribuição Geográfí

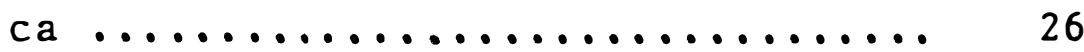

2.3.5. Disponibilidade de Tecnologia ..... 27

2.3.6. Grau de Acesso às Políticas Agrícolas .......................... 29

2.4. Subdivisōes da Agricultura .......... 30

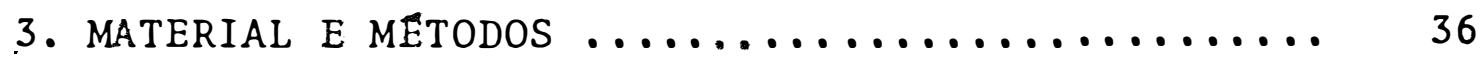

3.1. Análise Discriminante ............... 55

3.2. Anālise Fàtorial ................. 73

3.2.1. Componentes Principais .......... 74

3.2.2. Método dos Fatores Principais ..... 84

4. RESUltados DA ANÁLISE FATORIAL $\ldots \ldots \ldots \ldots \ldots . . . .94$

5. ANALISE DOS VALORES DOS FATORES ............. 108

5.1. Relação entre Produtividade e Valores dos Fatores ......................... 108 
pāgina.

5.2. Anālise Discriminante a partir dos valores

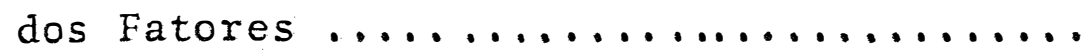

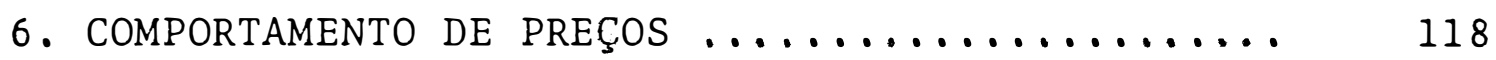

7. DISTRI BUIÇÃO GEOGRĀFICA E CREDITO RURAL ....... 129

7.1. Distribuição geogräfica ............. 130

7.2. Crëdito rural $\ldots \ldots \ldots \ldots \ldots \ldots \ldots \ldots .140$

8. Discussão dos Resultados e conclusoes ......... 151

LITERATURA CITAdA $\ldots \ldots \ldots \ldots \ldots \ldots \ldots \ldots \ldots \ldots \ldots$

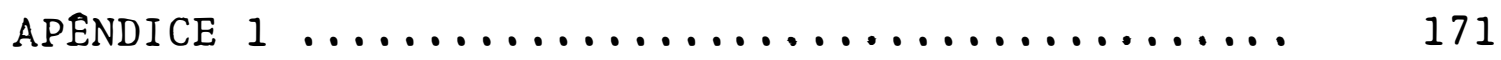

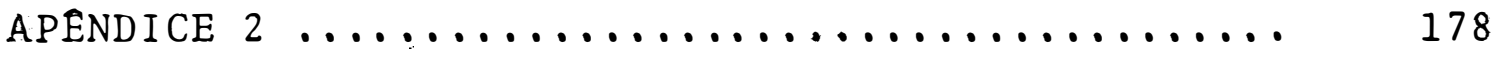

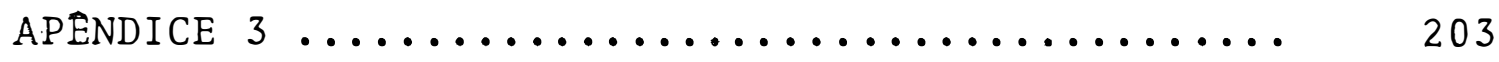


Tabela 1. Indice de Instabilidade de Preços e Produtividade para Alguns Produtos em S. Paulo.

Tabela 2. Area Colhida e Valor da Produção das Principais Culturas Brasileiras em 1974 para o Brasil

Tabela 3. Fração do Número de Informantes, Quantidade Produzida, Area e Valor da Produção obtida em função de Culturas com uso de Se=

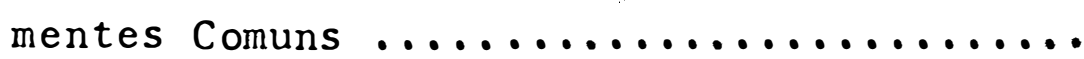

Tabela 4. Fração do Nưmero de Informantes, Quantidade Produzida, Area e Valor da Produção obtida por produtores classificados como Pro

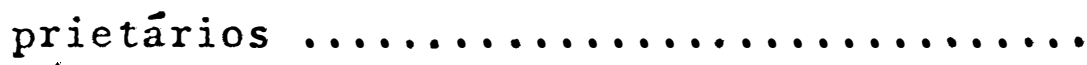

Tabela 5. Fração do Nưmero de Informantes, Quantidade Produzida, Area e Valor da Produção obtida por Produtores Classificados como Par

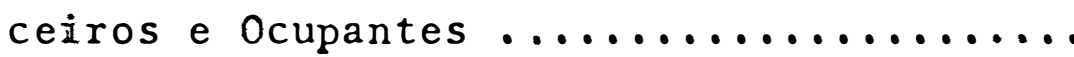

Tabela 6. Fração do Nưmero de Informantes, Quantidade Produzida, Area e Valor da Produção obtida por produtores classificados como Arrendatärios $\ldots \ldots \ldots \ldots \ldots \ldots \ldots \ldots \ldots \ldots$

Tabela 7. Fração do Número de Informantes, Quantidade Produzida e Área Obtida em funçãa de cul turas em cultivo simples $\ldots \ldots \ldots \ldots \ldots \ldots$

Tabela 8. Fração do Nưmero de Informantés, Quantida- 
dade produzida, área e valor obtida em Função de Culturas cujo Destino é o Consu

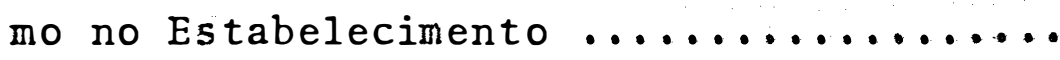

Tabela 9. Fração do número de informantes, quantida de produzida, ärea e valor obtida em função de culturas cujo destino é a venda di

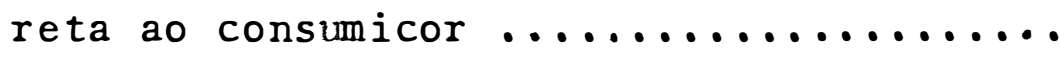

Tabela 10. Fração do número de informantes, quantida de produzida, ārea e valor obtida em função de culturas cujo destino é a venda a

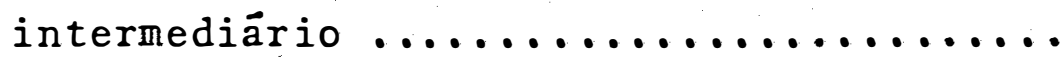

Tabela 11. Fração do nümero de informantes, quantida de produzida e área obtida por produtores classificados como parceiros e ocupantes para 1970 e 1975

Tabela 12. Fração do número de informantes, quantida de produzida e área obtida em função de culturas em cultivo simples para 1970 e 1975

Tabela 13. Valores agregados das várias variáveis cạ culados a partir da média aritmética do conjunto de valores das culturas por Esta

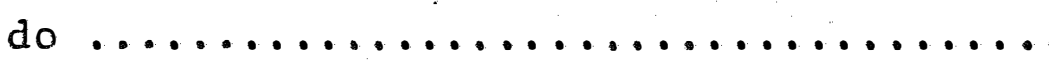

Tabela 14. Matriz de correlaçōes simples, para o con junto das 11 variâveis consideradas, incluindo a variável dependente $Y$ que assume exclusivamente valores 0 a 1 de acordo com o tipo de cultura ............... 
.viii.

pägina

Tabela 15. Anālise de regressão linear multipla. Variações nos ajustamentos com eliminação de variāveis altamente correlacionadas .....

Tabela 16. Matriz de correlações simples para o Grupo A, culturas "Não-Modernas" (arroz, fe jão e milho) $\ldots \ldots \ldots \ldots \ldots \ldots \ldots \ldots \ldots$

Tabela 17. Matriz de correlações simples para o Grupo B, culturas "Modernas" (algodão, cana-

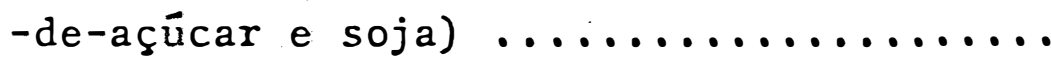

Tabela 18. Média e desvio padrão das variâveis nos dois grupos de culturas ............. 66

Tabela 19. Estimativas dos parâmetros e do valor médio da função de duas funções discriminan tes com alterações no conjunto de variāveis utilizadas procurando eliminar problemas de multicolinearidade ...........

Tabela 20. Listagem dos resultados obtidos por cultu ra e por estado do valor da função discri minante nos dois modelos considerados, com a respectiva classificação; Grupo A: culturas "não-modernas"; Grupo B: culturas "modernas" .........................

Tabela 21. Resultados da análise fatorial; raízes ca racterísticas e percentagem acumulada no

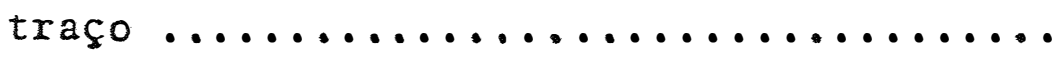

Tabela 22. Matriz inicial dos "Pesos dos Fatores" 
("fator loadings"). "Normalized Unro-

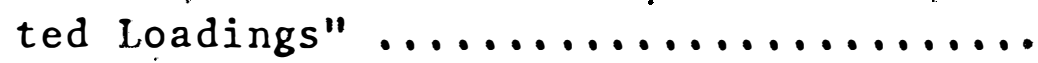

Tabela 23. Matriz dos pesos dos fatores após Rota çāo Ortogonal Varimax ...............

Tabela 24. Resultados obtidos nos ajustamentos de funçōes por cultura; a variável dependen te consiste na méaia aritmética da produ tividade nos anos de 1974, 1975 e 1976 e as variáveis independentes são os valo

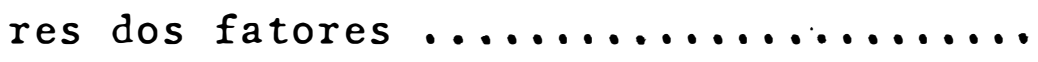

Tabela 25. Valores do desvio padrão da variável dependente (produtividade) dividido pela média respectiva de cada cultura e os respectivos coeficientes de determinação obtidos nos diversos ajustamentos ......

Tabela 26. Valor da função discriminante e respecti va classificação: 1. incluindo todos os fatores; 2. incluindo os dois primeiros fatores; 3 . incluindo somente os valores do fator $1 \ldots \ldots \ldots \ldots \ldots \ldots \ldots \ldots$

Tabela 27. Razão entre :preços médios recebidos pelos agricultores e preços médios: Inter nacionais em $\operatorname{Cr} \$, 1948 / 65 \ldots \ldots \ldots \ldots \ldots$

Tabela 28. Razão entre preços médios recebidos pelos agricultores e preços médios-interna cionais em Cr $\$$. 1966/77 ............. 
Tabela 29. Indices de Gini da distribuição da ārea de colheita por cultura e por estado para

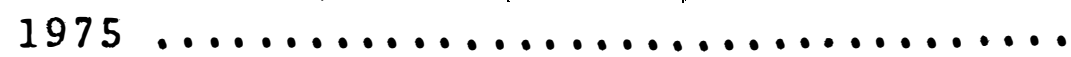

Tabela 30. Indices de Gini da distribuição da área de colheita para o Brasil, 1975 ........

Tabela 31. Indices de concentração da distribuição de estabelecimentos segundo a atividade econômica em 1970 e 1975 para o Brasil ....

Tabela 32. Distribuição da produção por região e por estado em termos de proporçōes de quantidade produzida e área de produção ......

Tabela 33. Gráficos circulares, mostrando a distribuição por estado da quantidade produzida em ordem decrescente de $\dot{v}$ alor percentual segundo a Tabela $32 \ldots \ldots \ldots \ldots \ldots \ldots$

Tabela 34. Indice de Gini da distribuição do crédito para a agricultura concedido pelo Banćo do Brasil de acordo com o valor dos con-

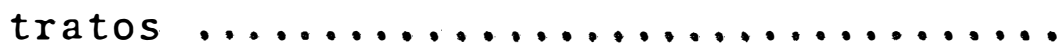

Tabela 35. Percentagem da área, valor da produção e crédito rural recebido em relação ao total, pelos diferentes estratos, segundo os Censos Agropecuários de 1970 e 1975 ....

Tabela 36. Participação percentual do $n^{9}$ de estabele cimentos, área, valor da produção, emprés timos obtidos por estabelecimento e distri 
buição regional do valor dos empréstimos, por região do Brasil, $1970 \ldots \ldots \ldots \ldots \ldots .144$

Tabela 37. Participação percentual do $n^{\circ}$ de estabele cimentos, ärea, valor da produção, emprés timos obtidos por estabelecimento e dis tribuição regional do valor dos empres̄timos, por região do Brasil, 1975 ........

Tabela 38. Distribuição do crédito de custeio entre culturas em $n^{\circ}$ de contratos e valor .....

Tabela 39. Distribuição do crédito de comercialização entre culturas em $\mathrm{n}^{8}$ de contratos e valor $\ldots \ldots \ldots \ldots \ldots \ldots \ldots \ldots \ldots \ldots \ldots$

Tabela 40. Relaçōes entre valor de crédito e valor da produção com o respectivo valor médio do contrato de custeio por cultura ..... 148 
.xii.

LISTA DE FIGURAS

pägina

Figura 1. Conceito de "Excedente" do Produtor e Consumidor $\ldots \ldots \ldots \ldots \ldots \ldots \ldots \ldots \ldots \ldots \ldots$

Figura 2. Alteraçōes nos "Excedentes" de acordo com modificaçōes na inclinação da curva de demanda $\ldots \ldots \ldots \ldots \ldots \ldots \ldots \ldots \ldots \ldots \ldots$

Figura 3. Anălise discriminante ............ 58 
Gráfico 1. Valores dos fatores ortogonais 1 e 2, para a cultura de algodão, por Estado ..... 101

Gráfico 2. Valores dos fatores ortogonais 1 e 2, para a cultura de cana-de-açücar, por Esta-

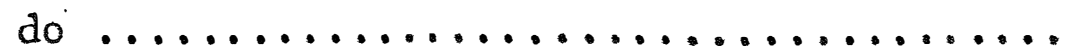

Gräfico 3. Valores dos fatores ortogonais, para a cultura de-soja, por Estado .......... 103

Gráfico 4. Valores dos fatores ortogonais, para a cultura de arroz, por Estado ......... 104

Gräfico 5. Valores dos fatores ortogonais, para a cultura de feijão, por Estado .......... 105

Gráfico 6. Valores dos fatores ortogonais, para a cultura de milho, por Estado .......... 106

Gräfico 7. Razão entre preços médios segundo as tabe

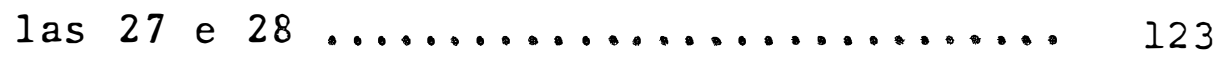

Gräfico 8. Evolução da produtividade da soja, Brasil 123

Gräfico 9. Razão entre preços médios, segundo as tabelas 27 e 28 para a cultura de algodão. 124

Gräfico 10. Evolução da produtividade da cultura de

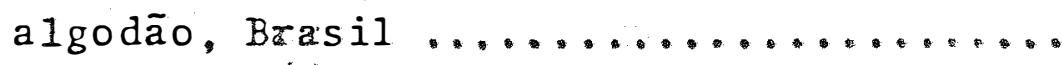

Gráfico 1l.Razão entre preços médios seguncio as tabe las 27 e 28 para a cultura de cana-de-zéu

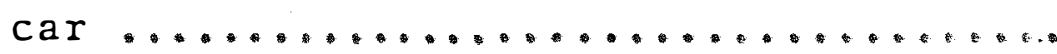


.xiv.

pägina,

Gräfico 12. Evolução da produtividade da cana-de-açŭ car, Brasil .................... 125

Gräfico 13. Razão entre preços médios, segundo as ta belas 27 e 28 , para a cultura de milho • 126

Gráfico 14. Evolução da produtividade do milho, Brasil ........................ 126 
RESUMO

\author{
MODERNIZAÇAO DA AGRICULTURA: \\ ANÁLISE DE SEIS CULTURAS NO BRASIL
}

Autor: BERNARDO M.T. DE S.PACHECO DE CARVALHO Orientador: Prof. RODOLFO HOFFMANN

0 presente estudo procura caracterizar um grupo de culturas que seja razoavelmente representativo da agricultura brasileira. As culturas selecionadas foram algodão, cana-de-açūcar, soja, arroz, feijão e milho. Utilizou-se basicamente dados do Censo Agropecuärio de 1975, cal culando o valor de 11 variäveis para cada uma das seis culturas em cada um dos Estados da Federação, onde são ativida des importantes da agropecuária, à exceção da região Norte. Essas variáveis foram selecionadas de maneira a caracterizar 3 aspectos de cada cultura: nível tecnológico, estrutura de produção e de comercialização. Com esse conjunto de variāveis foram feitas análises estatísticas (anālise discriminante e fatorial) visando evidenciar as diferenças entre grupos de culturas com caracteristicas distintas: de um lado produtos alimentares e, de outro lado, produtos exportados e industrializados. Evidenciou-se também a estrutura de relações entre as variâveis, construindo-se indices suscetíveis de utilização na caracterização dos vários aspectos do sistema produtivo, permitindo comparações entre culturas e até mesmo entre rẹ̆iões.

Neste contexto encontra-se fundamento para uma anIise do setor agrícola numa perspectiva "dualista". Evidenciou-se o menor desenvolvimento tecnológico (menor modernização) dos produtos tipicamente alimentares e ve 
rificou-se que o relativo atraso técnico dessas culturas tem-se mantido ou agravado ao longo do tempo, com prováveis consequências nos pröprios preços desses produtos. Argumen ta-se que a modernização desses produtos ocorre em ültimo lugar, assinalando-se tambêm, a maior homogeneidade entre culturas em regiões mais desenvolvidas.

Todo o esforço desenvolvido insere-se numa tentativa de identificar fatores importantes e suas inter relações no processo de modernização a nível macroeconômico, em função da influência que exercem na alocação e geração de "excedentes" na agricultura. Procura-se contribuir para o melhor desempenho de politicas agrícolas e para o mais rápido processo de modernização, dentro de uma preocupação de identificação e realização de "excedentes potenciais". 


\section{SUMMARY}

MODERNIZATION OF AGRICULTURE:

ANALYSIS OF SIX CROPS IN BRAZIL

Author: BERNARDO M.T.DE S. PACHECO DE CARVALHO Adviser: Prof. RODOLFO HOFFMAN

The objective of this study was to

characterize a group of six crops which are reasonably representative of Brazilian agriculture. Cotton, sugarcane, soybeans, rice, beans, and corn were the crops selected. Basically, data from the "Censo Agropecuário de 1975" were utilized. The value of 11 varibles was computed for each of the six crops, in each state of the country where they are important agricultural activities, with the exception of the North region. Statistical analysis (discriminant and factorial) were carried out with the set of variables in order to establish the differences between crops with distinct characteristics: on one side food products, and on the other, export and industrialized products. The factor analysis shows the structure of the relationships between variables. The factor scores can be used in characterizing the various aspects of the production system and in comparisons between crops, and even between regions.

Within this context, an analysis of the agricultural sector under a "dualistic" perspective is possible.

\section{A lower technological development was}

observed in connection with food products and also that the relative backwardness of these crops has been maintained or aggravated over time, with probable consequences on the prices of these products. It was found that the 
.xviii.

modernization of these products occurs in the last place and that the technological level of different crops is more homogeneous in more developed areas.

This work is an attempt to identify important factors as well as their interrelationships in the modernization process at the macroeconomic level, in terms of the influence which they exert on the allocation and generation of agricultural surplus. A contribution towards a better performance of agricultural policies and a faster modernization process within the concern for identifying and realizing "potential surplus" is sought. 


\section{INTRODUÇAO}

O papel da agricultura no desenvolvimento eco cômico do país tem sido um dos temas de maior relevância na pesquisa econômica. A participação ativa do setor agropecuá rio torna-se imprescindível a um desenvolvimento equilibra do. Vários modelos de análise de desenvolvimento econômico caracterizam o processo de geração de "excedentes" na agri cultura e sua transferência intersetorial. A intensificação da participação do setor dependerā de uma maior geração de "excedentes" e de sua consequente transferência.

BARAN (1972, p. 74) em termos de estática comparativa distingue três variantes do conceito de exceden te econômico :

1) Excedente econômico efetivo

2) Excedente econômico potencial

3) Excedente econômico planejado

Excedente econômico efetivo é definido como a diferença entre o produto social efetivo de uma sociedade e 
seu efetivo consumo $1 /$.

0 excedente econômico potencial é definido co mo a diferença entre o produto social que poderia ser obti do em um dado meio natural e tecnológico com o auxílio dos recursos produtivos realmente disponíveis e o que se pode considerar como consumo indispensāvel.

O excedente econômico planejado, como defin $\underline{i}$ do, tem correspondência com o excedente potencial numa so ciedade de economia planejada.

Praticamente todas as formaçōes sócio-econômi cas geram excedente econômico efetivo (poupança) ou promo vem a formação de capital. O excedente econômico potencial é, por outro lado, de enorme interesse científico. A iden tificação de possibilidades de realizar "excedentes poten ciais" na agricultura é de enorme importância na medida em que poderá determinar um maior desenvolvimento econômico.

O estudo de como se processa a modernização do setor está intimamente relacionado às formas de aloca cão dos excedentes gerados no setor ( que relacionaremos às características dos produtos, tanto a nível micro como e, essencialmente, a nível macroeconômico) ao mesmo tempo que a própria modernização é um fator da maior importância na determinação de uma maior geração de excedentes.

I/ O excedente econômico efetivo compreende, obviamente, parcela menor do produto social que a abrangida pela no ção marxista de "mais valia". A "mais valia" é representada pela diferença entre o produto líquido global e a ren da real da força de trabalho. O excedente econômico abrange apenas a parcela da mais valia que é acumulada. 


\section{1 objetivos}

o objetivo que rege o presente trabalho cons titui-se numa tentativa de caracterizar a agricultura pro curando o melhor entendimento do processo de modernização. A forma analítica constará, essencialmente, de uma análí se comparada de um grupo de culturas que represente aproxi madamente a agricultura no Brasil.

A caracterização de todo o sistema produtivo de várias culturas representativas segundo um grupo de va riāveis selecionadas a partir de informações censitárias disponíveis (Censo Agropecuário - IBGE) permitirá estabele cer uma matriz através da qual a análise objetiva das rela ções sócio-econômicas intra e intersetoriais se torne viá vel e, permitirá também, identificar fatores associados a um maior desenvolvimento agrícola.

\subsection{Hipótese Geral}

A modernização da agricultura não se tem pro cessado de forma homogênea e sim, sistematicamente, de for ma dispar entre culturas. Determinadas características dos produtos, principalmente, o fato de ser exportado ou indus trializado, condicionam todo o sistema produtivo e oproces so de acumulação.

\subsection{Hipōteses Específicas}

1. Uma comparação entre culturas identificarā situações distintas que podemos referir, também, como dualismo em relação aos seguintes aspectos: 

a) Nível tecnológico
b) Estrutura de Produçāo
c) Processo de comercialização
d) Grau de acesso às políticas agrícolas (crédito, poíi tica de preços mínimos, etc).
e) Distribuição e concentração geográfica

2. No entendimento do processo de modernização é essencial que se considerem as características específicas de ca da produto. A industrialização ou exportação do produto agrícola são fatores, senão determinantes, associados. a uma maior modernização.

3. Deve ser possível encontrar e justificar diferentes com portamentos nos preços dos vários produtos, face a um processo de "modernização díspar" entre culturas. 
2. REVISAO BIBLIOGRAFICA

Neste capítulo discute-se "dualidade econômi
ca", segundo diferentes enfoques, desde "dualismo" como for
ma analítica, aos modelos de desenvolvimento, até às várias
formas em que surge na própria análise do setor agrícola (dualidade ou multiplicidade tecnológica, etc). Na sequên cia resumem-se de forma genérica os diferentes aspectos da teoria da modernização mais difundidos e reconhecidos justi ficando-se a inclusão de outra perspectiva, a relação entre modernização e diferentes características dos produtos agrí colas. Na parte final do capítulo faz-se referência a dife rentes formas em que a agricultura tem sido subdividida.

\section{1 "Dualismo"}

A escola clássica de Economia Política teve como preocupação principal elaborar uma "teoria do desenvol vimento econômico". Isto é bem ilustrado pelo próprio títú lo da obra de ADAM SMITH - "Investigação sobre a Natureza e as Causas da Riqueza das Naçōes". O estudo de como era gerada a renda e como esta se distribuía traduz essencial mente essa preocupação. 
Os modelos "dualistas" de desenvolvimento se constituem em formas de análise do sistema, do processo de acumulação e crescimento econômico. A tradição clássica es tá presente nestes modelos analíticos por vezes explicita mente, como no trabalho elaborado por Lewis sobre o desen volvimento com oferta ilimitada de mão-de-obra.

A "dualidade" não deixa de ser um conceito analítico que facilita a análise e a exposição das interre laçōes dentro de um sistema econômico, partindo da carać terização diferenciada desse sistema. Para o próprio setor agrícola encontramos essa tendência analítica. A dualidade ou multiplicidade tecnológica na agricultura é, talvez, um dos tópicos mais conhecidos que confirma na literatura essa tendência analítica.

RANIS e FEI (1966) escrevem : "Desde os pri mórdios de nossa ciência os economistas têm tentado uma compreensão melhor do desempenho do crescimento da econo mia. No recente ressurgimento do interesse pelo desenvolvi mento, depois do longo interregno Neoclássico, tem havido algum esforço para coligir o máximo possível de informa çōes úteis a partir de trabalhos anteriores. Tanto os au tores antigos como os modernos, cada vez mais parecem con cordar em que a verdadeira essência mundial de um sistema em desenvolvimento não pode ser significativamente "captú rada" pela análise agregativa convencional e que a busca de relaçōes e assimetrias intersetoriais significantes po derá muito bem fornecer a chave da maior compreensão que procuramos".

0 modelo de Lewis talvez tenha sido o traba Iho que mais incentivou o desenvolvimento de modelos duais. LEWIS (1954, p. 407) define o seu propósito da seguinte forma : "Descobrir o que se pode aproveitar do marco clás 
sico para resolver os problemas da distribuição, acumula ção e crescimento". De acordo com os clássicos (de Smith a Marx), Lewis pressupõe uma oferta ilimitada de mão-de-obra a salários de subsistência e analisa a problemática da de terminação da distribuição de renda e do crescimento da mesma. Justifica, por outro lado, o fato de na éra Neoclás sica deixar de existir preocupação com análises do crescí mento econômico dada a impressão de que a expansão econômi ca poderia ser vista como algo automático.

Tem, no entanto, perfeita consciência das li mitações de sua hipótese analítica : "Nossa finalidade não é superar a economia Neoclássica, mas, simplesmente, ela borar esquema diferente para aqueles países que não podem ser encaixados dentro das hipóteses Neoclássicas ( nem Keynesianas)".

A análise intersetorial supõe, por hipótese, um setor de subsistência que identifica com a agricultura, constituído de camponeses que produzem alimentos, enquanto o setor capitalista produz o restante. Esta hipótese é ne cessária pois, no momento em que os capitalistas investi rem na "agricultura de plantação" ao mesmo tempo que inves tem na indústria, pode-se falar de um setor capitalista au tárquico. Por outro lado.o modelo evidencia a necessidade de equilíbrio entre setores em função das relações de pre ços. "E também por esse motivo que as revoluções industriais e agrícolas se verificam sempre concomitantemente e que nas economias onde a agricultura se encontra estagnada não se verifica nenhum desenvolvimento industrial" (LEWIS, 1954, p. 438).

No modelo de Ranis e Fei as pressuposições de que a produtividade marginal da mão-de-obra é igual a zero e que uma taxa de salário é determinada institucional 
mente no setor de subsistência são mantidas inicialmente.

Distinguem três tipos principais de sistemas econômicos : agrarianismo, dualismo e maturidade econômica. Descartam o estudo do sistema em maturidade econômica e mos tram a importância da distinção entre economia agrária e dualista e sua relação com a melhor compreensão das contri buicooes anteriores (Fisiocratas e Clássicos) ao estudo atual da economia menos desenvolvida.

A característica central do agrarianismo é a preponderância da agricultura, tendo as outras ativida des econômicas um carāter secundário, tanto no sentido quantitativo como qualitativo.

0 "dualismo" é definido pela existência de um grande setor agrícola com um ativo e dinâmico setor in dustrial. "A economia dualista esforça-se por ajustar-se à preponderância da agricultura, deslocando gradualmente o seu centro de gravidade em direção à indústria através de redistribuição de fatores" (RANIS e FEI, 1966). Os exceden tes econômicos podem ser gerados tanto no setor industrial como no setor agrícola e a poupança total da economia é, agora, composta de dois tipos de excedentes, lucros indus. triais e excedentes agrícolas.

E neste período de "dualismo econômico" que começa a processar-se uma mudança na produção agrícola. No próprio campo começa a ocorrer também o avanço do sistema de produção tipicamente "capitalista" ou empresarial. Este tipo de alteração é referido por Ranis e Fei: "Ademais, uma vez que as classes dos proprietários rurais começam a ver na aquisição de ativos industriais algo mais desejável do que "fazer guerras" ou luyar uma "boa vida" no contexto do ag arianismo, assistimos à transição para o dualismo e hả um importante "feedback" sobre o incentivo para aumentos adi 
cionais da produção agrícola".

"Na realidade, é nisto que estā a essência da diferença entre agrarianismo e o dualismo. No agrariani mo, não há um mecanismo em ação para provocar as inovações, não existe um grupo de empresários sensíveis às oportunida des de gerar excedente dentro e fora da agricultura" (RANIS e FEI, 1966).

PAIVA (1971, p. 171) observa que : "uma das características da agricultura dos países em fase de desen volvimento é a falta de uniformidade nos niveis tecnoló gicos adotados pelos agricultores". Propõe referir a dive sidade tecnológica como "grau de modernização" ou "grau de dualismo tecnológico".

Os países em desenvolvimento caracterizam-se, segundo PAIVA (1971), pela diversidade do grau de moderniza ção entre agricultores, entre diferentes regiōes e entre produtos numa mesma região.

A análise das diférenças entre produtos, em relação ao grau de modernização, é feita a partir da classí ficação de três situações distintas :

1) Produtos em que praticamente todos os agricultores em pregam técnicas modernas.

2) Produtos em que praticamente todos os agricultores em pregam técnicas tradicionais.

3) Caso intermediário, onde tanto técnicas modernas como tradicionais são empregadas.

Com dois grupos de variáveis, convencionais 
na teoria econômica, referentes à "qualificação dos agricul tores" e aos preços de fatores e de produtos, explica o di ferente grau de modernização que ocorre entre agricultores e entre regiões.

Para explicar as diferenças entre produtos em uma mesma região, considera a diferença de produtividade (em termos físicos) dos fatores de produção modernos em re lação aos tradicionais, que varia de produto para produto dentro de uma mesma região.

PAIVA (1971, p. 182) afirma que : "os estu彑 diosos do processo de modernização agrícola nos países em desenvolvimento não têm dado a devida atenção a essas dife rentes modalidades de variações do "grau de modernização. (...) a existência de produtos numa mesma região, produzí dos tanto por agricultores que adotam técnicas modernas co mo primitivas, constituiu, em si, um problema da maior sig nificação, pois nele o "dualismo tecnológico" se identifica com uma situação de fato de dualismo econômico, (em que am bos os agricultores modernos e tradicionais obtêm retornos financeiros suficientes para se manterem economicamente pro dutivos) situação essa de maior importância no contexto ge ral do processo de desenvolvimento econômico, pois se os agricultores tradicionais não estão economicamente margina lizados, significa isto, que oferecem maior resistência a mudanças tecnológicas e, por conseguinte, maiores dificulda des no processo de desenvolvimento do país". Esta constata ção, não é nada mais do que a identificação da "dualidade " dentro da própria agricultura.

A constatação, de forma sistemätica, de dife mas significativas entre culturas (tecnológicas e estru $\therefore$ is), constitui um outro aspecto da maior significação 
na compreensão do processo de modernização da agricultura, que de acordo com a análise de PAIVA poderá também ser re ferido como "grau de modernização" no sentido de, a un maior grau de modernização, corresponder maior homogeneidade. Além disso, mostra a relação existente entre esses dois setores, tradicional e moderno, e de como interagem segundo o está gio de desenvolvimento econômico, o setor moderno assumindo a liderança quando a economia evolui para a plena maturida de. NICHOLLS (1973) desenvolve a anālise da interrelação en tre esses dois sistemas produtivos de forma mais detalhada.

PEREIRA DE QUEIROZ (1972) (citado por ANTU NIASSI) mostrou a adequação da perspectiva de GURVITCH(1971) ao estudo sociológico do tradicional e do moderno, que apa recem como opostos, quando de fato são complementares. 0 tradicional e o moderno passam a ser vistos como parte de um fenômeno social total cuja característica é a interrela ção dinâmica de suas partes. Segundo PEREIRA DE QUEIROZ (1972), o processo de modernização e a alteração das rela çōes de trabalho não estão diretamente relacionados, jā que essas transformações se operam tanto em estabelecimentos or ganizados de forma moderna, como nos que utilizam tecnolo gia rudimentar. E necessário ter presente todo o conjunto de alterações por que passa uma sociedade e a forma como a sociedade brasileira acompanha as correntes gerais que im pulsionam as sociedades capitalistas atuais, numa economia heterogênea (como a brasileira) em que se combinam as for mas pré-capitalistas, capitalistas clássicas e capitalistas modernas.

GUIMARAES (1979, p. 190) chama a atenção pa ra o fato de a discussão sobre ćrise agrária não poder ser feita com base exclusiva nas concepcões teóricas dos clássi cos do capitalismo ou do socialismo mas também em funçáó das novas condições criadas pelo processo de industrializa 
ção da agricultura e das novas relaçōes que se estabelecem entre economia agrícola e industrial.

"A crise agrária estrutural, nos seus 100 anos de vida, não levou ao desaparecimento da pequena pro priedade camponesa, como se chegou a admitir em determinada fase do crescimento agrícola, em meados do século XIX. Ela também não levou ao desaparecimento da grande propriedade, como houve também quem prenunciasse (...) Isso porque o crescimento da agricultura capitalista fez-se, ao longo do tempo, sobre a base de uma crescente complementariedade " .

\subsection{Aspectos da Teoria da Modernizaçāo Amplamente Reco nhecidos.}

1 - "Declínio secular da importância da agricultura". Quan to maior o desenvolvimento econômico, menor a importân cia relativa da agricultura. Esta afirmação deve ser ponderada com cuidado, pois ocorre também grande expan são de vários ramos da economia ligados direta e indi retamente à agricultura, como indústrias de insumos agrí colas, indústrias de processamento dos produtos agrope cuários, atividades comerciais, etc.

2 - Refuta-se a incapacidade da agricultura tradicional de se modernizar e de contribuir efetivamente no desenvol vimento econômico. SCHULTz (1965) mostra que o compor tamento do agricultor tradicional é, em princípio, ra cional. o "dualismo econômico" seria o resultado da de sigualdade nos preços relativos dos fatores e no custo desigual da obtenção de novos fatores e informação. Pa ra SCHULTz a oferta de fatores de produção é o elemento chave para quebrar o equilíbrio da agricultura tradicio nal. 
3 - A "Teoria da Modernização Agrícola" colocou o problema da modernização em bases econômicas. A modernização pas sou a depender não só das decisões do "governo" e "von tade dos agricultores" mas também da existência de "opor tunidades econômicas", ou seja, da relação de preços de insumo e de produtos.

GRILICHES (1957) tentou mostrar que a relação entre pre ços do produto e dos fatores influenciava a taxa à qual a nova tecnologia seria empregada.

4 - HAYAMI e RUTTAN (1971) tentam explicar em termos econô micos o direcionamento do desenvolvimento tecnológico em função da dotação de recursos. Além disso, no proces so de modernização há alteração na importância dos fa tores responsáveis pelo crescimento da produção. Os au tores confirmam empiricamente essa mudança. Concluem que para países desenvolvidos o capital humano e insu mos técnicos são as causas determinantes do crescimento da produção e que a diferença de recursos naturais res ponde por parte cada vez menor da crescente diferença de produtividade entre naçōes 1 '.

1'RUTTAN (1973, p. 41), citado por PAIVA (1979,p.27) resume essas conclusões: "Nos países desenvolvidos o capital hu mano e os insumos técnicos tornam-se causas determinantes do crescimento da produção. A diferença de recursos natu rais responde por parte cada vez menor da crescente di ferença de produtividade entre nações. Diferenças de prọ dutividade na agricultura são cada vez mais uma função de investimentos na educação rural e na capacidade cien tífica e industrial do que da dotação de recursos na turais." 
5 - Mostrando até onde é possível ocorrer o processo de mo dernização, ou melhor, a forma como ocorre uma diminui ção no processo de expansão da nova tecnologia, a aná lise de PAIVA é amplamente reconhecida $\underline{1}$.

6 - Disponibilidade de tecnologia, investimento em pesquisa e educação são, de diferentes formas, considerados ele mentos indispensáveis no processo de modernização.

SCHUH (1973) lembra (criticando Paiva) que a idéia de disponibilidade de tecnologia não é uma realidade, mos trando a especificidade e localizaçao da aplicação de tecnologia agrícola.

"Embora os princípios gerais da pesquisa se apliquem sem restrições, as novas variedades e grande parte dos demais elementos que compõem a tecnologia de produção são específicos aos produtos. Isto explica em grande parte porque a produção de algumas culturas está mo dernizada e porque isto nāo acontece em outras". (SCHUH, 1973, p. 82); "Quando queremos explicar a dife rença na modernização entre dois produtos e duas re giōes é necessário examinar principalmente as diferen ças no esforço e sucesso das pesquisas. Ocorreu um

\section{$1 /$}

PAIVA reconheceu o "ciclo vicioso" da introdução de nova tecnologia identificando problemas na "mobilização do excedente potencial"existente. "Ciclo vicioso" no sentido de que a não existência de mercado, em grande parte devido aos baixos níveis de renda da população. , é função da incapacidade de realização da "renda (exce dente) potencial" devido à não existência de merca do. 
invulgar aumento de progresso técnico na produção de algodão em São Paulo. O motivo foi que o Estado de São Paulo investiu maciçamente na pesquisa biológica de algodão e instituiu politicas complementares que.facili taram a adoção da nova tecnologia assim produzida. 0 Estado não investiu na mesma medida nas pesquisas em torno de culturas alimentares como o arroz, feijão e o. milho. Em consequência, foi muito menor a modernização nessas culturas" (SCHUH, 1973, p. 81).

As possibilidades de transferência tecnológi ca, como as dificuldades na sua implantação, são distintas entre culturas, não sendo difícil, através da literatura , a comprovação deste fato. A importância do investimento em educação tem sido outro tema extremamente discutido e com provado. Devemos lembrar que é elemento muito importante na "mobilização" ll/ do fator mão-de-obra da agricultura para outros setores, diminuindo os custos de transferência e a mentando o custo de oportunidade do indivíduo do campo, que terá então, maior possibilidade de escolha.

Alguns comentārios aos ítens relatados permi tirão realçar aspectos relevantes na discriminação entre culturas.

0 primeiro item não é mais do que a constata ção do deslocamento do fulcro da economia da agricultura pa ra outros setores, perfeitamente de acordo com as altera ções esperadas no processo de desenvolvimento.

0 segundo item mostra que a "dualidade econọ mica" não é consequência da irracionalidade na produção mas

$1 /$

"Mobilização" no sentido de transferência de recur sos. 
sim função do pröprio funcionamento do mercado, com desi gualdade nos custos de novos fatores e de informação.

O terceiro ítem destaca também o funcionamen to do mercado e a necessidade de existência de "oportunidades econômicas".

0 quarto ítem, em termos agregados, coloca o processo de modernização e o seu direcionamento em fun ção da dotação de recursos e das relações de preços e . portanto, em função do mecanismo de mercado, enquanto o quinto ítem explica, também de acordo com o sistema de me cado, até onde é possível a expansão da nova tecnologia.

0 ültimo aspecto relatado (disponibilidade de tecnologia, investimento em pesquisa e educação) que aparentemente independente do funcionamento do mercado, aca ba se relacionando indiretamente com esse funcionamento, já que, a possibilidade de apropriação dos excedentes gera dos pela introdução de nova tecnologia é responsável, em grande parte, pelas pesquisas realizadas e, também, pelo seu sucesso ou insucesso (PASTORE et alii, 1976).

A educação e a informação são aspectos es senciais na correção de muitas imperfeições do mercado, além de facilitarem o processo de ajustamento interseto rial que se faz necessário ao desenvolvimento econômico.

Verificamos que, a compreensāo do processo de modernização tem-se limitado, em grande parte, ao funcionamento do mercado.

E preciso lembrar, então, das grandes imper feições do mercado, das políticas governamentais e modelo 
de desenvolvimento econômico adotado (como do próprio está gio de desenvolvimento econômico) assim como das diferentes características do produto, elementos com fortes . implica ções na geração e alocação de excedentes gerados e, portan to, no processo de acumulação e de modernização.

\subsection{Modernização e Diferentes Caracteristicas dos Pro dutos agricolas}

A agricultura empresarial é direcionada de acordo com o tipo de produto e exploração onde as possibilí. dades de apropriação do excedente gerado (pela introduçāo de tecnologia e capital) são maiores. Podemos distinguir dois níveis de fatores diretamente relacionados ao tipo do produto, determinantes dessas possibilidades :

A) Fatores importantes ao nível da tomada de decisão da firma : variações na produção e produtividade (suscepti bilidade a doenças e pragas - risco inerente ao processo produtivo), variações nos preços dos produtos, processo de comercialização e características importantes do pro duto como perecibilidade, facilidade de transporte, etc, assim como todo um conjunto de variáveis relacionadas a mercado de fatores e de produtos.

B) Fatores importantes a nível agregado:

1. Produto exportável

2. Industrialização do produto agrícola

3. Independência em relação à alimentaçāo básica

4. Concentração è distribuição geográfica

5. Disponibilidade de tecnologia 
6. Grau de acesso às políticas agrícolas

SCHUH (1973), de acordo com Hayami e Ruttan, conclui que os economistas vêm dispensando pouca atenção à anālise e compreensão dos processos de modernização. Têm-se concentrado principalmente na compreensão do papel da agrí cultura no desenvolvimento econômico sem procurar determi nar os fatores responsāveis pela direção que a agricultura toma à medida que se moderniza; "o problema em grande parte da discussão da mudança tecnológica na agricultura é que muitos estudiosos não separam os efeitos diretos no nível do estabelecimento agrícola, dos efeitos agregativos, ou de equilíbrio geral" (SCHUH, 1973, p. 71).

PASTORE et alii (1976) reconhecem a importân cia das características dos produtos como periodicidade, es pecificações, padronização, bem como as possibilidades de industrialização ou existência de mercados mais exigentes, tanto na geração quanto na difusão tecnológica.

Para o grupo de fatores importantes ao nível da decisão da firma não se fará maiores considerações, por serem bem discutidos na literatura e facilmente explicáveis pela teoria econômica. Observa-se, no entanto, alguns resul tados do cálculo de indices de variabilidade de preços e produtividade, para várias culturas, que mostram, com poucas exceçōes, maiores variações nos preços do que na produtiví dade.

A Tabela 1 apresenta os resultados para o cál. culo de indices de variabilidade de preços e produtividade utilizando o método denominado de "variabilidade média re 


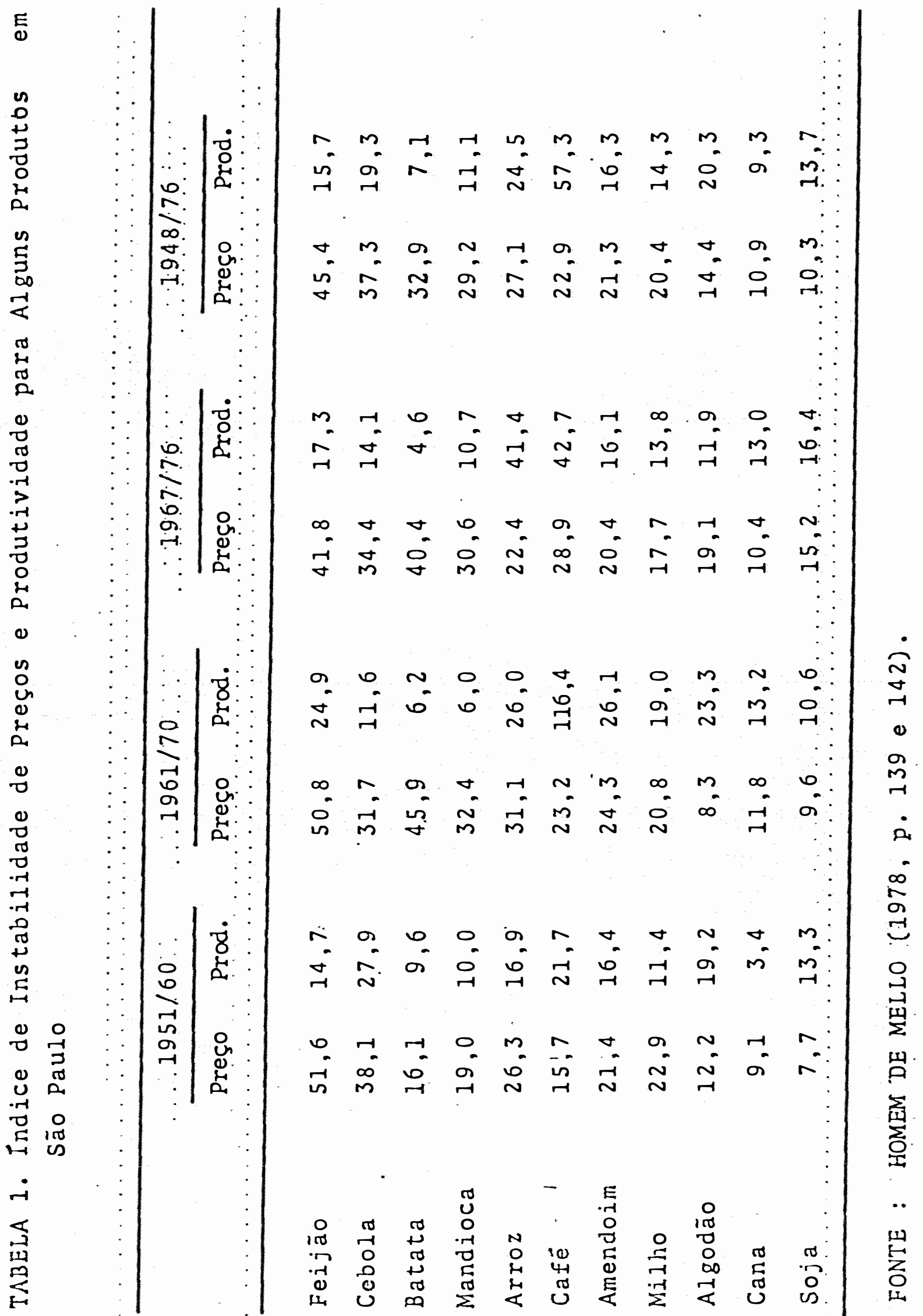


lativa" $1 /$. Foram utilizadas séries históricas de preços reais recebidos pelos produtores e dados sobre produtivida de no cálculo dos vários indicadores. HOMEM DE MELO (1978). observou consistência entre os vários indicadores, verifi cando que os preços dos produtos de consumo interno são invariavelmente mais instāveis que os de exportação.

Para os fatores considerados importantes a ni vel agregado faz-se necessārio uma maior discussão. Aos dois primeiros fatores considerados, produto exportado ou industrializado, se associam características específicas em relação aos outros ítens, fato que ficará posteriormente bem esclarecido.

\subsubsection{Produto Exportāuel}

Consideremos a característica de produto ex portável e suas implicações. Em termos agregados o produto "enfrenta" uma demanda muito mais elástica, ou em outros termos, maior independência em relação ao mecanismo de "au to-controle", o que significa menores variações de preços devido a variações na produção. Para evidenciar a importân cia desta característica, consideremos o conceito de "exce dente Econômico" de Marshall e o modelo muitas vezes utili zado para análise de custo/benefício. Principais premissas :

1) đārea total sob a curva de demanda à esquerda de uma dada quantidade representa a utilidade total desta quan

1/ Variação relativa média (HONEY, 1974), é a média de variação percentual ano a ano, durante um determinado período de tempo. 
tidade $1 /$.

2) A curva da oferta reflete os custos de oportunidade dos recursos variáveis utilizados para produzir cada quantí dade.

Definições :

1) De acordo com a definição proposta por Marshall, : "ex cedente do consumidor" é a maior soma de dinheiro que um consumidor estaria disposto a pagar por uma dada quantidade total de um bem, menos o total realmente pa go.

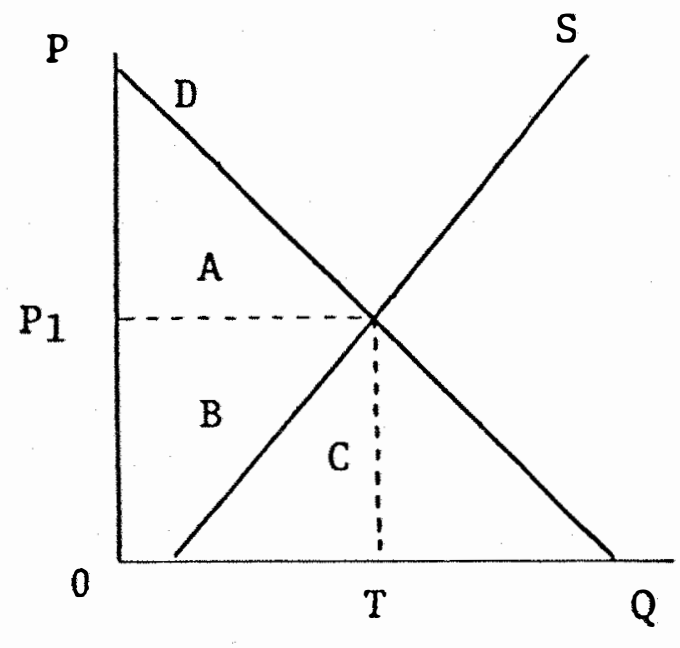

Figura 1 .

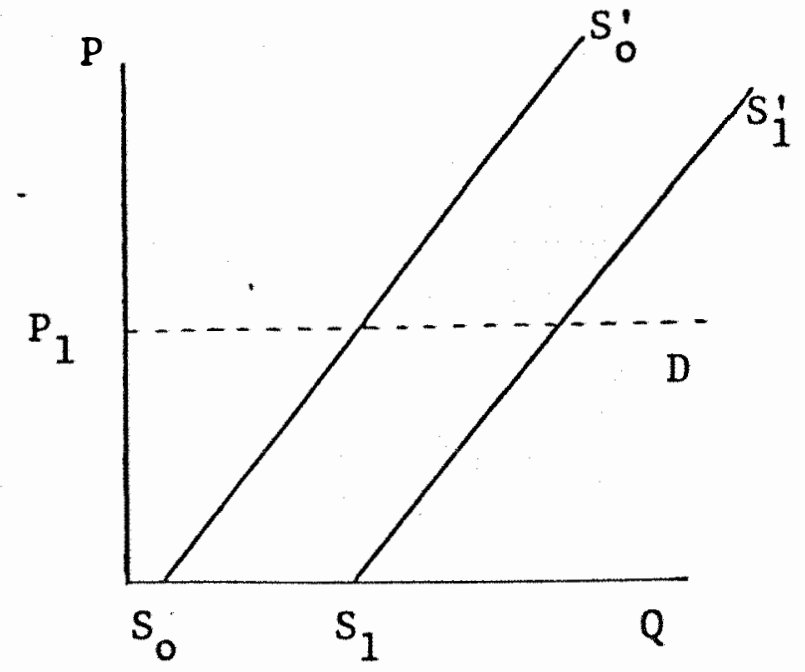

Pigura 2.

A aceitação dessa premissa baseia-se na pressuposição de que a utilidade marginal do dinheiro é a mesma para todo o consumidor. 
2) 0 conceito de excedente do produtor introduzido por Marshall é um conceito análogo ao do excedente do con sumidor. O conceito se refere à diferença entre o que é recebido da venda de um bem e o total mínimo requeri do para induzir o vendedor a se desfazer do bem 1 .

A figura $I$ ilustra os conceitos de "exceden te" : à ärea A corresponde o "excedente do consumidor"; $\bar{a}$ área B o conceito de "excedente do produtor"; a área C re presenta os custos de oportunidade dos recursos utilizados para produzir a quantidade $O T$. O excedente total é igual à área $A+B$.

Na figura 2 considera-se uma curva de demanda hipotética infinitamente elástica para ilustrar o fato de que todo o excedente neste caso constitui exclusivamente o excedente do produtor. Um deslocamento na curva de oferta para a direita proporcionarā um excedente econômico que se rá totalmente apropriado pelos produtores. A medida que a curva de demanda se torna mais inelástica os acréscimos no excedente do consumidor se tornarão cada vez maiores.

A nível de agregado é muito mais interessante pa ra os produtores ampliar a sua produção em produtos cuja demanda é relativamente mais elástica. E fácil perceber as implicações deste fato na utilização de insumos modernos e tecnologia e, no longo prazo, no próprio desenvolvimento tecnológico.

1/ Para maiores detalhes, ver SANCHES DA FONSECA, M.A.', "Retorno Social aos Investimentos em Pesquisa na Cultu ra do Café". Piracicaba, 1976. 


\subsubsection{Industrialização do Produto Agrïcola}

A industrialização do produto agrícola é um fator que poderá induzir ou ao qual frequentemente se associam fortes alterações em todo sistema produtivo. A industri alização altera as condições de demanda pelo produto, normal mente, via ampliação do mercado e através da própria trans formação do produto proporcionando melhores condições de comercialização.

Da mesma forma que a exportação, pode proporcionar condições de realizar "excedentes potenciais". Ao promober a absorção de mão-de-obra agrícola, agiliza transferência de reçursos ou "excedentes de fator", que a processo essencial ao desenvolvimento econômico.

A maior incorporação de trabalho e capital ao produto, por outro lado, aumenta as possibilidades de "capitalizar", além de ter uma influência positiva no desenvolvimento de uma agricultura onde se imponha um espírito empresarial.

\subsubsection{Produtos de Alimentação Básica}

Produtos que podem ser enquadrados dentro des ta categoria estão sujeitos a um conjunto de fatores que limitam as possibilidades de uma modernização rápida.

Lembremos de algumas funções normalmente atri buídas à agricultura, como o fornecimento de mão-de-obra . A agricultura tem uma função estabilizadora quanto à mão-de-obra. Se o setor não agrícola falhar em criar oportunidades de emprego, o excesso de mão-de-obra no setor não agrícola transforma-se em desemprego, enquanto na agricultura se processa uma absorção passiva na forma de sub-em- 
prego.

Esta função de "reservatório" de mão-de-obra, com uma produção típica de subsistência concentrada em de terminados tipos de produto (alimentação básica) em que eventualmente um excesso de produção chega ao mercado. cria situação facilmente previsivel de preços para esses produtos.

PAIVA (1979, p. 122) refere-se a esse tema de forma diferente, enfatizando as imperfeições do mercado que promovem a manutenção dos preços dos produtos agríco las em níveis relativamente baixos : "Essas imperfeições são em geral agravadas pelo fato do setor agrícola nos países em desenvolvimento agir como setor "residual" da economia, ou seja, o setor onde não há propriamente expuI são de mão-de-obra e de empresários mais ineficientes mas onde ficam todos aqueles que não tem melhores oportunida des".

Dadas essas características, ocorre uma pro dução que pode ser adquirida a baixo custo. Consideremos então a política de extração de excedente do setor agríco $1 \mathrm{a}$.

Analisando-se a política de extração de exce dentes agrícolas no Brasil e em outros países, conclui-se que essa política tem atuado sistematicamente contra os preços dos produtos agrícolas.

LOPES e SCHUH (1979) fazem análise das políti cas adotadas no Brasil e mostram que, de uma forma ou de outra, tentaram extrair os excedentes agrícolas através de práticas que atuaram primariamente no mercado de produtos. 
Um de seus objetivos foi desenvolver análise do impacto de políticas alternativas ou da combinação de políticas de forma a extrair o excedente agrícola. Concluem que os re cursos extraídos por meios fiscais diretos (imposto sobre a propriedade da terra) têm menos impacto na utilização de fatores, produzindo menor distorção na utilização de recur sos.

Além da política econômica atuando ao nível do preço do produto, orientada para o abastecimento do me cado interno, o que conduz à obtenção de preços tão ba xos quanto possível para uma produção suficiente ao consu mo interno, há ainda a considerar os aspectos da comercia lização em que o agricultor tem pouco poder de barganha, o que pode significar impossibilidade de se apropriar do excedente gerado na produção.

ACCARINI (1978) procura examinar as razōes que determinan diferenciais de preços no mercado agrícola brasileiro. Os produtos analisados são algodão, soja, mi 1ho, arroz e feijão. Examina as distribuições, para os dí ferentes produtos, da percentagem de preços recebidos pelo produtor rural em relação ao preço médio do Estado onde es tá localizado. Verifica-se que a dispersão dos percentuais para produtos como soja e algodão é menor do que para pro dutos como arroz e feijão. Esta ocorrência mostra que a eficiência na comercialização é, provavelmente, menor para produtos como arroz e feijão.

A posição do setor agríicola "vis-a-vis" ou tros setores de estrutura competitiva diferente pode ser problemátiva. No confronto entre uma estrutura dispersa e competitiva e uma concentrada, os termos de troca são ge ralmente ditados pela concentrada. E de fácil percepcão o 
agravamento desta posição da agricultura em determinados produtos.

Os três primeiros itens mencionados mostram as diversas implicações das características consideradas. Quanto maior o enquadramento de determinado produto dentro de uma destas características mais fortes serão as impli caçōes respectivas. Os ítens seguintes, fatores importantes a nível macro-econômico, estão associados aos primeiros e entre si. Não determinamos relações de causalidade e de dependência, mas argumenta-se que é possível estabelecer determinadas relações. $\therefore$

De acordo com as hipóteses estabelecidas ao longo desta pesquisa, determina-se, através de dois grupos representativos, de um lado, produtos essencialmente expor tados e industrializados e, de outro lado, produtos tipica mente de alimentação básica, diferenças em todo o sistema produtivo (nível tecnológico, estrutura de produção e processo de comercialização) e, posteriormente, as relação dos dois grupos com outros fatores macro-economicos. Omite-se maiores análises da disponibilidade de tecnologia a que se faz referência neste capítulo, dadas algumas evidências em píricas na literatura e amplitude do tema.

\subsubsection{Concentração e Distribuição Geogrä́fica}

O grau de concentração geográfica da produ ção, independentemente da estrutura fundiária de produção, tem importantes repercussões no processo de modernização.

PASTORE et alii (1976) consideram o grau de concentração geográfica exercendo importantes efeitos so 
bre as possibilidades de desenvolvimento de pesquisa agrí cola. A formação de grupos de interesse e de pressão sobre as instituiçōes, assim como a própria formulação de proble mas concretos com maior grau de especificidade agilizam a comunicação e a resposta a esses problemas.

A concentração geográfica, além de ocorrer em função de condiçōes ecológicas, tende tambēm a homogene zar as áreas de cultivo, facilitando todo o processo de ge ração e difusão tecnológica. Quando existe dispersão da produção os estímulos são vagos e não se concretizam em problemas específicos de pesquisa, assim como as próprias diferenças ecológicas dificultam a aplicação das pesquisas efetuadas.

A agricultura : đmpresarial e a concentração geo gráfica se relacionam frequentemente visto que as melhores condiçōes ecológicas e econômicas interagem determinando essa relação. A interação entre agricultores também é fá cilitada aumentando o nível informativo do agricultor, seu poder de barganha na comercialização e, até mesmo,diminuin do os próprios custos da comercialização.

\subsubsection{Disponibilidade de Tecnologia}

E de fácil percepção a interrelação entre to dos os itens considerados a nível agregado. Cabe, neste momento, tecer algumas considerações adicionais sobre aspec tos relevantes na disponibilidade de tecnologia.

Sabe-se que a possibilidade de transferência tecnológica é distinta entre produtos. Por outro lado, a própria transferência e adaptação dependem, da mesma forma que a atividade de pesquisa, de um conjunto de fatores, re 
lacionados entre si e que determinam a maior ou menor pos sibilidade de "internalização"' do excedente gerado.

HOMEM DE MELO (1978, p. 89), discutindo a questão de disponibilidade de tecnologia, considera que po dem surgir problemas caso excessiva confiança seja deposi tada nas forças de mercado, como consequência de caracte rísticas de determinados bens. Assim, considera que o pro duto da atividade de pesquisa apresenta caracteristicas de bens públicos, ou pelo menos de bens com efeitos externos significativos $1 /$.

Quando os produtores não têm condições de se apropriar de..parte dos benefícios decorrentes do investi mento realizado, tem-se o caso tradicionalmente conhecido como incapacidade de mercado (market failure). Bens com efeitos externos, do ponto de vista de eficiência alocati va, tem tendência a que, a quantidade ofertada, ünica e exclusivamente regulada pelas forças de mercado, seja dife rente da ótima.

Conclui-se que a participação do setor públi co deve ser importante para determinado tipo de pesquisa para se chegar a um nível de investimento socialmente ade

$1 /$ Efeitos externos, segundo HOMEM DE MELO (1978, p.89), ficam caracterizados como existindo, entre produtores, entre consumidores ou entre representantes destes dois grupos, desde que duas condições sejam obedecidas: "em primeiro lugar, interdep̣endência nas ações de indiví duos ou firmas, em termos de funções de utilidade e funções de produção e, em segundo lugar, o fato de não se verificar a compensação monetária entre as partes envolvidas (Nath, 1969)". 
quado. Em relação aos diferentes tipos de culturas é impor tante reconhecer também que a intervenção. do Estado deve ser distinta na geração de tecnologia, assim como na difu são da mesma.

\subsubsection{Grau de Acesso àspoliticas Agricolas}

Outro aspecto que pode ter repercussōes sen síveis no processo de modernização é o grau de acesso às políticas agrícolas. A facilidade de obtenção de crédito é talvez o fator mais característico. Este fator considerado em função do produto está extremamente relacionado à con centração e distribuição geogräfica da produção.

Produtos que possuem uma maior concentração em termos de ārea de colheita ou são produzidos essencial mente por produtores com estabelecimentos de grandes dimen sōes têm, normalmente, maiores facilidades no financia mento de sua produção.

Atualmente, a política governamental tem pro curado obter maiores facilidades para os pequenos e mé dios produtores visando corrigir esta distorção.

A concentração geogräfica da produção facili ta o contato entre as instituições e os produtores e a própria distribuição da produção em āreas de maior ou me nor desenvolvimento altera as condições de acesso às "pó líticas agrícolas". 


\subsection{Subdivisōes da Agricultura}

As subdivisões que se realizam no setor, na anālise econômica, são as mais variadas. Existem, contudo, algumas mais frequentes e mais recentes que é necessārio referir.

De forma geral são mais comuns as seguintes divisōes :

1) Agricultura de mercado externo versus agricultura de mercado interno.

2) Agricultura comercial versus agricultura de subsistên cia ou ainda moderna versus tradicional.

3) Várias "nuances" das formas referidas com maior ou me nor grau de especificidade.

MENDONÇA DE BARROS e GRAHAM (1978) estudam dois aspectos relevantes :

a) se é razoável considerar a agricultura brasileira com posta de dois setores, doméstico e internacional ou ex portāiel;

b) imcompatibilidade entre abastecimento doméstico e ex portação e quais as consequências de um maior grau de abertura ao exterior. 
Consideram três regiōes, Nordeste, Estado de São Paulo e Centro Sul (excluindo São Paulo) para as quais constroem indices de produçāo e produtividade por produto no período de 1962-76. Concluem que a produçāo agrícola total cresceu, nos últimos 15 anos, a taxas mais elevadas que a média histórica das ủitimas décadas, produtos domés ticos crescendo persistentemente menos que os exportáveis, especialmente entre 1968 e 76. Em termos de produtividade - grupo de produtos domésticos apresenta evolução extre mamente desfavorável, com exceção de São Paulo.

A análise regional mostra que o crescimento da produção no Sul do país se faz muito mais em direção aos produtos exportáveis. No Nordeste, ocorre o oposto, elevando-se a importância do setor doméstico. Ao analisar- grau de abertura ao exterior mostram que a agricultura tem tido uma participação crescente embora percentualmente menor, como é esperado em função $\rightarrow$ de maior desenvolvimento econômico. No agregado o valor das exportaçōes como parce la da produção agrícola vendida tem vindo a aumentar, pro cesso que evidencia uma maior abertura ao exterior.

HOMEM DE MELO (1978) aborda dois aspectos importantes da divisāo que, inicialmente, realiza da agri cultura : incerteza e disponibilidade de tecnologia. classifäcaçāo adoptada, segundo a participaçāo do produto na pauta de exportações e medidas governamentais utiliza das é a seguinte :

1) Produtos de mercado interno : arroz, feijāo, batata, ce bola e mandioca.

2) Produtos de mercado externo : algodāo, soja, café 
cana.

3) Produtos intermediários milho e amendoim.

4) Produtos administrados cana e café.

A utilização de modelos econométricios de de terminação de preços recebidós pelos agricultores mostra a consistência da divisão efetuada.

PATRICK (1975) analisa as fontes de cresci mento da agricultura e utiliza, também, a classificação de culturas em "Modernas" e "Tradicionais" segundo a inten sidade de uso de insumos adquiridos. Uma versão modificada do modelo Shift-Share foi utilizado ao quantificar as fon tes de crescimento.

As culturas "modernas" mostraram um cresc $\underline{i}$ mento a taxas mais elevadas. As fontes de crescimento di feriram bastante entre os dois grupos. Os diferentes pa drões de crescimento, segundo o autor, não surpreenderam, dada a diversidade de condiçōes econômicas e agronômicas, sugerindo que a forma mais econômica de se obter um aumen to na produção varia entre regiões e culturas. E importan te a colocação conclusiva do autor : "A questão crítica que não é respondida neste estudo é como deveria o Gover no intervir para encorajar um crescimento agrícola social mente desejado, a fim de atingir os objetivos nacionais-de desenvolvimento".

DELGADO (1979) discute o impacto das poI îti cas econômicas recentes, sobre diversos segmentos do setor agrícola, segundo a classificação em : Subsetor "Moderno", Subsetor "Arcaico" e Subsetor "Fronteira Agrícola". 
Ilustramos a diversidade de formas em que a agricultura é subdividida na anālise econômica. Com maior grau de especificidade também ocorrem as subdivisōes que se procura ilustrar com mais algumas citaçōes.

PASTORE (1971), ao estudar a oferta de produ tos agrícolas na Brasil subdivide os produtos de consumo interno em dois sub-grupos : produtos consumidos sem pré via transformação industrial, produtos de "alimentação" e produtos consumidos depois de uma transformação industrial ("industrializáveis"). Justifica essa sub-divisão pela constatação de que produtos de alimentação tèm um desenvol vimento tecnológico menor do que os produzidos como maté ria-prima para a "indústria".

PAIVA (1979), a o analisar o comportamento de preços segundo as diferentes classes de produtos, classi fica os produtos de consumo interno em três categorias :

a) Culturas comerciais "restritas"

b) Culturas comerciais "generalizadas"

c) Culturas não comerciais e de "autoconsumo"

$\mathrm{Na}$ primeira categoria de produtos inclui cul turas exigentes em questōes de solo e clima, susceptíveis a pragas e moléstias, não facilmente cultivadas pela maio ria dos agricultores. Criam-se condiçōes de restrição de oferta e seus preços se elevam. Deixa de existir o "exces so de capacidade potencial" de produção que caracteriza os demais produtos de mercado interno.

Na segunda classe inclui produtos que não sọ 
frem restrições de solo ou clima, podendo ser cultivados por grande número de agricultores, empregando tanto técni cas modernas como tradicionais.

"Os preços dos produtos desta classe ao con trário dos da classe anterior, não se situam em níveis sa tisfatórios para os agricultores devido ao excedente poten cial de produção de que vimos falando" (PAIVA, 1979, p. 128).

$\mathrm{Na}$ terceira categoria inclui produtos bás cos de alimentação produzidos de forma não comercial com maior independência do nível de preços e dos custos de produção o que dificulta a entrada no mercado de produções comerciais com moderna tecnologia.

MOREIRA E CASTRO (1977) desmembram a agricuI tura brasileira de exportação em três grupos:

a) Produtos tradicionais, reunindo produtos que de longa data participam da pauta de exportações (café, açúcar. a l godão) .

b) Produtos dinâmicos, onde incluem os produtos exportáveis que se caracterizam por resposta pronta e contínua aos estímulos do mercado internacional (soja, cacau, laran ja e sucos).

c) Potencialmente significativos, incluindo os produtos que encontram obstáculos em reagir às oportunidades inter cionais (desorganização do mercado, baixo nível tecnoló gico, falta de apoio na comercialização, limitações do comércio internacional). 


$$
.35 \text {. }
$$

Verifica-se que as subdivisōes sāo inúmeras e dependem do objeto da análise, mas, de forma geral, nāo deixam de poder ser enquadradas no àmbito das formas refe ridas inicialmente. 

O objeto do estudo constitui-se de um peque- no número de culturas selecionadas segundo os seguintes critérios:

1) Obter dois grupos de culturas que representam produtos com características distintas; produtos essencialmente exportados ou industrializados e produtos típicos de ali mentação básica.

2) Maior representatividade possível da agricultura em fun ção da importância relativa do valor da produção e área ocupada na agricultura brasileira.

3) Disponibilidade de informações.

A escolha recaiu nas seguintes culturas: cana-de-açūcar, algodão 1/, soja, milho, arroz e feijão.

1/ Para algodão é necessário mencionar que não se considerou a cultura arbórea no cálculo das variáveis selecionadas. 
Cana-de-açūcar, algodão e soja representam os produtos que participam do comércio externo além de se rem, tambëm, matéria-prima para a indústria nacional; as culturas de feijão e arroz representam os produtos típicos de alimentação básica, sem participação significativa na pauta de exportações e não constituindo matéria-prima para a indústria; a cultura de milho ocupa uma posição intermediāria, com participação esporādica na pauta de exportações, como grande potencial como matéria-prima industrial ao mesmo tempo que pode ser considerado um produto de alimenta ção.

A Tabela 2 fornece uma idéia da importância relativa deste grupo de culturas na agricultura brasileira com aproximadamente $60 \%$ do valor total da produção e $73 \%$ da área colhida (de um grupo de 38 culturas contabilizadas).

A caracterização das diferentes culturas è feita, inicialmente, em relação a três aspectos:

1) Nível tecnológico-utilização de insumos modernos.

2) Estrutura produtiva e fundiāria.

3) Si-tema de comercialização.

A caracterização das cultruas restringiu-se às informações censitārias disponíveis (Censo Agropecuário, IBGE), assim como as variáveis foram escolhidas e construí das procurando captar todos os aspectos relevantes dessas informações. A especificação das variäveis pode se tornar pouco clara caso não se faça referência à organização das informações. 
.38 .

TABElA 2 - Area Colhida e Valor da Produção das Principais Culturas Brasileiras, 1974

1) Herbáceo e arbóreo; 2) Das águas e das secas;

3) Total de 38 culturas.

Cultura

Area colhida

(1.000.ha)
8 Valor da Produçāo

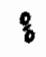

(Cr $\$ 1.000 .000,00)$

\begin{tabular}{lcccc} 
Milho & 9.914 & 25,6 & 5.086 & 11,3 \\
Arroz & 4.795 & 12,4 & 4.436 & 9,8 \\
Algodão (1) & 4.319 & 11,2 & 3.903 & 8,6 \\
Feijão (2) & 3.815 & 9,8 & 4.317 & 9,5 \\
Soja & 3.615 & 9,3 & 5.552 & 12,3 \\
Mandioca & 2.119 & 5,5 & 3.413 & 7,6 \\
Café em coco & 2.080 & 5,4 & 3.987 & 8,8 \\
Cana-de-açūcar & 1.959 & 5,1 & 3.276 & 7,3 \\
Trigo & 1.893 & 4,8 & 1.470 & 3,3 \\
Subtotal & 34.428 & 89,1 & 35.391 & 78,5 \\
Outros & 4.230 & 10,9 & 9.687 & 21,5 \\
\hline T o T A L (3) & 38.658 & 100,0 & 45.078 & 100,0 \\
\hline
\end{tabular}

FONTE : Fundação Instituto Brasileiro de Geografia e Esta tística (FIBGE), In : Suplan (1975). 
Todas as variáveis, à exceção de índices de concentração da área de colheita, são definidas em rproporções, podendo ser calculadas a partir do número de infor mantes, quantidade produzida, área, ou ainda, valor da pró dução.

As informações referentes ao nível de utili zação de insumos modernos (tecnologia) estão organizadas inicialmente segundo a utilização de sementes selecionadas e sementes comuns e, dentro destes dois grupos, se inserem as informações quanto a outros insumos ou técnicas como irrigação, defensivos e adubação.

As variáveis que representam a estrutura de produção são, além dos índices de concentração da área de colheita, relativas à condição do produtor envolvido na pro dução e à forma de cultivo. As informações censitárias dis poníveis estão organizadas segundo a condição do produtor em 4 tipos : proprietário, arrendatário, parceiro e ocupan te. As formas de cultivo consideradas são : cultivo sim ples, cultivo associado e cultivo intercallado e misto.

Em relação ao processo de comercialização as informações são organizadas segundo o destino... da produção considerando as seguintes opções :

1) Consumido no estabelecimento

2) Entregue à cooperativa

3) Entregue à indústria

4) Entregue ao intermediário

5) Venda direta ao consumidor 
As variāveis selecionadas são calculadas a partir de informações para consumo no estabelecimento, ven da direta ao consumidor e produção entregue a intermediá rio.

Seguem-se, agora, as especificações do conjun to de variáveis utilizadas em todas as análises estatístí cas.

$x_{1}$ - Fração da produção proveniente de culturas com utiliza ção de sementes comuns e sem qualquer đrática "moder: na.

$x_{2}$ - Fração da produção proveniente de culturas com utiliza ção de sementes selecionadas comou sem outros tipos de práticas modernas.

$x_{3}$ - Fração da produção proveniente de culturas com utiliza ção de qualquer tipo de tecnologia excluindo o uso iso lado de sementes selecionadas.

$x_{4}$ - Fração da produção proveniente de culturas com utiliza ção de adubação.

$\mathrm{X}_{5}$ - Fração do número de informantes na produção de cultú ras efetuadas por parceiro e ocupante.

$x_{6}$ - Fração da produção cujo destino é o consumo no estabe lecimento.

$x_{7}$ - Fração da produção cujo destino é a venda direta ao consumidor.

$x_{8}$ - Fração da produção cujo destino é a venda ao interme diário.

$x_{9}$ - Fração da produção proveniente de culturas efetuadas 
em cultivo simples.

$\mathrm{X}_{10}$ - Indice de Gini da área de colheita estimado, segundo HOFFMANN (1979), considerando desigualdade dentro dos estratos, pressupondo que a distribuição dentro dos estratos tem função de densidade linear e, no ültimo estrato quando aberto à direite, função de Pareto com dois parâmetros.

$\mathrm{X}_{11}$ - Indice de Theil da área de colheita estimado de forma idêntica ao Indice de Gini.

o conjunto de variáveis escolhidas possui, então, a seguinte estrutura:

a) Quatro variāveis $\left(x_{1}, x_{2}, x_{3}\right.$ e $\left.x_{4}\right)$ procurando captar 0 nível de utilização de insumos modernos.

b) Quatro variáveis $\left(x_{5}, x_{9}, x_{10}\right.$ e $\left.x_{11}\right)$ representando a estrutura de produção.

c) Três variáveis $\left(x_{6}, x_{7}\right.$, e $\left.x_{8}\right)$ procurando caracterizar o tipo de comercialização.

Em termos agregados, para o Brasil, realiza- se uma análise (tabular) comparada entre cultunas considerando as várias informações disponíveis além das escolhidas para a espeficicação das variáveis. 
Denomina-se progresso tecnológico ll à parcela do crescimento da produção nāo explicada pela expansão dos fatores, ou seja, o resíduo correspondente ao aumento na produçāo menos a contribuição dos fatores especificados em tal produção. Uma tecnologia é considerada mais avançada ou preferível quando o conjunto de processos produ tivos que a compoom possibilita produzir a mesma quantidade do produto empregando menor quantidade de fatores que as demais tecnologias ou quando a soma dos gastos com os fatores é inferior para a mesma produção. (VERA FILHO e TOLLINI, 1979).

E de consenso comum, contudo, que a utiliza ção de sementes selecionadas ou adubação, por exemplo sāo fatores determinantes de uma maior modernizaçāo, sendo mais imediata essa relação a nível agregado.

As 4 primeiras variáveis são facilmente asso ciadas a uma maior ou menor modernização. Para as restantes variáveis procurar-se-á através de análise temporal e regional inferir qual a forma como se relaciona com uma maior ou menor modernização.

A Tabela 3 apresenta à informaçōes disponíveis para o cálculo da primeira variável para as diferentes culturas. Verifica-se que as percentagens da quantidade produzida, área de produçāo ou valor da produção com

If As expressões progresso tecnológico, modernização e maior tecnificação serão consideradas sinônimas. 
sementes comuns são nitidamente distintas para as culturas de cana, algodão e soja. As culturas de milho e arroz apre : sentam uma posição intermediária e o feijão o extremo opos to.

TABELA 3 - Fração do número de informantes, quantidade pro duzida, área e valor da produção obtida em fun ção de culturas com uso de sementes comuns, sem qualquer prática moderna. Brasil, 1975.

\begin{tabular}{lcccc}
\hline & \multicolumn{4}{c}{ Proporção de } \\
\cline { 2 - 5 } Culturas & Inf. & Quant.(t) & Area(ha) & Valor \\
\hline Cana & 0,759 & 0,079 & 0,123 & 0,093 \\
Algodão & 0,439 & 0,060 & 0,169 & 0,061 \\
Soja & 0,429 & 0,099 & 0,138 & 0,090 \\
Milho & 0,664 & 0,360 & 0,472 & 0,353 \\
Arroz & 0,768 & 0,375 & 0,425 & 0,328 \\
Feijão & 0,752 & 0,719 & 0,713 & 0,684 \\
\hline
\end{tabular}

FONTE de dados básicos : Fundação Instituto Brasileiro de Geografia e Estatística - Censo Agropecuário 1975

A comparação da percentagem de informantes que utilizam sementes comuns mostra o mesmo padrão de com portamento anterior, com exceção da cultura de cana, com elevada percentagem, que se justifica pela alta concentra ção de sua produção (compare-se a percentagem de informan tes e percentagem produzida com sementes comuns) e forma de reprodução vegetativa. 
O conjunto das restantes variáveis referentes à utilização de "insumos modernos" apresentam icomportamento semelhante, motivo pelo qual se omite a sua apresentação e discussão prévia a nível agregado.

Em relação à estrutura produtiva e fundiāria as Tabelas 4,5 e 6 apresentam os resultados segundo - tipo de produtor e, a Tabela 7 , os resultados segundo a prática de cultivo simples. Os índices de concentração serão apresentados posteriormente.

Na análise da Tabela 4 (produção pelo proprietário) verifica-se que as culturas com valores inferiores (de acordo com a quantidade produzida, área e valor) são arroz, feijão e algodão.

A comparação entre os valores relativos obtidos mostrará mais algumas peculiaridades. A relação entre a proporção da quantidade produzida e a proporção da área mede a produtividade relativa da terra, neste caso de um tipo de produtor em relação aos restantes. A rela ção entre a proporção do valor obtido e a proporção da quantidade produzida dá-nos o preço de venda relativo no presente caso, de um tipo de produtor em relação aos restantes.

De acordo com este critério os proprietários detêm menor produtividade nas culturas de algodão, arroz e feijão e menor preço de venda relativo na comercialização de cana e feijão. 
TABELA 4 - Fração do número de informantes, quantidade pro duzida, área e valor obtida por produtores. classificados como proprietários.

\begin{tabular}{lcccc}
\hline & \multicolumn{4}{c}{ Proporção de } \\
\cline { 2 - 5 } Culturas & Inf. & Quant.(t) & Area (ha) & Valor \\
\hline Cana & 0,852 & 0,857 & 0,857 & 0,852 \\
Algodão & 0,571 & 0,666 & 0,690 & 0,676 \\
Soja & 0,769 & 0,832 & 0,822 & 0,833 \\
Milho & 0,649 & 0,801 & 0,779 & 0,815 \\
Arroz & 0,559 & 0,624 & 0,680 & 0,644 \\
Feijão & 0,679 & 0,744 & 0,755 & 0,742 \\
\hline
\end{tabular}

FONTE de dados básicos : Fundação Instituto Brasileiro de Geografia e Estatística (FIBGE) - Censo Agropecuário 1975 .

Através da Tabela 5 pode-se concluir que a produção por Parceiro e Ocupante (conjuntamente) tem menor importância nas culturas de cana-de-açúcar, algodão e soja. A produtividade relativa é menor do que 1 para as culturas de arroz, feijão e algodão e o preço de venda relativo é também inferior a 1 para todas as culturas à exceção da ca na-de-açūcar.

0 arrendatário assume maior importância na produção de algodão e arroz. A produtividade relativa é me nor que 1 unicamente na produção de soja e milho, enquanto o preço de venda relativa é relativamente baixo apenas no ca 
TABELA 5 - Fração do número de informantes, quantidade pró duzida, área e valor obtida por produtores. classificados como parceiros e ocupantes.

\begin{tabular}{lcccc}
\hline & \multicolumn{4}{c}{ Proporção de } \\
\cline { 2 - 5 } Culturas & Inf. & Quant. $(t)$ & Area(ha) & Valor \\
\hline Cana & 0,110 & 0,023 & 0,027 & 0,024 \\
Algodão & 0,219 & 0,126 & 0,123 & 0,122 \\
Soja & 0,172 & 0,071 & 0,077 & 0,060 \\
Milho & 0,239 & 0,129 & 0,149 & 0,124 \\
Arroz & 0,279 & 0,193 & 0,183 & 0,174 \\
Feijão & 0,229 & 0,180 & 0,174 & 0,174 \\
\hline
\end{tabular}

FONTE de dados básicos : Fundação Instituto Brasileiro de Geografia e Estatística (FIBGE) - Censo Agropecuário 1975 .

so da soja.

A estrutura produtiva é caracterizada também pelo cálculo da proporção da produção em cultivo sim ples. Essa variável é, provavelmente, muito relacionada às variáveis que medem a utilização de insumos modernos, pois está fortemente relacionada com o caráter empresarial que a cultura pode assumir.

Salvo raras exceções reconhece-se tecnicamen te que a cultura com utilização intensiva de insumos moder nos e alta produtividade, tem que ser desenvolvida em cul 
TABELA 6 - Fração do número de informantes, quantidade pro duzida, área e valor obtida por produtores e classificados como arrendatários.

\begin{tabular}{llccc}
\hline & \multicolumn{4}{c}{ Proporção de } \\
\cline { 2 - 5 } Culturas & Inf. & Quant. (t) & Area (ha) & Valor \\
\hline Cana & 0,037 & 0,120 & 0,116 & 10,123 \\
Algodão & 0,211 & 0,208 & 0,176 & 0,202 \\
Soja & 0,059 & 0,097 & 0,101 & 0,045 \\
Milho & 0,112 & 0,070 & 0,072 & 0,070 \\
Arroz & 0,162 & 0,184 & 0,138 & 0,182 \\
Feijão & 0,921 & 0,077 & 0,071 & 0,083 \\
\hline
\end{tabular}

FONTE de dados básicos : Fundação Instituto Brasileiro de Geografia e Estatística (FIBGE) - Censo Agropecuário 1975 .

tivo simples. Esta afirmação é, pelo menos parcialmente, comprovada na análise da Tabela 7 ao calcularmos a produ tividade relativa na produção, evidentemente em relação aos outros tipos de cultivo.

A observação da Tabela 7 , em termos da quanti dade produzida, permite discriminar, de acordo com anālises anteriores, dois grupos de culturas; o primeiro incluindo as culturas de cana-de-açúcar, algodão e soja, o segundo incluindo as culturas restantes. Não devemos esquecer, contudo, que a aptidão para o cultivo intercaládo ou associado varia entre culturas. 
TABELA 7 - Fração do número de informantes, quantidade pro duzida e área obtida em função das culturas em cultivo simples.

\begin{tabular}{lccc}
\hline \multirow{2}{*}{ Culturas } & $\cdots$ & Proporcão de & $\cdots \cdots$ \\
\cline { 2 - 4 } & Inf. & Quant.(t) & Area(ha) \\
\hline Cana & 0,927 & 0,991 & 0,986 \\
Algodão & 0,396 & 0,880 & 0,707 \\
Soja & 0,449 & 0,830 & 0,774 \\
Milho & 0,259 & 0,503 & 0,390 \\
Arroz & 0,619 & 0,792 & 0,756 \\
Feijão & 0,263 & 0,297 & 0,206 \\
\hline
\end{tabular}

FONTE de dados básicos : Fundação Instituto Brasileiro de Geografia e Estatística (FIBGE) - Censo Agropecuário 1975.

0 último aspecto considerado, sistema de co mercialização, é caracterizado pelas variáveis : consumo no estabelecimento, venda direta a consumidor e venda a intermediário. A análise destas variáveis calculadas a ní vel agregado segundo a percentagem de número de informan tes, percentagem da quantidade produzida, percentagem da área e percentagem do valor merece alguns comentários. (Ob serve Tabelas 8,9 e 10 ).

Supōe-se frequentemente que a produção para consumo no estabelecimento corresponde a uma produção de baixa tecnologia. Os resultados apresentados na Tabela 8 confirmam essa suposição, já que a produtividade relativa 
TABELA 8 - Fração do número de informantes, quantidade pro duzida, área e valor obtida em função das cul turas cujo destino é o consumo no estabelecimen to.

\begin{tabular}{llccc}
\hline & \multicolumn{4}{c}{ Proporção de } \\
\cline { 2 - 5 } Culturas & Inf. & Quant.(t) & Area (ha) & Valor \\
\hline Cana & 0,657 & 0,051 & 0,084 & 0,665 \\
Algodão & 0,013 & 0,002 & 0,002 & 0,002 \\
Soja & 0,030 & 0,006 & 0,008 & 0,008 \\
Milho & 0,504 & 0,353 & 0,387 & 0,387 \\
Arroz & 0,422 & 0,094 & 0,139 & 0,139 \\
Feijão & 0,528 & 0,228 & 0,290 & 0,290 \\
\hline
\end{tabular}

FONTE de dados bāsicos : Fundação Instituto Brasileiro de Geografia e Estatística (FIBGE) - Censo Agropecuário 1975 .

na produção (relação entre proporções de produção e área) é menor do que 1 para todas as culturas. Em termos gerais e no agregado não se cometerá grande erro ao aceitar essa afirmativa, embora existam exceções, mais frequentes em de terminados produtos, por exemplo o milho.1/ Na cada-de-açúcar a proporção elevada de informantes deve-se ao grande número de. "mini-produtores" que não produzem para a indústria.

A análise dos resultados da Tabela 9 permite chegar a conclusões aproximadamente idênticas às anteriores para a variável "consumo no estabelecimento".

1/ A cultura do milho e, também a cultura de cana-de-açúcar, são frequentemente utilizadas como forragem para a limentação animal no próprio estabelecimento. 
TABELA 9 - Fração do número de informantes, quantidade pro duzida, área e valor obtida em função das cultú ras cujo destino é a venda direta ao consumidor.

\begin{tabular}{llccc}
\hline & \multicolumn{4}{c}{ Proporção de } \\
\cline { 2 - 5 } Cultura & Inf. & Quant(t) & Area(ha) & Valor \\
\hline Cana & 0,026 & 0,004 & 0,006 & 0,005 \\
Algodão & 0,018 & 0,008 & 0,011 & 0,008 \\
Soja & 0,012 & 0,011 & 0,012 & 0,011 \\
Milho & 0,065 & 0,063 & 0,065 & 0,066 \\
Arroz & 0,032 & 0,030 & 0,034 & 0,030 \\
Feijão & 0,063 & 0,064 & 0,069 & 0,070
\end{tabular}

FONTE de dados básicos : Fundação Instituto Brasileiro de Geografia e Estatística (FIBGE) - Censo Agropecuário 1975.

TABELA 10 - Fração do número de informantes, quantidade pro duzida, área e valor em função das culturas cujo destino é a venda a intermediário.

\begin{tabular}{lclcc}
\hline & \multicolumn{4}{c}{ Proporção de } \\
\cline { 2 - 5 } Cultura & Inf. & Quant.(t) & Area(ha) & Valor \\
\hline Cana & 0,088 & 0,024 & 0,032 & 0,028 \\
Algodão & 0,848 & 0,491 & 0,606 & 0,465 \\
Soja & 0,635 & 0,341 & 0,370 & 0,330 \\
Milho & 0,414 & 0,514 & 0,500 & 0,507 \\
Arroz & 0,456 & 0,612 & 0,636 & 0,597 \\
Feijão & 0,401 & 0,686 & 0,627 & 0,698 \\
\hline
\end{tabular}

FONTE de dados básicos: Fundação Instituto Brasileiro de Geografia e Estatística (FIBGE) - Censo Agropecuärio 1975 
Para a variāvel. "venda a intermediärio" (Tabela 10), verifica-se existir, também, uma separação entre dois grupos de culturas. A produtividade relativa na produ ção é inferior a 1 para todas as culturas à exceção de feijão e milho. O preço de venda relativo é maior que 1 para a cana-de-açúcar e principalmente para o feijão.

A melhor compreensão do comportamento das va riáveis escolhidas em relação ao conceito de maior ou menor. "modernização" é possível pela anālise no tempo (assumindo evolução positiva no sentido de uma maior moderniza(̧ão) e inter-regional. Na análise temporal surgem limitações de informação que restringem as possibilidades de comparações .

Para as variäveis que procuram medir o nivel de utilização de insumos modernos, dadas as restrições de informação e as expectativas obvias do sentido das alterações no tempo 1/ omite-se a análise dessa evolução. Quanto à estrutura produtiva, algumas comparações no tempo foram possíveis. A Tabela 11 apresenta as alterações na produção por parceiro e ocupante de forma conjunta. Verifica-se uma diminuição da importância relativa destes tipos de produtores, a menor alteração ocorrendo para o feijão, as culturas de arroz, milho e cana-de-açúcar com pequenas alterações e as culturas de algodão e soja com as maiores modificações.

1/ Foram analisadas as informações disponíveis para 1970 e 1975 que permitiram obter fundamento a esta afirmação; $\mathrm{x}_{1}$ tende a diminuir de valor, enquanto $\mathrm{x}_{2}, \mathrm{x}_{3}$ e $\mathrm{x}_{4}$ tendem a um aumento. 
TABELA 11 - Fraçāo do número de informantes, quantidade pró duzida e área obtida por produtores classifi cados como parceiros e ocupantes, para 1970 e 1975 , Brasil.

\begin{tabular}{lccccccc}
\hline & \multicolumn{4}{c}{1970} & & \multicolumn{3}{c}{1975} \\
\cline { 2 - 4 } & Inf. & $\begin{array}{c}\text { Quant. } \\
(\mathrm{t})\end{array}$ & $\begin{array}{c}\text { Area } \\
(\text { ha })\end{array}$ & & Inf. & $\begin{array}{c}\text { Quant } \\
(\mathrm{t})\end{array}$ & $\begin{array}{c}\text { Area } \\
\text { (ha) }\end{array}$ \\
\hline Cana & 0,123 & 0,035 & 0,047 & 0,110 & 0,023 & 0,027 \\
Algodão & 0,253 & 0,164 & 0,180 & 0,219 & 0,126 & 0,133 \\
Soja & 0,210 & 0,122 & 0,120 & 0,172 & 0,071 & 0,077 \\
Milho & 0,240 & 0,150 & 0,162 & 0,239 & 0,129 & 0,149 \\
Arroz & 0,290 & 0,211 & 0,202 & 0,279 & 0,193 & 0,183 \\
Feijão & 0,229 & 0,188 & 0,181 & 0,229 & 0,180 & 0,174 \\
\hline
\end{tabular}

FONTE de dados básicos : Fundação Instituto Brasileiro de Geografia e Estatística (FIBGE) - Censo Agropecuário 1970 e 1975 . 
TABELA 12 - Fração do número de informantes, quantidade pro duzida e área obtida em função das culturas em cultivo simples, para 1970 e 1975.

\begin{tabular}{|c|c|c|c|c|c|c|}
\hline & \multicolumn{3}{|c|}{1970} & \multicolumn{3}{|c|}{1975} \\
\hline & Inf. & $\begin{array}{l}\text { Quant. } \\
\text { (t) }\end{array}$ & $\begin{array}{l}\text { Area } \\
\text { (ha) }\end{array}$ & Inf. & $\begin{array}{l}\text { Quant. } \\
(t)\end{array}$ & $\begin{array}{l}\text { Area } \\
\text { (ha) }\end{array}$ \\
\hline Cana & 0,910 & 0,973 & 0,963 & 0,927 & 0,991 & 0,986 \\
\hline Algodão & 0,434 & 0,873 & 0,690 & 0,396 & 0,880 & 0,707 \\
\hline Soja & 0,232 & 0,477 & 0,423 & 0,449 & 0,830 & 0,774 \\
\hline Milho & 0,252 & 0,389 & 0,321 & 0,259 & 0,503 & 0,390 \\
\hline Arroz & 0,601 & 0,774 & 0,723 & 0,619 & 0,792 & 0,756 \\
\hline Feijão & 0,239 & 0,233 & 0,164 & 0,263 & 0,297 & 0,206 \\
\hline
\end{tabular}

FONTE de dados básicos : Fundação Instituto Brasileiro de Geografia e Estatística (FIBGE) - Censos Agropecuã rios 1970 e 1975.

A produção em cultivo simples (Tabela 12) so freu um incremento generalizado entre 1970 e 1975 de forma mais intensa na cultura de soja.

A apresentação e análise dos índices de con centração, variáveis importantes na caracterização da estru tura produtiva, será feita posteriormente.

A análise no tempo das variáveis que caracte rizam o sistema de comercialização não foi possível, por deficiência de informações. 
Dispondo do cálculo das variāveis para cada cultura $1 /$ por Estado (unidade analitica utilizada e que denominaremos de "observação") de acordo com a especifica ção das variáveis descritas inicialmente, a análise regional através da agregação dos dados obtidos para as várias culturas por Estado pode evidenciar o diferente comportamen to das variáveis em diferentes estados em estágios diferen ciados de desenvolvimento tecnológico.

A Tabela 13 apresenta os resultados agregados para quatro Estados: São Paulo, Minas Gerais, Paraná e Mato Grosso em termos da média aritmética dos valores encontrados para as seis culturas consideradas. Para Mato Grosso foi possível contabilizar somente a média para as culturas de cana-de-açúcar, arroz, milho e feijão. Verifica-se, por exemplo, que a variāvel $x_{1}$ (fração da quantida de produzida com sementes comuns) tem o menor valor para São Paulo. Para as outras variáveis que medem diretamente o nível de utilização de "insumos modernos", $x_{2}, x_{3}$ e $x_{4}$, verifica-se situação inversa.

$1 /$ o cälculo de todas as variáveis foi realizado por cultura em cada una das unidades da Federação, à exceção das unidades que constituem a região Norte (apresentado em:Apêndice). 
TABELA 13 - Valores agregados das värias variáveis calcula dos a partir da média aritmética dos valores do conjunto de culturas por Estado.

\begin{tabular}{lccccccccc}
\hline $\begin{array}{l}\text { Estado/ } \\
\text { Var. }\end{array}$ & $x_{1}$ & $x_{2}$ & $x_{3}$ & $x_{4}$ & $x_{5}$ & $x_{6}$ & $x_{7}$ & $x_{8}$ & $x_{9}$ \\
S.Paulo & 0,111 & 0,633 & 0,849 & 0,805 & 0,163 & 0,052 & 0,037 & 0,431 & 0,942 \\
M.Gerais & 0,191 & 0,484 & 0,766 & 0,565 & 0,065 & 0,176 & 0,055 & 0,473 & 0,711 \\
Paraná & 0,354 & 0,442 & 0,559 & 0,419 & 0,245 & 0,083 & 0,015 & 0,530 & 0,720 \\
M.Grosso & 0,657 & 0,225 & 0,309 & 0,206 & 0,337 & 0,163 & 0,096 & 0,516 & 0,627 \\
\hline
\end{tabular}

FONTE de dados básicos : Fundação Instituto Brasileiro de Geografia e Estatística (FIBGE) - Censo Agropecuário 1975 .

\subsection{Anālise Discriminante}

A análise tabular realizada permite distin guir, essencialmente, dois grupos de culturas com comporta mento distinto em relação aos três aspectos considerados : nível tecnológico, estrutura produtiva e sistema de comer cialização.

$\mathrm{Na}$ falta de melhor denominação, adota-se a terminologia de "culturas modernizadas" e culturas "não mo dernizadas" para distinguir os dois grupos de culturas.

Explicitamente admite-se que as relaçōes de cada variável com uma maior ou menor modernização são as 
seguintes :

Variāvel

$x_{1}$

$\mathrm{x}_{2}$

$\mathrm{x}_{3}$

$x_{4}$

$x_{5}$

$x_{6}$

$x_{7}$

$x_{8}$

$x_{9}$
Relação com

"maior modernização"

$$
\begin{aligned}
& \text { negativa } \\
& \text { positiva } \\
& \text { positiva } \\
& \text { positiva } \\
& \text { negativa } \\
& \text { negativa } \\
& \text { indefinida } \\
& \text { indefinida } \\
& \text { positiva }
\end{aligned}
$$

A especificação das variāveis é identica à descrita inicialmente, utilizada na breve análise regional entre Estados e nas análises estatísticas seguintes.

Verifica-se que a discriminação entre os dois grupos de culturas segundo o padrão de comportamento das diferentes variáveis não é perfeita e torna-se por vezes difícil de ser efetuada. O uso das médias das variáveis po de não ser suficiente para permitir classificação adequada ao se realizar análises ao nível de cultura por Estado. Con tudo, é possível encontrar uma combinação linear das várias variáveis, cuja distribuição para os dois grupos possuirá pouca sobreposição. Essa combinação pode então ser usada na construção de um indice que classificará, através dos valores das várias variáveis, uma nova observação num dos 
dois grupos de culturas. Segue-se, então, uma apresentação sumária do método de análise discriminante para dois grú pos.

Seja $x_{i j} \circ$ valor da j-ésima observação da i-ésima variāvel. Vamos admitir que temos $n$ variảveis, com $\mathrm{N}_{1}$ observações classificadas no primeiro grupo e $\mathrm{N}_{2}$ obser vações classificadas no segundo grupo. O nümero total de observações é $N=N_{1}+N_{2}$. Se colocarmos as $N_{1}$ observações classificadas no primeiro grupo antes das $\mathrm{N}_{2}$ observações do segundo grupo, os dados podem ser representados por :

$$
\begin{aligned}
x_{i j}, \operatorname{com} i & =1, \ldots \ldots, n \\
e j & =1, \ldots \ldots, N_{1}, N_{1}+1, \ldots . N
\end{aligned}
$$

Consideremos uma combinação linear das $\mathrm{n}$ va riảveis :

$$
w_{j}=\sum_{i=1}^{n} \theta_{i} X_{i j}
$$

0 problema consiste, então, em determinar os valores dos $\theta_{i}$ de maneira que $o$ valor de $W$ permita dife renciar, da melhor maneira possível, os membros dos dois grupos.

Para fazer uma representação gräfica do pro blema, vamos considerar que haja apenas duas variáveis, is to é, $n=2$. A função discriminante fica:

$$
w_{j}=\theta_{1} x_{i j}+\theta_{2} x_{2 j}
$$


Em um sistema de eixos cartesianos ortogonais com coordenadas $X_{1}, X_{2} e w$, essa equação corresponde a um plano passando pela origem dos eixos, como mostra a Figura 3.

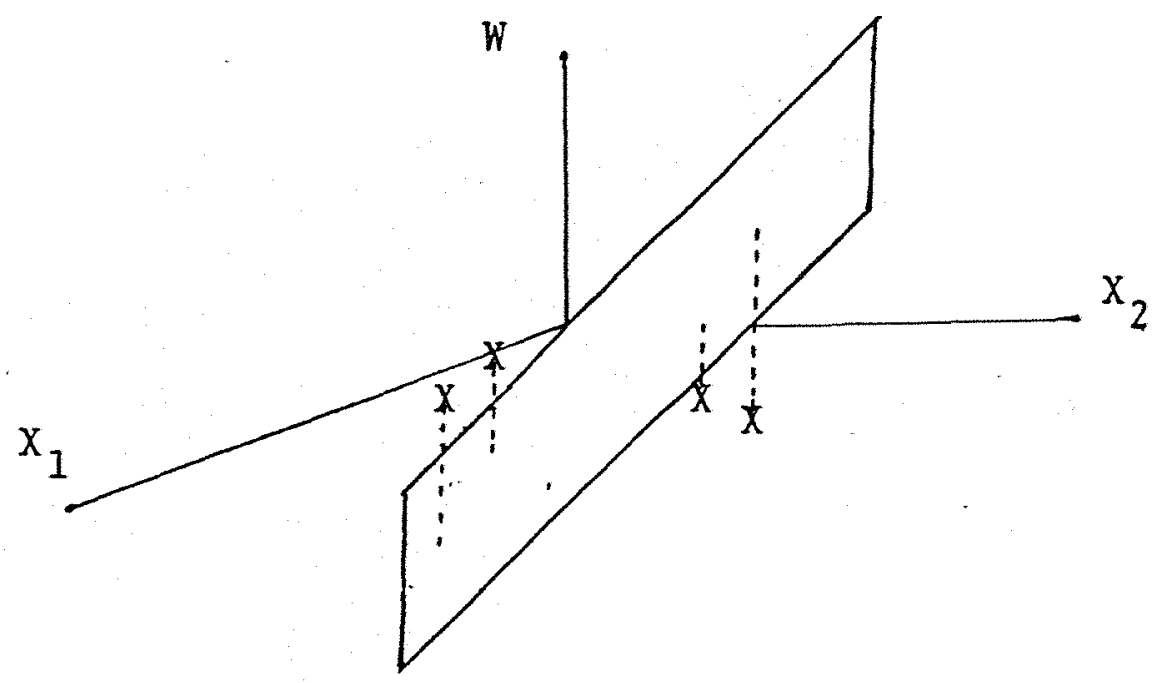

Figura 3 .

Torna-se necessārio, então, escolher um plano que maximize a variância dos valores de W entre grupos em relação à variância dos valores de w dentro dos grupos. Em outras palavras, trata-se de determinar os valores de $\theta_{1}$ e ${ }_{2}$ que maximizam a relação :

$$
\psi=\frac{\left(\bar{w}_{1}-\bar{w}_{2}\right)^{2}}{\sum_{j=1}^{N_{1}}\left(w_{j}-\bar{w}_{1}\right)^{2}+\sum_{j=N_{1}+1}^{N}\left(w_{j}-\bar{w}_{2}\right)^{2}}
$$


onde $\bar{W}_{1}$ e $\bar{W}_{2}$ são as médias dos valores de $W$ para o primei ro e para o segundo grupo, respectivamente. Entretanto, es sa condição ainda não permite determinar os valores dos ${ }_{i}$ pois o valor de $\psi$ não é alterado se multiplicarmos todos os $\theta_{i}$ por uma constante qualquer. Para obter uma solução única é necessärio impor uma restrição aos valores dos $\theta_{i}$. Pode mos, por exemplo, fixar $\theta_{1}=1$ ou estabelecer que o denomi nador de $\psi$ seja igual a 1 .

0 método estatístico de análise discriminante permite verificar a existência de diferenças sistemáticas entre culturas, segundo dois grupos estabelecidos (cana-de - açúcar, algodão e soja, grupo "modernizado" e as restantes culturas, grupo "não modernizado") .

A anālise tabular inicial, a nível agregado para o Brasil, foi suficiente para estabelecer "substrato" para uma análise estatística mais detalhada.

Dois caminhos são possíveis na análise dis criminante. Um dos caminhos alternativos é o estabelecimen to de dois grupos distintos, através da seleção das "obser vações" $1 /$ típicas (exclusivamente em função do valor das variāveis) de forma a ajustar uma função discriminante em condições de classificar as restantes "observações". 0 se gundo consiste na pré-classificação segundo a hipótese es tabelecida de dois grupos de culturas distintos (em relação a todas as variáveis e que denominamos de grupo "moderniza do" e grupo "não modernizado") estabelecendo uma função dis

I/ Entende-se por "observação." o valor de todas as varia veis com referência a uma determinada cultura por Esta do. 
criminante que detectarā as "observações" prë-classificadas erroneamente (que não se incluem no grupo no qual foram pré -classificadas).

o primeiro procedimento é dificultado pelo estabelecimento à priori das "observações" típicas.

Optou-se pelo segundo procedimento, cujos re sultados são apresentados e analisados. A análise de regres são linear múltipla, a variável dependente assumindo valor zero para as culturas consideradas "não modernizadas" e va lor 1 para o grupo de culturas consideradas "modernizadas", é um método equivalente. Como a variável dependente assume exclusivamente valores zero e um, não se pode pressupor que tenha distribuição normal e, consequentemente os valores de"F'e "t"não podem ser utilizados para efetuar testes de significância, sendo apenas indicadores da qualidade do ajustamento.

A Tabela 14 apresenta a matriz de correlações simples, incluindo agora as variāveis $X_{10}, X_{11}$ e $Y$ que são respectivamente dois indices de concentração da colheita(ín dice de Gini e indice de Theil) e a variável dependente (Y) utilizada na análise de regressão linear múltipla.

A observação da matriz de correlações permi te visualizar todas as interrelações entre as variáveis con sideradas. E importante a constatação de que se confirmam as relações que havíamos admitido quanto ao comportamento das variáveis em todos os sentidos (observe-se as relações de todas as variáveis com as quatro primeiras, para as quais mais facilmente se aceita sua relação com uma maior modernização). As variāveis $x_{7}$ e $x_{8}$, para as quais não se tí nha estabelecida uma relação com maior modernização, mos 
.61.

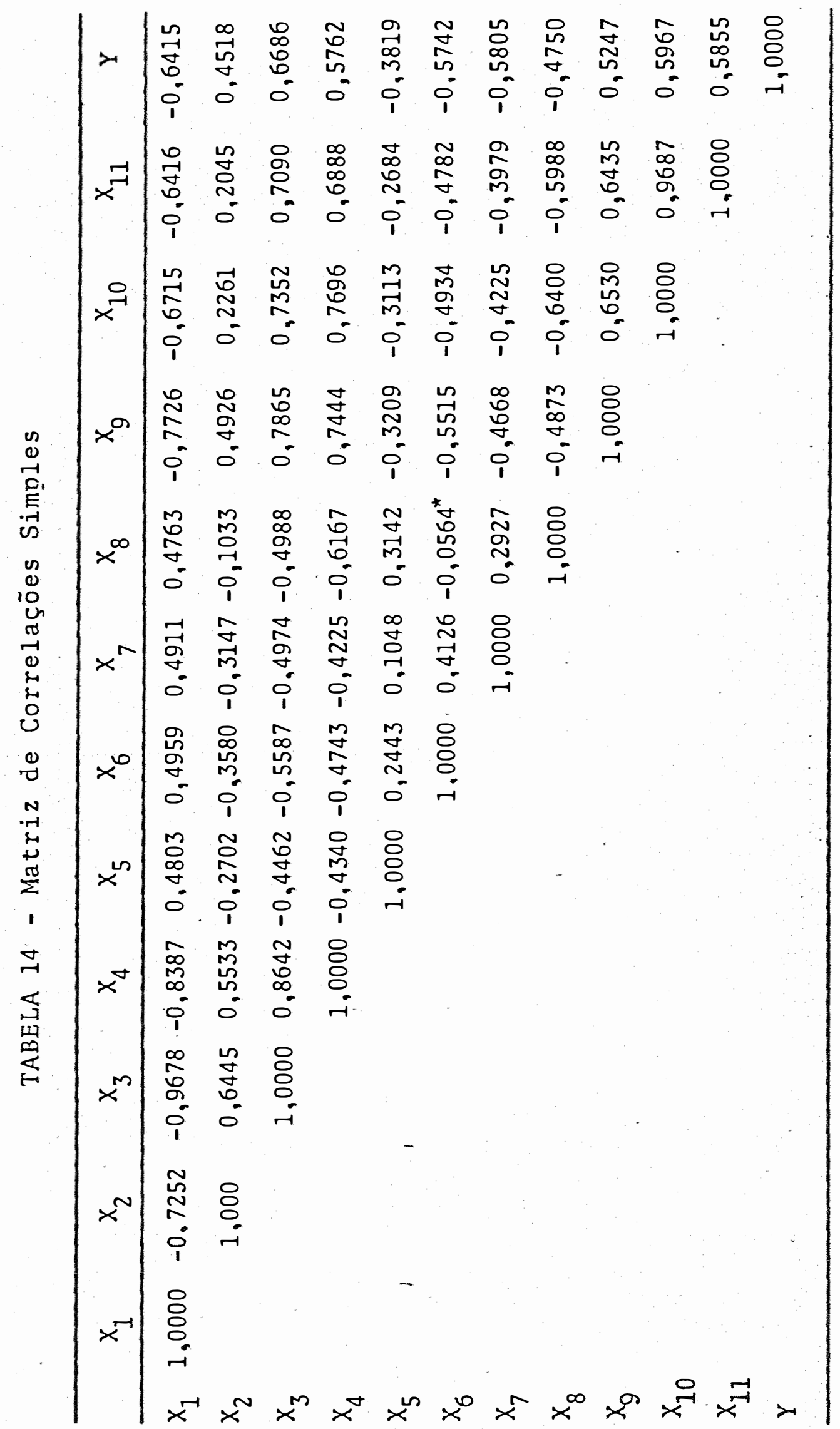


tram agora uma relação negativa, coerente, não só com as variáveis referentes à tecnologia mas com todo o conjunto de variáveis. As variáveis que apresentam relações entre si que.não de harmonia com o sentido geral determinado são assinaladas com asterístico. Na análise da Tabela 14 o úni co sinal que se poderia questionar é o correspondente à correlação entre $x_{6}$ (consumo no estabelecimento) e $x_{8}$ (ven da a intermediário) que apresenta valor próximo de zero.

Outro aspecto importante na análise da matriz de correlações é a ocorrência de valores elevados que po dem significar problemas de multicolinearidade. Para ten tar eliminar este problema prossegue-se com a análise de regressão linear múltipla suprimindo variáveis que apresen tam correlações de valor elevado.

$\mathrm{Na}$ Tabela 15 resume-se os resultados obtidos com a eliminação de algumas variáveis no ajustamento da fun ção.

TABELA $1 \not b$ - Análise de Regressão Linear Mūltipla

\begin{tabular}{|c|c|c|}
\hline Variāyeis & Coef.De term. & Teste $\mathrm{F}$ \\
\hline Todas as variáveis & 0,7358 & 17,72 \\
\hline Exclusão variāvel $x_{11}$ & 0,7329 & 19,48 \\
\hline Exclusão variáveis $X_{11}$ e $X_{3}$ & 0,7285 & 21,46 \\
\hline Exclusão variāveis $x_{11}, x_{3}$ e $X_{1}$ & 0,7243 & 23,97 \\
\hline
\end{tabular}

Verifica-se que a alteração no coeficiente de determinação é muito pequena enquanto o valor do teste $F$ au menta no sentido de uma maior significância. 
A anālise discriminante foi realizada, então, para duas situações distintas. Excluiu-se a vaviāvel $x_{11}$ no primeiro caso e, no segundo além da variável $x_{11}$ ex cluiu-se também a variável $x_{3}$, eliminando-se os maiores valores na matriz de correlações.

As Tabelas 16 e 17 constituem as matrizes de correlações para os dois grupos de culturas. Verifica - se que ocorreram algumas modificações no sentido das correla ções em relação à matriz de correlações para o conjunto das seis culturas. As principais alterações ocorrem nas variá veis que caracterizam o processo de comercialização. As "especulações" sobre o significado destas ocorrências, como a própria comparação entre as matrizes de correlações para os dois grupos de culturas, podem ser interessantes, mas não são relevantes ao presente estudo.

Na Tabela 18 apresenta-se o valor médio de cada variável nos dois grupos e o respectivo desvio padrão através dos quais se confirmam todas as diferenças espera das entre os dois grupos de culturas.

As estimativas dos parâmetros das duas fun çōes discriminantes ajustadas, são apresentadas na Tabela... 19. 


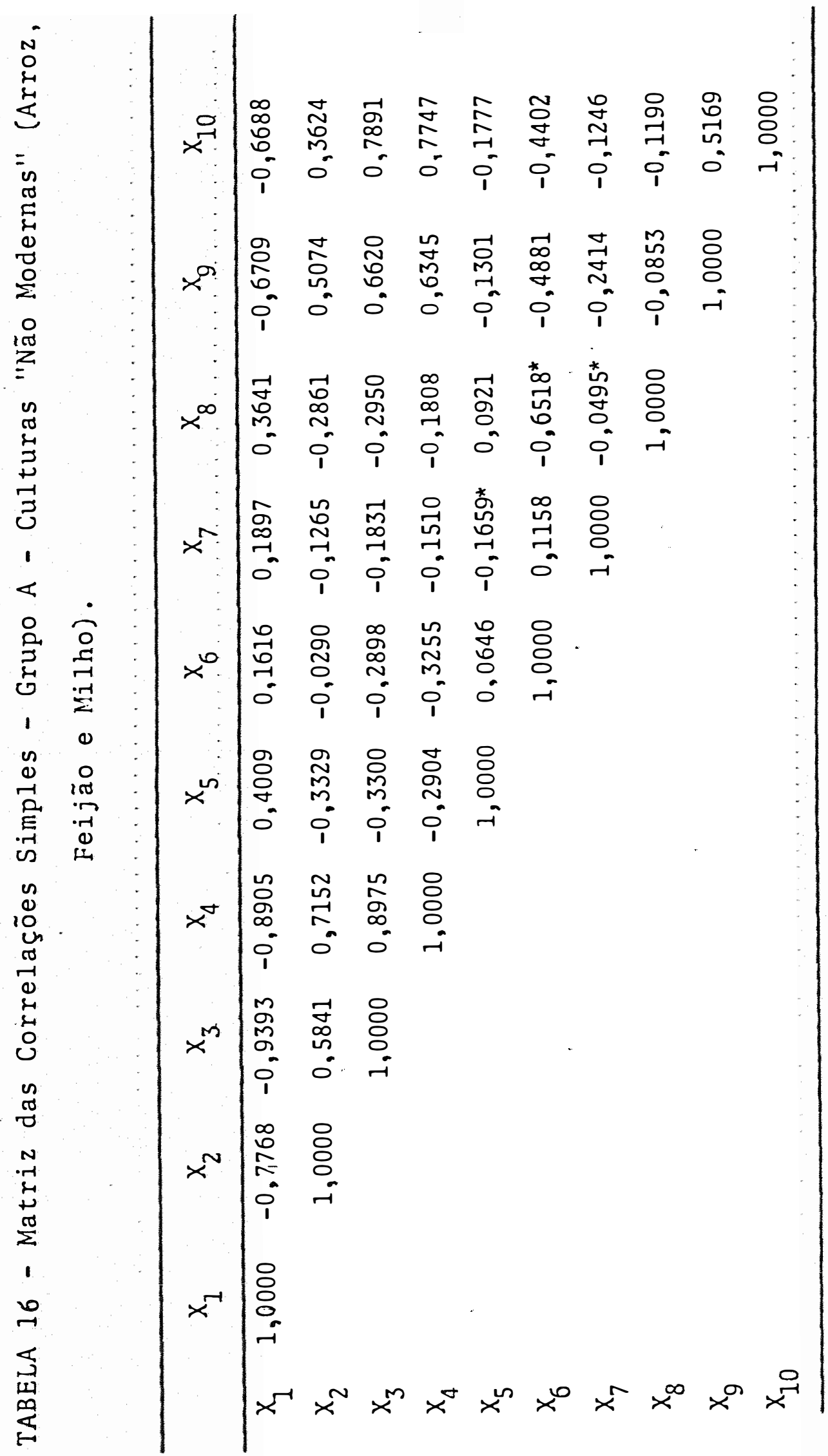




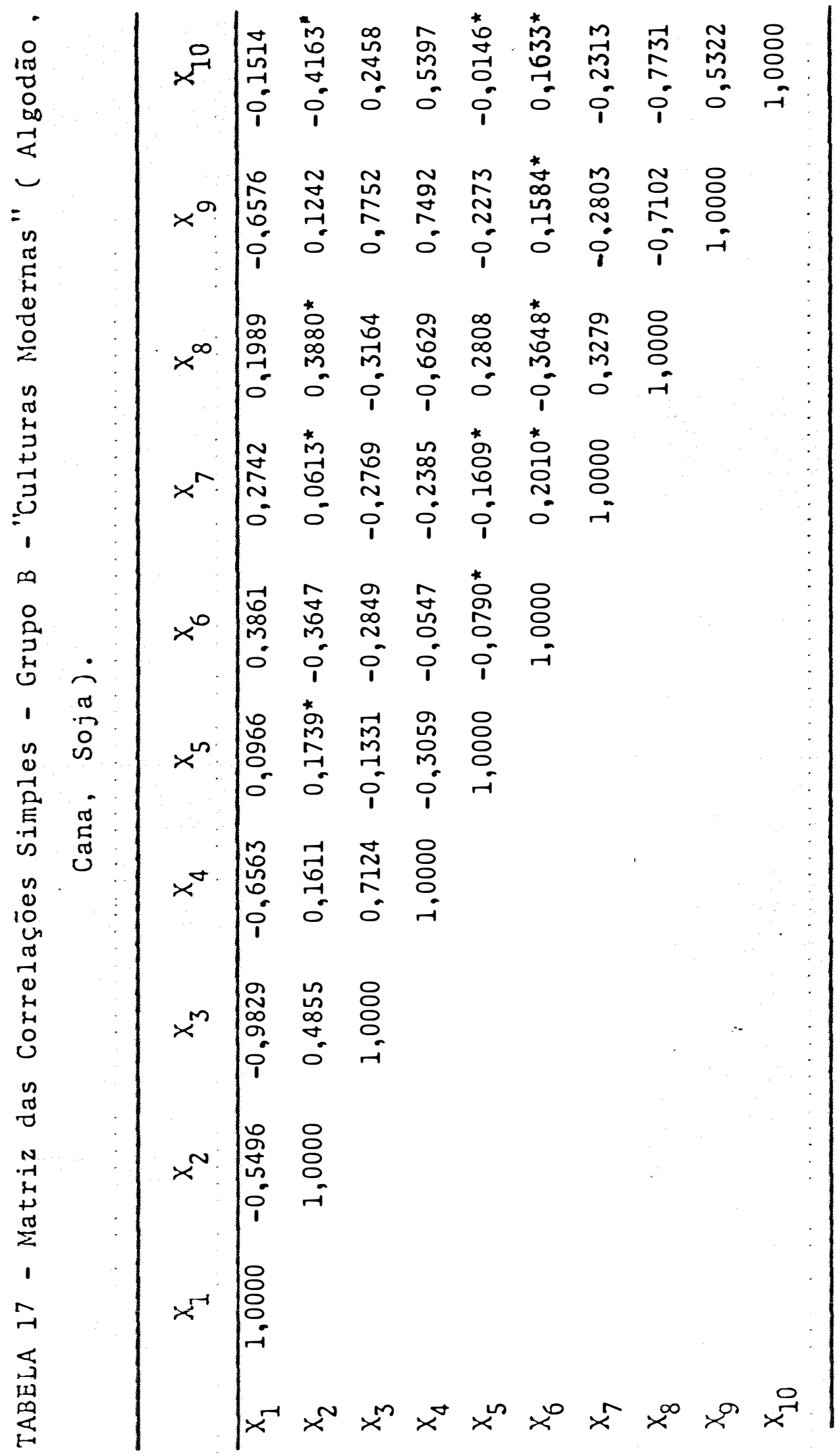




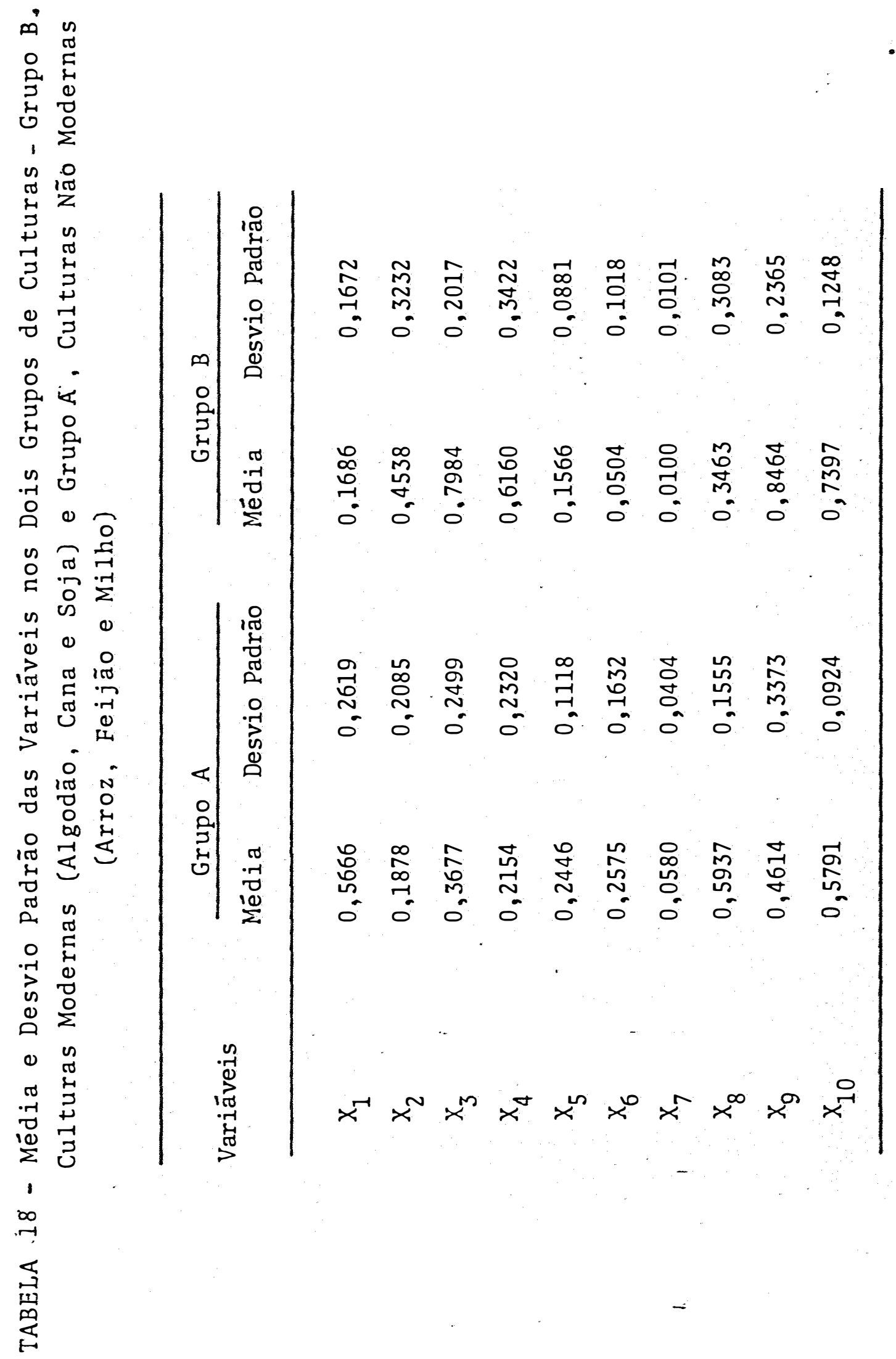

.66. 
TABELA 19 - Estimativas dos parâmetros e do valor médio da função de duas funções discriminantes com alte ração no conjunto de variāveis utilizadas, pro curando eliminar problemas de multicolinearidade.

Modelo I

Variāvel
Estimat.dos parâmetros Exclui $x_{11}$
Modelo II

Estimat.dos parâmetros

Exclui $x_{11}$ e $x_{3}$

\begin{tabular}{lcc}
\hline$x_{1}$ & $-2,8471$ & 4,5039 \\
$x_{2}$ & $-8,2387$ & $-7,3467$ \\
$x_{3}$ & $-8,0399$ & - \\
$x_{4}$ & 9,2210 & 8,2786 \\
$x_{5}$ & 6,5638 & 5,5021 \\
$x_{6}$ & 25,7808 & 26,8245 \\
$x_{7}$ & 43,2957 & 41,8242 \\
$x_{8}$ & 19,3005 & 19,2234 \\
$x_{9}$ & 6,3698 & 6,3233 \\
$x_{10}$ & $-2,4580$ & $-3,0226$ \\
\hline
\end{tabular}

Valor Médio da Função

Grupo A

19,6013

26,2166

Grupo B

8,0650

14,9354 
Parece ocorrer ligeira melhora nas estimati vas dos parâmetros no segundo ajustamento, em função das re lações esperadas (matriz de correlações).

A listagem dos resultados obtidos para o va lor de "W" e a respectiva classificação mostra que não exí te grande alteração entre os dois ajustamentos, a classificação sendo quase idêntica ll/. (Omite-se a apresentação das respectivas probabilidades da classificação em cada um dos grupos. O valor de "W" pode funcionar como um verdadeiro ín dice permitindo comparaçōes).

As estimativas das funções discriminantes não produziram uma relação funcional apropriada entre: as variáveis e um indice de "modernização", ou seja, o valor da função discriminante (valor de "W"). Apesar do valor da função poder ser usado para discriminar os grupos, os valores dos coeficientes não indicam corretamente a relação entre as variáveis e o "grau de modernização". Surgiram pro blemas de multicolinearidade difíceis de eliminar semgrande perda de informações dada a natureza das variáveis utilizadas. A análise discriminante, por outro lado, não permite evidenciar a estrutura de relaçōes entre as variáveis. A análise fatorial tornará possível eliminar muitas destas de ficiências. Contornando o problema de multicolinearidadé, a análise fatorial permite utilizar todas as informações dis poníveis colocando em evidência a estrutura das relaçōes en tre todas as variáveis.

\section{$1 /$}

Ocorreram somente duas alterações para algodão nos Es tados da Bahia e Pernambuco. 
TABELA 20 - Listagem dos resultados obtidos por cultura e por Estado, do valor da função discriminante nos dois modelos conside rados, com a respectiva classificação; Grupo A : culturas não modernas; Grupo B : Culturas modernas.

\begin{tabular}{llllll}
\hline Obs. & \multirow{2}{*}{ Cultura/Estado } & \multicolumn{2}{c}{ Modelo I } & \multicolumn{2}{c}{ Modelo I I } \\
\hline 01 & Milho/M.Gerais & 18,7306 & A & 26,2618 & A \\
02 & Milho/S.Paulo & 18,7820 & A & 25,2149 & A \\
03 & Milho/R.Janeiro & 21,7382 & A & 27,2118 & A \\
04 & Milho/Esp.Santo & 17,2811 & A & 23,1288 & A \\
05 & Milho/Paraná & 19,3899 & A & 24,1560 & A \\
06 & Milho/S.Catarina & 19,6969 & A & 24,3344 & A \\
07 & Milho/R.Gde Sul & 20,9399 & A & 27,0510 & A \\
08 & Milho/Mt. Sul & 22,7068 & A & 29,3250 & A \\
09 & Milho/Mato Grosso & 24,4226 & A & 31,1160 & A \\
10 & Milho/Goiás & 17,7214 & A & 24,4667 & A \\
11 & Milho/Maranhão & 20,3263 & A & 27,0644 & A \\
12 & Milho/Piauí & 22,4950 & A & 29,3868 & A \\
13 & Milho/R.Gde Norte & 19,5717 & A & 26,7347 & A \\
14 & Milho/Paraíba & 20,6412 & A & 27,7238 & A \\
15 & Milho/Pernambuco & 17,6596 & A & 24,5576 & A \\
16 & Milho/Alagoas & 18,6078 & A & 25,2665 & A \\
17 & Milho/Sergipe & 18,4937 & A & 25,3328 & A \\
18 & Milho/Bahia & 21,4667 & A & 28,0099 & A \\
19 & Milho/Ceará & 19,2023 & A & 26,1688 & A \\
20 & Arroz/M.Gerais & 18,5359 & A & 25,5394 & A \\
21 & Arroz/S.Paulo & 14,3283 & A & 20,7248 & A \\
& Arroz/R.Janeiro & 11,7163 & B & 18,6946 & B
\end{tabular}


.70 .

Obs. Cultura/Estado

$$
\text { Modelo I }
$$

Modelo II

Valor de $\mathrm{W}$ CL Valor de $\mathrm{W}$ Cl

$\begin{array}{llllll}23 & \text { Arroz/Esp.Santo } & 17,1080 & \text { A } & 24,1598 & \text { A } \\ 24 & \text { Arroz/Paraná } & 17,6200 & \text { A } & 24,0319 & \text { A } \\ 25 & \text { Arroz/Sta Catarina } & 13,4486 & \text { B } & 20,4508 & \text { B } \\ 26 & \text { Arroz/R.Gde Sul } & 8,7870 & \text { B } & 15,8184 & \text { B } \\ 27 & \text { Arroz/Mt Sul } & 17,5137 & \text { A } & 24,0523 & \text { A } \\ 28 & \text { Arroz/Mato Grosso } & 22,6401 & \text { A } & 28,9574 & \text { A } \\ 29 & \text { Arroz/Goiás } & 21,2397 & \text { A } & 27,8510 & \text { A } \\ 30 & \text { Arroz/Maranhão } & 19,7173 & \text { A } & 26,2955 & \text { A } \\ 31 & \text { Arroz/Piauí } & 22,5478 & \text { A } & 29,4889 & \text { A } \\ 32 & \text { Arroz/Sergipe } & 12,9312 & \text { B } & 19,5918 & \text { B } \\ 33 & \text { Arroz/Bahia } & 22,7468 & \text { A } & 29,6208 & \text { A } \\ 34 & \text { Arroz/Ceará } & 19,7669 & \text { A } & 26,5297 & \text { A }\end{array}$

35 Feijāo/M.Gerais

$20,1010 \quad$ A

$26,9349 \quad$ A

36 Feijāo/S.Paulo

24,1026

A

30,4926

A

37 Feijāo/R.Janeirö

23,8351

A

$29,7547 \quad$ A

38 Feijão/Esp.Santo

20,2283

A

27,3460

A

39 Feijāo/Paranā

19,7659

A

26,2648

A

40 Feijāo/S.Catarina

18,3975

A

25,0600

A

41 Feijāo Mt Sul

22,2452

A

28,6435

A

42 Feijāo/Mato Grosso

23,7301

A

30,0501

A

43 Feijāo/Goiảs

17,5996

A

24,3977

A

44 Feijāo/Maranhão.

23,9588

A

30,6814

A 
Obs. Oultura/Estado

Modelo I

Valor de $\mathrm{W} \quad \mathrm{Cl}$
Modelo II

Valor de $\mathrm{W} \quad \mathrm{Cl}$
45 Feijāo/Piauí

46 Feijāo/R.Gde Norte

47 Feijão/Paraíba

48 Feijāo/Pernambuco

49 Feijāo/Alagoas

50 Feijāo/Sergipe

51 Feijāo/Bahia

52 Feijāo/Ceará

53 Soja/M.Gerais

54 Soja/S. Paulo

55 Soja/Pàraná

56 Soja/S.Catarina

57 Soja/R.Grde Sul

58 Soja/Mt. Sul

59 Soja/Goiās

60 . Algodāo/M.Gerais

61 Algodão/S.Paulo

62 Algodāo/Paraná

63 Algodão/Mt. Sul

64 Algodão/Goiās
$22,4562 \quad \mathrm{~A}$

20,7615 A

$20,4125 \mathrm{~A}$

17,9227 A

18,3517 A

20,3761 A

$21,8159 \quad$ A

$22,6858 \quad A$

$10,9913 \quad \mathrm{~B}$

5,1223 B

6,9147 B

9,5294 B

4,9901 B

$12,1354 \quad$ B

$12,3193 \quad \mathrm{~B}$

$5,0230 \quad B$

$4,9734 \quad$ B

$6,0764 \quad \mathrm{~B}$

5,7592 B

$7,7113 \quad B$
29,4195

28,0895

27,5288

24,8463

24,8438

27,2914

28,4417

29,8568

A

$18,1650 \quad B$

$12,5593 \quad B$

$13,8532 \quad B$

$15,5651 \quad$ B

$11,8488 \quad$ B

$18,8294 \quad \mathrm{~B}$

$19,6881 \quad$ B

$12,7538 \quad B$

$12,3247 \quad B$

$13,6933 \quad B$

$13,7459 \quad B$

$14,8824 \quad$ B 
Módelo. I

Modelo II

Obs. Cultura/Estado

Valor de $W$ CL Valor de $W \quad C L$

65 Algodão/R.Gde Norte il,0009 B

$17,5892 \quad$ B

66 Algodão/Paraíba

$12,7570 \quad B$

$18,8606 \quad$ B

67 Algodão/Pernambuco

$13,8676 \quad$ A

20,1668

B

68 Algodão/Bahia

13,7830

B

20,6213

A

69 Algodão/Cearä

$6,7082 \quad$ B

12,9392

B

70 Cana/M. Gerais

$9,4594 \quad$ B

16,3817

B

71 Cana/R. Janeiro

$5,6842 \quad$ B

$12,2021 . \quad$ B

72 Cana/Esp.Santo

$5,7263 \quad$ B

$12,320.2 \quad B$

73 Cana/S. Paulo

$3,1666 \quad B$

$10,1084 \quad$ B

74 Cana/Paraná

4,3691

$10,9168 \quad$ B

75 Cana/Mt. Grosso

$4,0400 \quad B$

$11,0123 \quad$ B

76 Cana/R.Grde Norte.

8,4643

B

$15,0279 \quad B$

77 Cana/Paraíba

8,1146

B

$14,6404 \quad$ B

78 Cana/Pernambuco

$5,4306 \quad$ B

$12,0486 \quad$ B

7.9 Cana/Alagoas

$5,8280 \quad B$

$12,4933-B$

80 Cana/Sergipe

3,2639 B

$10,0072 \quad$ B

81 Cana/Bahia

$10,6400 \quad B$

$17,5707 \quad B$

82 ... Cana/Ceará.

18,1015

A

25,2467

A 


\subsection{Anālise Fatorial}

A análise fatorial desenvolveu-se inicialmen te em função de pesquisas em psicologia. Os modelos matemá ticos desenvolvidos e utilizados são de amplo interesse cientifico.

O principal objetivo da anālise fatorial é a transformação de um grupo de ñ variáveis em um pequeno número de fatores que facilitem a descrição de um fenômeno em termos lógicos. E um método que permite interpretar in terrelações existentes entre um grupo de variáveis. Atra vés da análise fatorial procura-se representar uma variável em termos de vários fatores implícitos.

0 modelo mais simples para descrever uma va riável em termos de várias outras é o modelo linear. Embora existam várias alternativas na construção de modelos depen dendo da estrutura de análise adotada, distinguem-se duas perspectivas principais:

1) Extração de máxima variância

2) Reprodução das correlações observadas

Um método prático para "reduzir" o número de variáveis tendo em vista extrair a máxima variância foi proposto inicialmente por Karl Person (1901) e desenvolvi do posteriormente por Harold Hotelling (1933). (Ver Harman, 1976, p. 14).

Trata-se do método de componentes principais, sumariamente descrito a seguir e posteriormente relacionado com a análise fatorial. 


\section{2 .1 Componentes Principais}

Vamos admitir que dispomos de $\underline{N}$ observações para $\underline{n}$ variāveis. Seja $x_{i j}(\operatorname{com} i=1, \ldots \ldots \ldots, n$ e $j=1$, $\ldots . . ., N)$ a $j$-ésima observaçāo da $i$-ésima variāvel. $1 /$

A média da i-ésima variāvel é :

$$
\bar{x}_{i}=\frac{1}{N} \sum_{j} x_{i j}
$$

Fazemos :

$$
x_{i j}=\frac{x_{i j}-\bar{x}_{i}}{\sqrt{\sum_{j}\left(x_{i j}-\bar{x}_{i}\right)^{2}}}
$$

Com essa transformaçāo temos $\Sigma x_{i j}^{2}=1$, isto $\bar{e}$, no espaço $N$-dimensional das observações os vetores $\left(x_{i}\right)$ correspondentes à cada variável tèm módulo igual a 1 .

$$
\text { Definimos a matriz: }
$$

$$
x=\left[\begin{array}{cccc}
x_{11} & x_{12} & \cdots & x_{1 N} \\
x_{21} & x_{22} & \cdots & x_{2 N} \\
\cdots & \cdots & \cdots & \cdots \\
x_{n 1} & x_{n 2} & \cdots & x_{n N}
\end{array}\right]=\left[\begin{array}{c}
x_{1}^{\prime} \\
x_{2}^{\prime} \\
\cdots \\
x_{n}^{\prime}
\end{array}\right]
$$


Verifica-se que a matriz $\mathrm{n} \times \mathrm{n}$ das correlações simples entre as variáveis é dada por:

$$
\mathrm{R}=\mathrm{XX}
$$

Vamos considerar, para cada observação, uma combinação linear das $\underline{n}$ variáveis transformadas

$$
\begin{aligned}
& g_{1 j}=c_{11} x_{1 j}+c_{12} x_{2 j}+\ldots \ldots+c_{1 n} x_{n j} \\
& (j=1, \ldots, N) \\
& \text { ou, em notação matricial, } \\
& g_{1}^{\prime}=c_{1} x
\end{aligned}
$$

onde $g_{i}^{\prime}$ é um vetor-linha com $\underline{N}$ elementos e $c_{i}^{\prime}$ é um vetor-1 nha com os n coeficientes da combinação linear considerada.

Por definição, o primeiro componente princi pal de $x$ é a combinação linear $g_{i}=c_{i} x$ com variância máa xima, sujeita à restrição $c_{1} c_{1}^{\prime}=1$.

Uma vez que $g_{1 j}$ é uma combinação linear de variáveis com média zero, sua média também é igual a zero. Então, sua variância é dada por:

$$
V\left(g_{1}\right)=\frac{1}{N} g_{1}^{\prime} g_{1}
$$

De acordo com (4) e (5) temos:

$$
V\left(g_{1}\right)=\frac{1}{N} c_{1}^{\prime} X X^{\prime} c_{1}=\frac{1}{N} c_{1}^{\prime} R c_{1}
$$


Portanto, para obter o primeiro componente prin cipal de $x$ devemos determinar o vetor $c_{1}, \operatorname{com} c_{1}^{\prime} c_{1}=1$, que maximiza $c_{1}^{\prime} \mathrm{Rc}_{1}$. De acordo com o método de Lagrange, formamos a função

$$
\emptyset=c_{1}^{\prime} R c_{1}-\lambda\left(c_{1}^{\prime} c_{1}-1\right)
$$

e obtemos

$$
\frac{\mathrm{d} \emptyset}{\mathrm{dc}}=2 \mathrm{Rc} \mathrm{c}_{1}-2 \lambda \mathrm{c}_{1}=0
$$

ou

$$
R c_{1}=\lambda c_{1}
$$

Substituindo esse resultado em (6) e lembran do que $c_{1}^{\prime} c_{1}=1$, obtemos

$$
V\left(g_{1}\right)=\frac{\lambda}{N}
$$

De (7) obtemos

$$
(R-\dot{\lambda} I) c_{1}=0
$$

Este é um sistema de $\underline{\text { n }}$ equações lineares homo gêneas com incógnitas $c_{1 i}(i=1, \ldots, n)$. Para que haja uma solução não-trivial devemos ter :

$$
|R-\lambda I|=0
$$


que é denominada equação característica. Admitindo-se que $R$ seja uma matriz não-singular, essa equação tem $\underline{n}$ raízes reais positivas, denominadas raízes caracteristicas de $R$, que passamos a indicar por $\lambda_{i}$.

Para obter o primeiro componente principal de vemos, de acordo com (8), escolher a maior raíz caracterís tica de $R$, que indicamos por $\lambda_{1}$.

A seguir, fazendo $\lambda=\lambda_{1}$ em (9) e lembrando que $c_{1} c_{1}=1$, podemos obter $c_{1}$, que $\overline{\mathrm{e}}$ o vetor característi co correspondente à maior raiz característica de $R$.

$$
\begin{aligned}
& \text { Com } \lambda=\lambda_{1} \text { as relações (7) e (8) ficam: } \\
& \mathrm{Rc}_{1}=\lambda_{1} \mathrm{c}_{1} \\
& \mathrm{e} \\
& \mathrm{V}\left(\mathrm{g}_{1}\right)=\frac{\lambda_{1}}{\mathrm{~N}}
\end{aligned}
$$

Passemos à determinação do segundo componente principal de $X$, isto é, a combinação linear $\dot{\mathrm{g}}_{2}^{\prime}=\mathrm{c}_{2}^{\prime} \mathrm{X}$ com va riância máxima, sujeita às restrições $c_{2}^{\prime} c_{2}=1$ e $c_{2}^{\prime} c_{1}=0$. E $\underline{s}$ ta ültima restrição faz com que $g_{1}$ e $g_{2}$ sejam vetores orto gonais entre sí, ou seja, garante que $g_{1 j}$ e $g_{2 j}$ sejam variá veis não correlacionadas.

da por :

E fácil verificar que a variância de $g_{2}$ é da

$$
V\left(g_{2}\right)=\frac{1}{N} g_{2}^{\prime} g_{2}^{\prime}=\frac{1}{N} c_{2}^{\prime} R c_{2}
$$


De acordo com o método de Lagrange, para maxi mizar $c_{2}^{\prime} R c_{2}$, com $c_{2}^{\prime} c_{2}=1$ e $c_{2}^{\prime} c_{1}=0$, formamos a função

$$
\emptyset=c_{2}^{\prime} R c_{2}-\lambda_{2}\left(c_{2}^{\prime} c_{2}-1\right)-\omega c_{2}^{\prime} c_{1}
$$

e obtemos

$$
\frac{d \emptyset}{d c_{2}}=2 R c_{2}-2 \lambda_{2} c_{2}-\omega c_{1}=0
$$

Pre-multiplicando por $c_{i}$ e lembrando $c_{1}^{\prime} c_{2}=0$ e $c_{1}^{\prime} c_{1}=1$, obtemos:

$$
c_{1}^{\prime R c_{2}}=\omega
$$

Uma vez que, de acordo com (11), temos $c_{1}^{\prime} R=$ $\lambda_{1} c_{1}^{\prime}$, segue-se que

$$
\omega=\lambda_{1} c_{1}^{\prime} c_{2}=0
$$

Substituindo esse resultado em (14) obtemos

$$
\mathrm{Rc}_{2}=\lambda_{2} \mathrm{c}_{2}
$$

ou

$$
\left(R-\lambda_{2} I\right) c_{2}=0
$$

mostrando que $\lambda_{2}$ é uma raíz característica de $R$ e $c_{2} \quad \bar{e} \quad o$ correspondente vetor característico. 
Substituindo (15) em (13) e lembrando que $c_{2}^{\prime c} c_{2}=1$, obtemos

$$
V\left(g_{2}\right)=\frac{\lambda_{2}}{N}
$$

Portanto, para maximizar $\mathrm{V}\left(\mathrm{g}_{2}\right) \operatorname{com} \mathrm{c}_{2}^{\prime} \mathrm{c}_{2}=1 \mathrm{e}$ $c_{2}^{i} c_{1}=0$, devemos escolher a segunda maior raíz caracterís tica de R.

Generalizando o racionínio desenvolvido an teriormente, podemos concluir que os sucessivos componentes principais de $X$ são dados por

com variância

$$
g_{i}^{\prime}=c_{i}^{\prime} X,
$$

$$
V\left(g_{i}\right)=\frac{\lambda_{i}}{N}
$$

Definindo as matrizes

$$
G=\left[\begin{array}{cccc}
g_{11} & g_{12} & \ldots & g_{1 N} \\
g_{21} & g_{22} & \cdots & g_{2 N} \\
\cdots & \cdots & \cdots & \cdots \\
g_{n 1} & g_{n 2} & \cdots & g_{n N}
\end{array}\right]
$$

$$
c=\left[\begin{array}{llll}
c_{1} & c_{2} & \ldots & c_{n}
\end{array}\right] \text {, }
$$


.80 .

onde cada coluna é um vetor característico de $R$, obtemos

$$
G=C^{\prime} X
$$

De acordo com (11) e (15), generalizando, te

$\operatorname{mos}$

$$
\begin{aligned}
& \mathrm{Rc}_{\mathbf{i}}=\lambda_{\mathbf{i}} \mathrm{c}_{\mathbf{i}} \\
& \mathrm{ou} \\
& \mathrm{RC}=\mathrm{C} \Lambda,
\end{aligned}
$$

onde

$$
\Lambda=\left[\begin{array}{cccc}
\lambda_{1} & 0 & \cdots & 0 \\
0 & \lambda_{2} & \cdots & 0 \\
\cdots & \cdots & \cdots & \cdots \\
0 & 0 & \cdots & \lambda_{n}
\end{array}\right]
$$

Uma vez que $c_{i}^{\prime} c_{i}=1$ e $c_{i}^{\prime} c_{k}=0$ para $k \neq i, a$ matriz C é ortogonal, isto ế,

$$
C^{\prime} C^{\prime}=C^{\prime}=I \text {. }
$$

Então, pré-multiplicando os dois membros de (20) por C', obtemos

$$
C^{\prime} R C=\Lambda
$$


Obtendo o traço dos dois membros dessa igual dade matricial, segue-se que

$$
\operatorname{tr}\left(C^{\prime} R C\right)=\operatorname{tr}(\Lambda)=\sum_{i} \lambda_{i}
$$

Uma vez que

$\operatorname{tr}\left(C^{\prime} R C\right)=\operatorname{tr}\left(R C C^{\prime}\right)=\operatorname{tr}(R)=n$,

obtemos :

$$
\sum \lambda_{i}=n
$$

Com a transformação

$$
f_{i}^{\prime}=\frac{1}{\sqrt{\lambda_{i}}} g_{i}^{\prime}
$$

os componentes principais passam a ser vetores com módulo igual a 1 . Se $F$ é uma matriz $n \times N$ onde cada linha corres ponde a um componente principal assim transformado, temos

$$
F=\Lambda-1 / 2 G
$$

De acordo com (18) segue-se que

$$
F=\Lambda^{-1 / 2} C^{\prime} X
$$

Lembrando (4) e (22) verifica-se que

$$
\mathrm{FF}^{\prime}=\mathrm{I}_{\mathrm{n}}
$$


.82 .

Pré-multiplicando os dois membros de (25) por

$$
A=C \Lambda^{1 / 2}
$$

e lembrando (21), obtemos

$$
X=A F
$$

ou

$$
x_{i j}=a_{i j} f_{i j}+a_{i 2} f_{2 j}+\ldots+a_{i n} f_{n j} \text {, }
$$

com

$$
i=1, \ldots, n \text { e } j=1, \ldots, N
$$

Tendo definido os componentes principais como combinaçōes lineares das variāveis $x_{i}$, verificamos agora que cada uma dessas variáveis pode ser consịderada uma combina ção linear de $\underline{n}$ componentes principais ortogonais entre si.

De (28), lembrando (4) e (26), obtemos

$$
\mathrm{R}=\mathrm{XX} \mathrm{X}^{\prime}=\mathrm{AA}^{\prime}
$$

Então

$$
x_{i}^{1} x_{i}=\sum_{j} x_{i j}^{2}=1=\underset{k}{\sum} a_{i k}^{2}
$$

Essa expressão mostra que $a_{i k}^{2}$ representa a fração da variância de $x_{i}$ devida ao k-ésimo componente prin cipal. 
Multiplicando (29) por $f_{k j}$, somando em relação a $j$ e lembrando (26), verifica-se que o coeficiente de correlação entre $x_{i j}$ e $f_{k j}$ é

$$
r\left(x_{i}, f_{k}\right)=a_{i k}
$$

Analogamente, verifica-se que

$r\left(x_{i}, x_{k}\right)=a_{i 1} a_{k 1}+a_{i 2} a_{k 2}+\ldots+a_{i n} a_{k n}$

De (27), lembrando (21), obtemos

$A \cdot A=\Lambda$

Então

$$
\sum_{i} a_{i k}^{2}=\lambda_{k}
$$

isto é, a soma das "contribuiçōes" $\left(a_{i k}^{2}\right)$ do k-ésimo componente principal para "explicar" as variâncias das $\underline{n}$ variáveis $x_{i}$ é igual a $\lambda_{k}$ que é a correspondente raiz caracterís tica de $R$.

Vamos admitir que as $\underline{n}$ raizes características de $\mathrm{R}$ sejam distintas e estejam ordenadas de maneira que $1 /$

$$
\lambda_{1}>\lambda_{2}>\lambda_{3} \ldots>\lambda_{n}
$$

1/ Quando hä raizes características iguais, também é possível obter as componentes principais mas a solução não é única. 
De (23). sabemos que $\Sigma \lambda_{i}=n$.

Logo a relação $\lambda_{i} / n$ f́ornece a percentagem da variância das $\underline{n}$ variáveis explicado pelo correspondente com ponente principal.

Na anālise de um problema é comum, então,pas sar a utilizar apenas os primeiros componentes principais, aos quais corresponde, geralmente, grande parte das variâncias das n variāveis. E claro que alguma informação é perdida quando substituimos as $\underline{n}$ variáveis por um número menor de compoenntes principais. Por outro lado, hā vantagens ób. vias em substituir um numero relativamente grande de variäveis, com problemas de multicolinearidade, por um número re lativamente pequeno de variáveis (componentes principais) não-correlacionadas.

3.2.2. Anādise Fatorial - Método dos fatores princi pais

0 modelo de análise fatorial tem grande seme lhança com a relação (28) ou (29), onde cada variāvel $x_{i} \bar{e}$ representada como uma combinação linear dos $\underline{n}$ componentes principais. No modelo de análise fatorial cada uma das $\underline{n}$ variāveis é uma combinação linear de $\underline{m}$ (com $m<n)$ fatores comuns e de um fator singular (unique factor). Para a i-ésima variāvel temos

$$
x_{i j}=a_{i 1} f_{1 j}+a_{i 2} f_{2 j}+\ldots+a_{i m} f_{m j}+u_{i} y_{i j}
$$

ou

$$
x_{i j}=\sum_{p=1}^{m} a_{i p} f_{p j}+u_{i} y_{i j},
$$


onde $f_{p j}$ representa o j-ésimo valor do p-ésimo fator comum, $a_{i p}(\operatorname{com} p=1, \ldots, m)$ e $u_{i}$ são coeficientes e $y_{i j}$ representa o j-ésimo valor do ïésimo fator singular.

Embora estejamos usando as letras $\underline{f}$ e $\underline{a}$ para representar os fatores comuns e os respectivos coeficientes, da mesma maneira que fizemos com os componentes princi pais, os $m$ fatores comuns não se confundem necessariamente, com os $\underline{m}$ primeiros componentes principais. A diferença ficará clàra na parte final dessa seção. Entretanto, é óbvio que há grande semelhança entre a relação (29) e o modelo (36).

Vamos pressupor que os fatores comuns são or togonais entre si (não-correlacionados), não considerando, no que se segue, o caso de fatores oblíquos.

Vamos pressupor, também, como é usual, que cada um dos fatores singulares $\left(y_{i}, \operatorname{com} i=1, \ldots, n\right) \vec{e}$ or togonal com todos os $\underline{m}$ fatores comuns $\left(f_{p}\right.$, $\left.\operatorname{com} p=1, \ldots, m\right)$.

Vamos admitir, ainda, que todos os fatores sāo variáveis com média zero e que os respectivos vetores, no espaço $N$-dimensional das observaçōes, tem módulo igual a 1 , isto é,

$$
\sum_{j} f_{p j}=\sum_{j} y_{i j}=0
$$

e

$$
\sum_{j} f_{p j}^{2}=\sum_{j} y_{i j}^{2}=1
$$

para $p=1, \ldots, m$ e $i=1, \ldots, n$.

Em notação matricial o modelo (36) fica 


$$
X=A F+U Y,
$$

onde $X$ é a matriz n $x$ N definida no início da seção anterior,

$$
\begin{aligned}
& F=\left[\begin{array}{cccc}
f_{11} & f_{12} & \cdots & f_{1 N} \\
f_{21} & f_{22} & \ldots & f_{2 N} \\
\cdots & \cdots & \cdots & \cdots \\
f_{m 1} & f_{m 2} & \cdots & f_{m N}
\end{array}\right], \\
& Y=\left[\begin{array}{cccc}
y_{11} & y_{12} & \cdots & y_{1 N} \\
y_{21} & y_{22} & \cdots & y_{2 N} \\
\ldots & \cdots & \cdots & \cdots \\
y_{n 1} & y_{n 2} & \cdots & y_{n N}
\end{array}\right] \\
& A=\left[\begin{array}{cccc}
a_{11} & a_{12} & \cdots & a_{1 m} \\
a_{21} & a_{22} & \cdots & a_{2 m} \\
\cdots & \cdots & \cdots & \cdots \\
a_{n 1} & a_{n 2} & \cdots & a_{n m}
\end{array}\right]
\end{aligned}
$$

e

$$
U=\left[\begin{array}{cccc}
u_{1} & 0 & \cdots & 0 \\
0 & u_{2} & \cdots & 0 \\
\cdots & \cdots & \cdots & \cdots \\
0 & 0 & & u_{n}
\end{array}\right]
$$

As condiçōes (37), juntamente com a ortogona lidade entre os $\underline{m}$ fatores comuns fazem com que tenhamos

$$
F F^{\prime}=I_{m}
$$


.87

A ortogonalidade dos $\underline{m}$ fatores comuns com os n fatores singulares permite escrever que

$$
F Y^{\prime}=0 \text {, }
$$

onde o segundo membro é uma matriz $m x \mathrm{n}$ de zeros.

Substituindo (38) em (4) e lembrando (39) e (40); obtemos

$$
R=X X^{\prime}=A A^{\prime}+U Y Y^{\prime} U^{\prime}
$$

1, segue-se que

Uma vez que $U$ é uma matriz diagonal.e $\sum_{j} f_{p j}^{2}=$

$$
R=A A^{\prime}+U^{2}
$$

De acordo com essa relação, considerando um. elemento da diagonal de $R$, temos

$$
1=\sum_{j=1}^{N} x_{i j}^{2}=\sum_{p=1}^{m} a_{i p}^{2}+u_{i}^{2}
$$

Os termos do ültimo membro dessa expressão nos dão as proporções da variância de $x_{i}$ devidas a cada um dos fatores. A parte associada aos m fatores comuns é deno minada comunalidade da variável e será indicada por

$$
h_{i}^{2}=\sum_{p=1}^{m} a_{i p}^{2}
$$

A proporção da variância da i-êsima variável devida ao fator singular é igual a $u_{i}^{2}$ e é denominada singularidade (uniqueness) da variāvel.

De acordo com (42) temos 


$$
h_{i}^{2}+u_{i}^{2}=1
$$

De (41), considerando um elemento fora

diagonal de $R$, obtemos

$$
r\left(x_{i}, x_{k}\right)=\sum_{p=1}^{m} a_{i p} a_{k p}
$$

Multiplicando os dois membros de (36) por $f_{p j}$, somando e lembrando que os fatores comuns e $y_{i}$ são vetores ortogonais entre si e com módulo igual a 1 , obtemos

$$
r\left(x_{i}, f_{p}\right)=a_{i p}
$$

Em notação matricial temos

$$
\mathrm{XF}^{\prime}=\mathrm{A}
$$

Verifica-se, portanto, que a i-ésima linha da matriz A é constituida pelos coeficientes de correlação da î-ésima variável com cada um dos m matriz é denominada de estrutura dos fatores ou, simplesmen te, estrutura.

Os coeficientes $a_{i p}$, que no caso de fatores ortogonais coincidem com os elementos da estrutura, são denominados pesos dos fatores (factor loadings) $\underline{l}$.

Há vārios métodos para efetuar uma análise fatorial. Uma exposição bastante completa do assunto pode

I/ No caso de fatores obliquos os coeficientes dos fatores comuns (a $a_{i p}$ ) não coincidem com os elementos da estrutura, is to $\bar{e}, r\left(x_{i}, f_{p}\right) \neq a_{i p}$. 
ser encontrada em HARMAN (1976). Um dos métodos mais usados é o dos fatores principais. De àcordo com esse método, os $\underline{\underline{m}}$ fatores comuns correspondem às m maiores raizes características da matriz $R^{*}$, que é obtida a partir de $R$ substituindo os elementos da diagonal por estimativas das comunalidades das n variáveis (ver HARMAN, 1976, pp. 135-141). Po de-se provar que o limite inferior para o valor da comunali dade de $x_{i}$ é dado pelo coeficiente de determinação da regressão de $x_{i}$ contra as $n$ - 1 variáveis restantes (ver HARMAN, 1976, p. 87). Por outro lado, de acordo com (44) a co munalidade não pode ser superior a 1 . Se admitirmos que $h_{i}^{2}=1$, o método dos fatores principais se confunde com o método dos componentes principais.

Neste trabalho foi utilizado o método dos fa tores principais, partindo-se da própria matriz R. Dessa ma

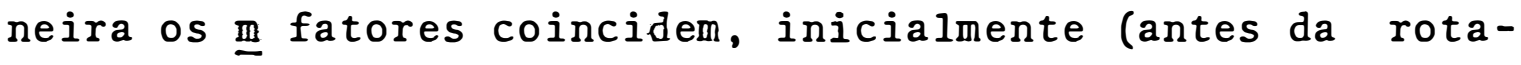
ção), com os m primeiros componentes principais e os pesos dos fatores são idênticos aos elementos das m primeiras colunas da matriz A definida em (27).

Entretanto, os valores dos fatores nāo coincidem com os valores com $\underline{m}$ componentes principais que seriam obtidos a partir de (25).

- Após determinar os m componentes principais (com $m=1,2$ ou 4 ), foi feita uma rotação dessas componentes, mantendo a ortogonalidade entre eles. O objetivo dessa rotação ortogonal é obter uma estrutura simples, isto é, obter uma nova matriz, $\mathrm{n} x \mathrm{~m}$ de coeficientes dos fatores de maneira que os valores absolutos dos elementos de cada colu na dessa matriz se aproximem, na medida do possível, de zero ou 1. Isso facilita a interpretação dos fatores pois ca da um dos novos fatores, após a rotação, deverá apresentar 
.90 .

correlação relativamente forte com uma ou mais variáveis e correlação relativamente fraca com as demais variáveis. Nes te trabalho a matriz (T) de transformação ortogonal foi obtida através do critério VARIMAX (ver HARMAN, 1976, pp. 290 -299). Tratando-se de una transformação ortogonal, temos

$$
\mathrm{TT}^{\prime}=\mathrm{I}_{\mathrm{m}}
$$

A partir de (38), desprezando o termo referente aos fatores singulares, temos

$$
\hat{X}=A F \text {, }
$$

onde A é uma matriz n $x \mathrm{~m}$ e $\mathrm{F}$ é uma matrix m $\times \mathrm{N}$.

$$
\begin{aligned}
& \text { De acordo com (47) podemos escrever } \\
& \hat{X}=\text { ATT'F } \\
& O \text { produto } \\
& T^{\prime} F=Q
\end{aligned}
$$

nos dá a matriz dos fatores após a rotação e o produto

$$
\mathrm{AT}=\mathrm{B}
$$

fornece a nova matriz $\mathrm{n} \times \mathrm{m}$ de pesos dos fatores.

E interessante assinalar que a rotação ou transformação ortogonal não altera a comunalidade das variā veis. De (51), lembrando (47), obtemos

$$
B B^{\prime}=A T T^{\prime} A^{\prime}=A A^{\prime}
$$


Finalmente, considerando um elemento da diagonal desses pro dutos matriciais e lembrando a definição de comunalidade da da em (43), conclui-se que

$$
\underset{p=1}{m} b_{i p}^{2}=\sum_{p=1}^{m} a_{i p}^{2}=h_{i}^{2}
$$

Substituindo (52) em (41), obtemos

$$
R=B B^{\prime}+U^{2}
$$

Pós-multiplicando os dois membros de por $T$ e lembrando (50) e (51), verifica-se que

$$
X Q^{\prime}=B
$$

Resta especificar como foram obtidas, neste trabalho, as estimativas dos fatores. Isso foi feito pelo método de regressão simplificado ("short" regression method). A seguir apresentamos uma dédução da expressão utilizada. I/ Para uma regressão múltipla de cada uma das linhas de $Q$ contra $x$, temos

$$
\bar{Q}=Q X^{\prime}\left(X X^{\prime}\right)^{-1} X
$$

ou

$$
\hat{Q}=Q X \cdot R^{-1} X
$$

1/ Uma demonstração mais geral, incluindo o caso de fatores obliquos, è apresentada por HARMAN (1976), p. 377. Uma comparação entre os värios métodos de obter os valores dos fatores pode ser encontrada no capitulo 16 desse 1ivro. 
De acordo com (55) segue-se que

$$
\bar{Q}=B^{\prime} R^{-1} X
$$

Se a matriz $R$ for não-singular, essa expressão pode ser utilizada para obter os valores dos fatores. A seguir vamos modificar essa relação, obtendo a expressão efetivamente utilizada neste trabalho.

Admitindo que todas as variáveis tem comunalidade menor do que 1 , ou seja, admitindo que todas as variāveis tem singularidade maior do que zero, a matriz $U$ é não-singular e existe $U^{-2}$. Então, pré-multiplicando por $\mathrm{B}^{\prime} \mathrm{U}^{-2}$, obtemos

$$
B^{\prime} U^{-2} R=\left(B^{\prime} U^{-2} B+I_{m}\right) B^{\prime}
$$

Pré-multiplicando por $\left(B^{\prime} U^{-2} B+I_{m}\right)^{-1}$ e pós-multiplicando por $\mathrm{R}^{-1}$ obtemos

$$
\left(B^{\prime} U^{-2} B+I_{m}\right)^{-1} B^{\prime} U^{-2}=B^{\prime} R^{-1}
$$

Substituindo o produto $B^{\prime} R^{-1}$ em (56) pela ex pressão equivalente dada por (57), obtemos

$$
\hat{Q}=\left(B^{\prime} U^{-2} B+I_{m}\right)^{-1} B^{\prime} U^{-2} X
$$

Ešta é:a expressão utilizada neste trabalho para obter os valores dos fatores.

Aparentemente a expressão (58) è mais comple xa do que a expressão (56). Entretanto, os cálculos exigidos por (58) podem ser mais simples pois, alêm da inversão da matriz diagonal das singularidades, que é imediata, 
expressão (58) só exige a inversão de uma matriz m $x \mathrm{~m}$, ao passo que a expressão (56) exige a inversão de uma matriz $n$ $x \mathrm{n}$. Deve-se assinalar que geralmente $\underline{m}$ é bem menor do que $\underline{n}$. 


\section{RESULTADOS DA ANALISE FATORIAL}

0 processamento dos dados foi realizado atra vés de programa da IBM (para o computador existente na Escola Superior de Agricultura "Luiz de Queiroz").

As raizes caracteristicas e a percentagem acumulada do traço (Tabela 21) justificam a escolha de quatro fatores representativos na formação de um novo conjunto de variáveis.

Omite-se a apresentação de raízes caracterís ticas de valor considerado não significativo e considera-se que a percentagem da variação explicada pelos quatro fatores é bastante elevada ( $\&$ acumulada do traço).

A quarta raiz característica, embora menor do que um, contribui com aproximadamente $7 \&$ na explicação da variação das "observações". 
TABELA 21 - Resultados da anālise fatorial; raízes características e percentagem acumulada do traço.

\begin{tabular}{cc}
$\begin{array}{c}\text { Raízes } \\
\text { Características }\end{array}$ & $\begin{array}{c}: \text { acumulada } \\
\text { do traço }\end{array}$ \\
\hline 6,3636 & 57,8516 \\
1,3383 & 70,0182 \\
1,0258 & 79,3445 \\
0,7834 & 86,4668 \\
\hline
\end{tabular}

O primeiro fator explica, só por si, quase 60 : das variações, enquanto os fatores restantes explicam percentagens bem inferiores, em torno de $10:$ da variação, de forma decrescente $(2 \circ$ fator $=13 \%$; fator $=9 \% ; 4$ fa

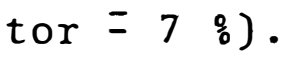

Para cada fator procurar-se-á uma caracter $\underline{i}$ zação, de forma a lhe podermos atribuir um significado em pírico. Essa caracterização é realizada através da análise da matriz de "pesos dos fatores"("factor loadings") que re presenta o "peso" de cada variável no respectivo fator. ou melhor, indica a extensão na qual o fator representa uma dada variāvel.

Através da matriz normalizada não rotaciona da dos "factor loadings" (Normalized Unrotated Factor Loadings) a caracterizaçāo dos fatores é difícil. A confí guraçāo particular obtida numa matriz não rotacionada de "lnadings" é, em grande parte, função do método utilizado. Eim face desta situaçāo desenvolveu-se o conceito de "estrú 
tura simples" estabelecendo-se critérios para a rotação ortogonal da matriz original de fatores para uma posição em que os fatores extraidos são mais facilmente caracterizados nos termos das variáveis originais. De acordo com este critério se os valores de um fator forem "plotados" conjuntamente com os valores de um outro fator num sistema de eixos cartesianos, algumas variáveis assumirão valores altos num fator e próximos a zeno no outro (válido para os vâa riós fatores). o objetivo é explicar a configuração das variáveis de tal forma que cada fator seja representado por apenas algumas variāveis.

A matriz rotacionada, de forma a obter "estrutura simples" através de técnicas computacionais das quais a mais conhecida é a rotação VARIMAX (KAISER, 1958). facilita a identificação dos fatores. A rotação VARIMAX mantém a propriedade da ortogonalidade entre os fatores (os fatores não são correlacionados).

Os resultados da rotação VARIMAX estão apre sentados na Tabela 23. Para evidenciar a caracterização dos fatores seleciona-se na Tabela 23 os coeficientes superiores a 0,5 (valores sublinhados). A identificação dos fatores é, agora, clara:

Fator 1 : Representa o nível de utilização de insumos modernos e pode ser denominado, portanto, por. fator de "tecnificação" ou de Atraso Técnico. Existe perfeita harmonia de sinais nos coeficientes de todas as variáveis, o que elimina a preocupação com os coeficientes que não sendo superiores a 0,5 apresentam, contudo, valores relativamente elevados neste fator. O coeficiente da variável 
TABELA 22 - "Normalized Unrotated Factor Loadings"

\begin{tabular}{|c|c|c|c|c|c|}
\hline Variāvel & Fator 1 & Fator 2 & Fator 3 & Fator 4 & $\begin{array}{c}\text { Commalida } \\
\text { des - }\end{array}$ \\
\hline$x_{1}$ & 0.9268 & 0,2033 & $-0,1700$ & $-0,1016$ & 0,9396 \\
\hline$x_{2}$ & $-0,5887$ & $-0,6181$ & 0,2653 & 0,2880 & 0,8820 \\
\hline$x_{3}$ & $-0,9484$ & $-0,1341$ & 0,0747 & 0,0420 & 0,9247 \\
\hline$x_{4}$ & $-0,9124$ & 0,0409 & 0,1271 & 0,0473 & 0,8526 \\
\hline$x_{5}$ & 0,4815 & 0,0466 & $-0,5984$ & 0,4825 & 0,8249 \\
\hline$x_{6}$ & 0,6034 & 0,4070 & 0,4574 & 0,4455 & 0,9574 \\
\hline$x_{7}$ & 0,5709 & 0,1269 & 0,4065 & $-0,3705$ & 0,6445 \\
\hline$x_{8}$ & 0,6109 & $-0,6385$ & $-0,2554$ & $-0,2618$ & 0,9146 \\
\hline$x_{9}$ & $-0,8519$ & $-0,0654$ & $-0,0707$ & 0,0464 & 0,7372 \\
\hline$x_{10}$ & $-0,8551$ & 0,3849 & $-0,2041$ & $-0,1485$ & 0,9431 \\
\hline$x_{11}$ & $-0,8210$ & 0,3889 & $-0,2459$ & $-0,1578$ & 0,9106 \\
\hline
\end{tabular}


.98 .

TABELA 23 - Matriz do peso dos fatores. após Rotação Ortogonal (VARIMAX).

Variáveis Fator 1 Fator 2 Fator 3 Fator

\begin{tabular}{|c|c|c|c|c|}
\hline$x_{1}$ & 0,7797 & $=0,4985$ & 0,2095 & 0,1971 \\
\hline$x_{2}$ & $-0,9282$ & $-0,0355$ & $-0,0971$ & $-0,0979$ \\
\hline$x_{3}$ & $-0,6996$ & 0,5715 & $-0,2829$ & $-0,1688$ \\
\hline$x_{4}$ & $-0,5896$ & 0,6620 & $-0,1663$ & $-0,1972$ \\
\hline$x_{5}$ & 0,2686 & $-0,2296$ & 0,0981 & 0,8308 \\
\hline$x_{6}$ & 0,2920 & $-0,1849$ & 0,9030 & 0,0494 \\
\hline$x_{7}$ & 0,4811 & $-0,3711$ & 0.2552 & $-0,4583$ \\
\hline$x_{8}$ & 0,1780 & $-0,8550$ & $-0,3763$ & 0,1006 \\
\hline$x_{9}$ & $-0,5626$ & 0,5674 & $-0,3110$ & $-0,0440$ \\
\hline$x_{10}$ & $-0,1737$ & 0,8933 & $-0,3314$ & $-0,0709$ \\
\hline$x_{11}$ & $-0,1350$ & 0,8763 & $-0,3502$ & $-0,0412$ \\
\hline
\end{tabular}

Denominação dos fatores: Fator 1 - Atraso Téñico; Fator $z$ - nível de concentração; Fator 3 - nível de auto-consumo; Fator 4 - nível de posse precária. 
"cultivo simples". é bastante significativo e supe rior a 0,5 em conjunto com os coeficientes das quatro primeiras variáveís, confirmando a relação de maior uso de insumos modernos com o tipo de cultivo.

Fator 2 : Este fator apresenta algumas semelhanças com " o primeiro, embora seja ortogonais. Entre todos os coeficientes do fator as relações de sinais são coerentes com as relaçōes estabelecidas entre as variáveis na matriz de correlações e também com as relaçōes estabelecidas no próprio fatọr 1 . A única exceção ocorre com o coeficiente da variável $x_{2}$ (utilização de sementes selecionadas) com valor próximo de zero. Este fator, como se obser va na Tabela 23, apresenta várias variáveis signi ficativas (com coeficientes superiores a 0,5 ) coincidentes com o primeiro. A principal característica que o distingue è a importância que as va riáveis de concentração (índices de concentração da área de colheita) possuem. E um fator que podemos associar, então, a nível de concentração.

Fator 3 : o coeficiente de maior valor corresponde ao da variável $x_{6}$ ("auto-consumo") de sinal contrário às variáveis que indiscutivelmente se associam a um maior nível de modernização. E um fator que quanto mais positivo menos "modernizada" podemos considerar determinada cultura. O segundo coeficiente de maior valor, embora menor que 0,5 corresponde à variável $x_{8}$ ("venda à intermediário") de sinal contrário. 0 fator contrapōe duas formas distintas de comercialização destacando os ní veis de auto-consumo. Parece, portanto, plausi- 
vel a sua identificação com "auto-consumo".

Fator 4 : Neste fator o coeficiente da variável $x_{5}$ (tipo de produtor) é o único superior a 0,5 . Esse coeficiente apresenta sinal contrário às variáveis que medem o uso de insumos modernos, associando-se ma iores valores do fator a menor modernização.

fator 4 é denominado por "posse precária".

A construção de gráficos de eixos cartesianos ortogonais (no eixo das abcissas o valor de um fator e no eixo das coordenadas o valor de outro fator) conduzem a uma melhor visualização das diferenças obtidas no valor dos fatores entre culturas ${ }^{1 /}$ (é possível distinguir também regiōes). Como ilustração construiram-se 6 gráficos plotan do os valores dos fatores 1 e 2 para cada cultura.

A interpretação dos gráficos (1 a 6) tem que ser efetuada com cuidado, principalmente quando os fatores estão associados ä várias características.

Em linhas gerais sabe-se que quanto mais negativos forem os valores no fator 1 mais "modernizada" podemos considerar uma cultura em relação ao emprego de insumos modernos. Em relação ao fator 2 quanto mais positivos os seus valores mais concentrada é a área de colheita de uma determinada cultura e menor percentagem da produção é comercializada por intermediário, ao mesmo tempo que, valores positivos, refletem também emprego de "insumos modernos".

1/ Os valores dos fatores são transformados de forma a que a estimativa de sua variância seja igual a 1 . 
GRAFICO 1 - Valores dos fatores ortogonais 1 e 2, para a cultura de Algodão por Estado.

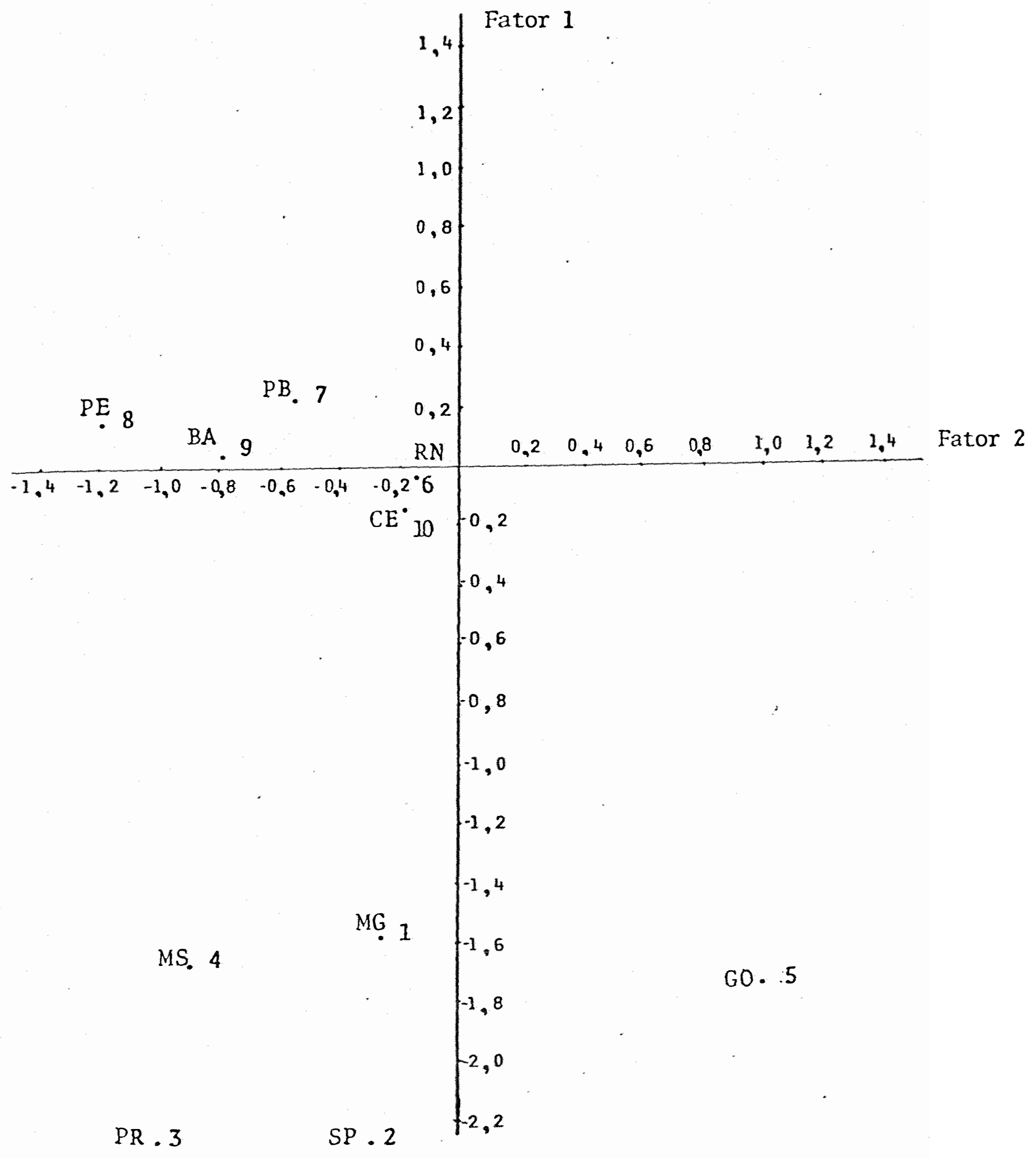


GRAFICO 2 - Walores dos fatores ortogonais 1 e 2, para a cul tura de Cana-de-açücar, por Estado.

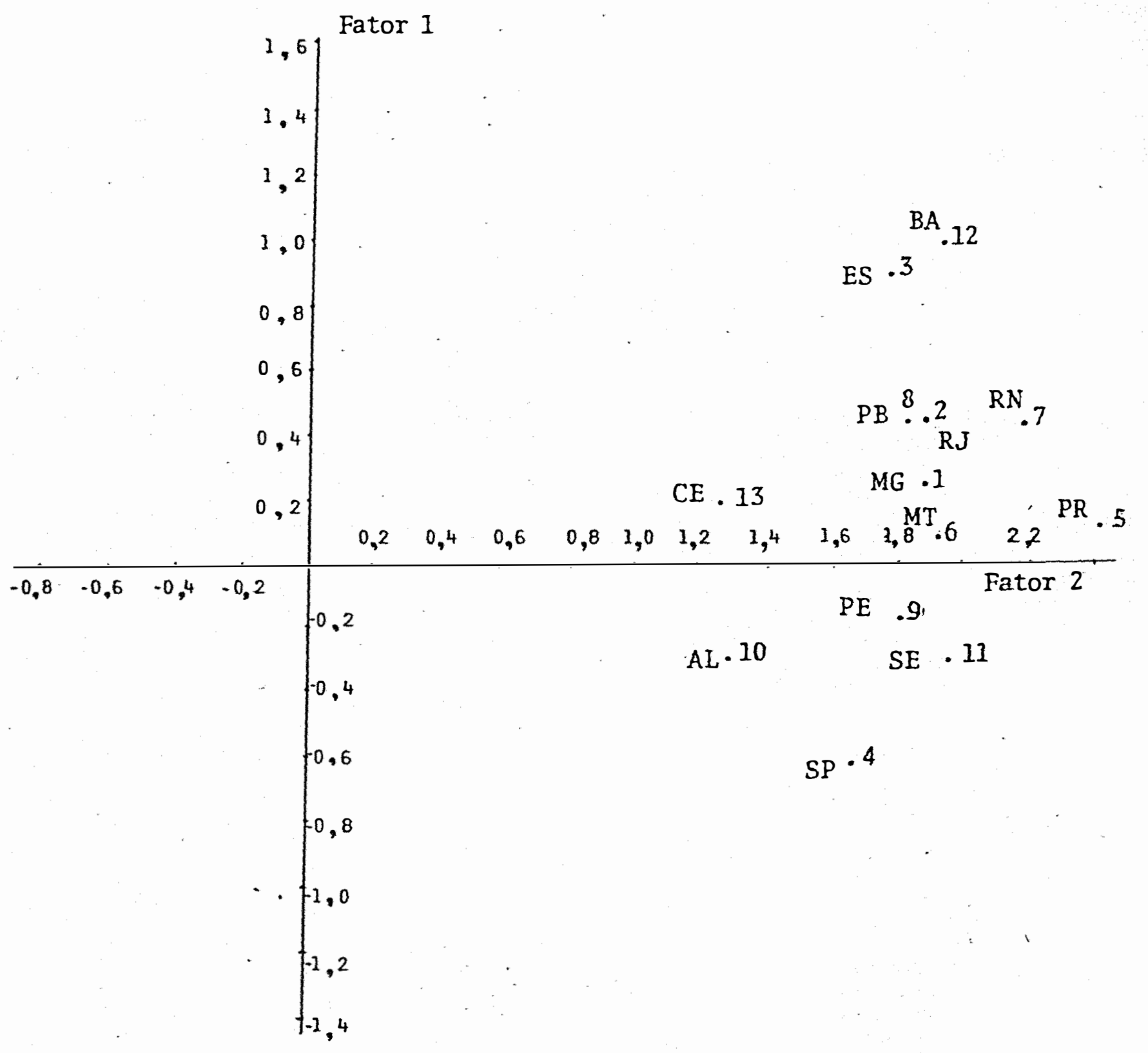


.103.

GRAFICO 3 - Valores dos fatores ortogonais 1 e 2 , para a cultura da Soja, por Estado

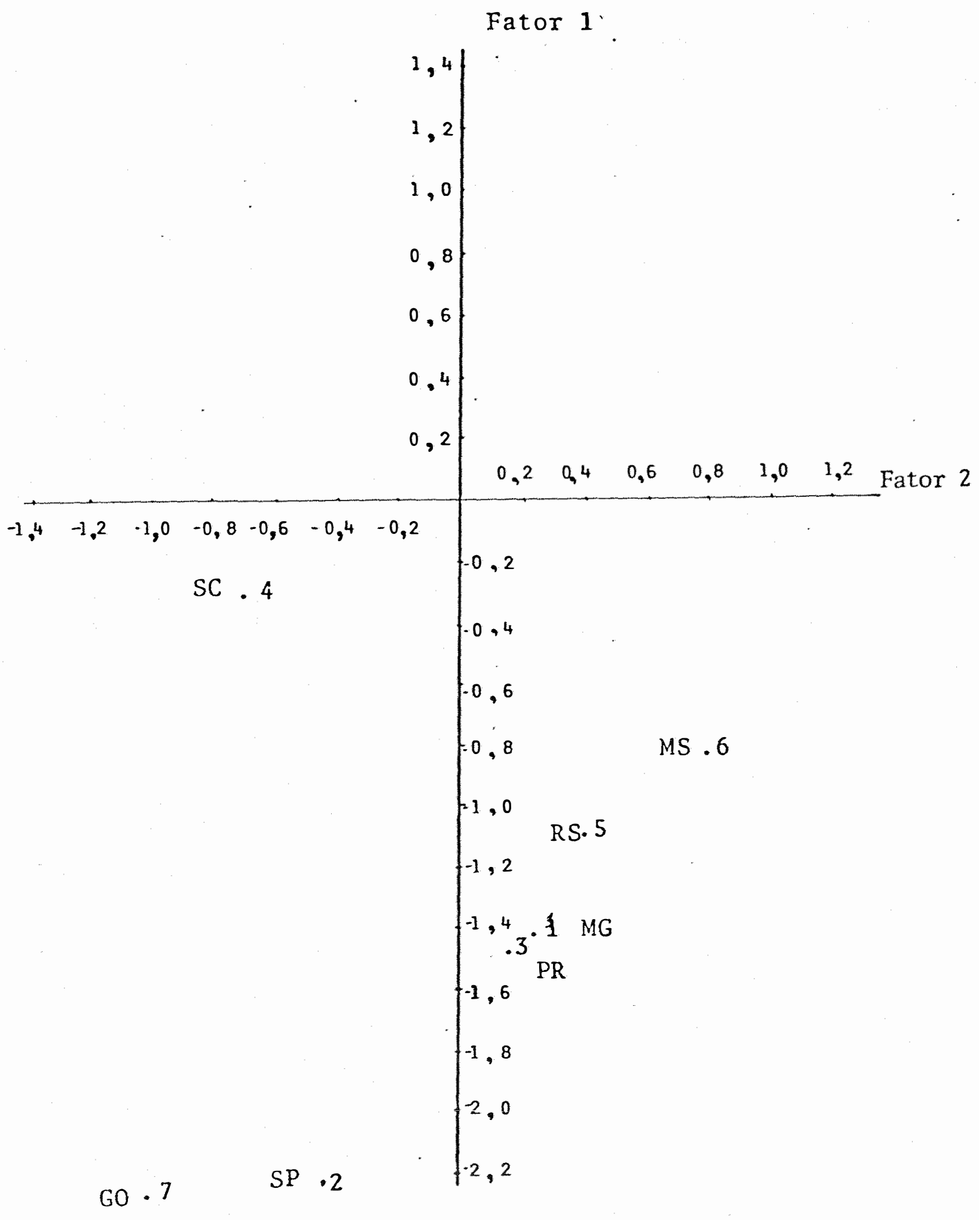




\section{GRAFICO 4 - Valores dos fatores ortogonais 1 e 2, para a cultura do Arroz, por Estado}

Fator 1 .

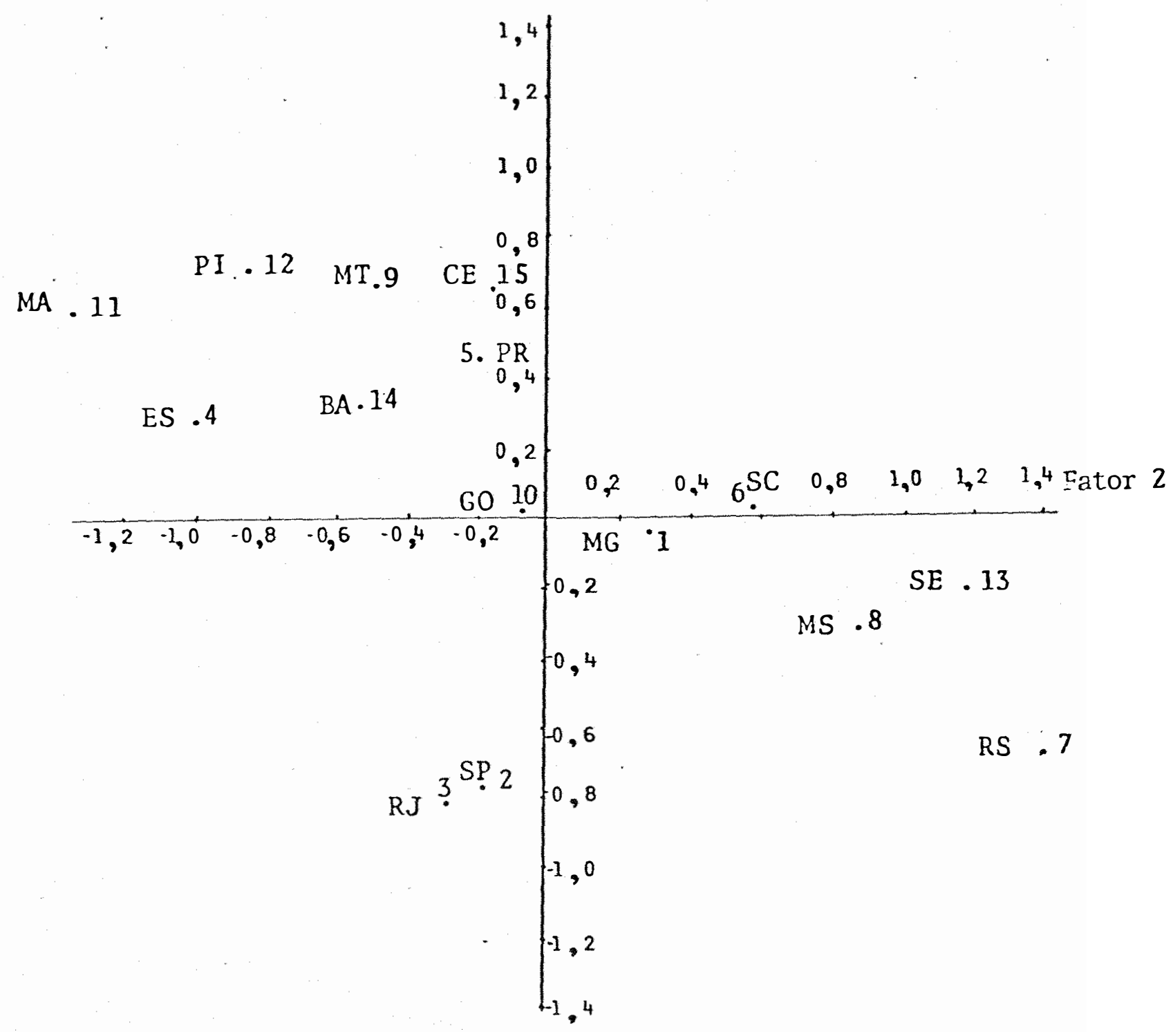


105

GRAFICO 5 -Valoxes dos fatores ortogonais 1 e 2, para a cultura de Feijão, por Estado.

Fator 1

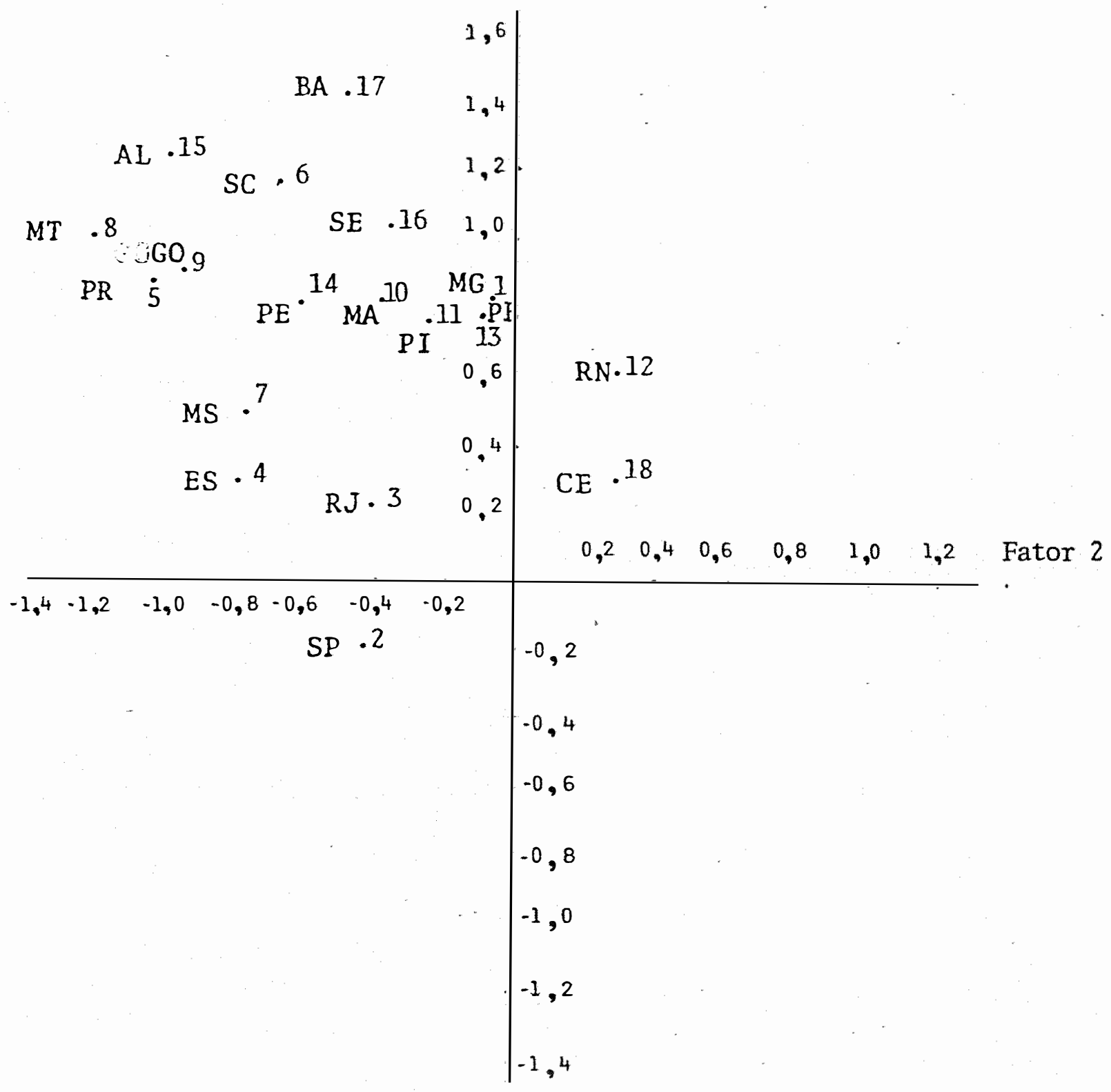


GRAFICO 6 - Valores dos fatores orotgonais 1 e 2, para a cultura de Milho por Estado.

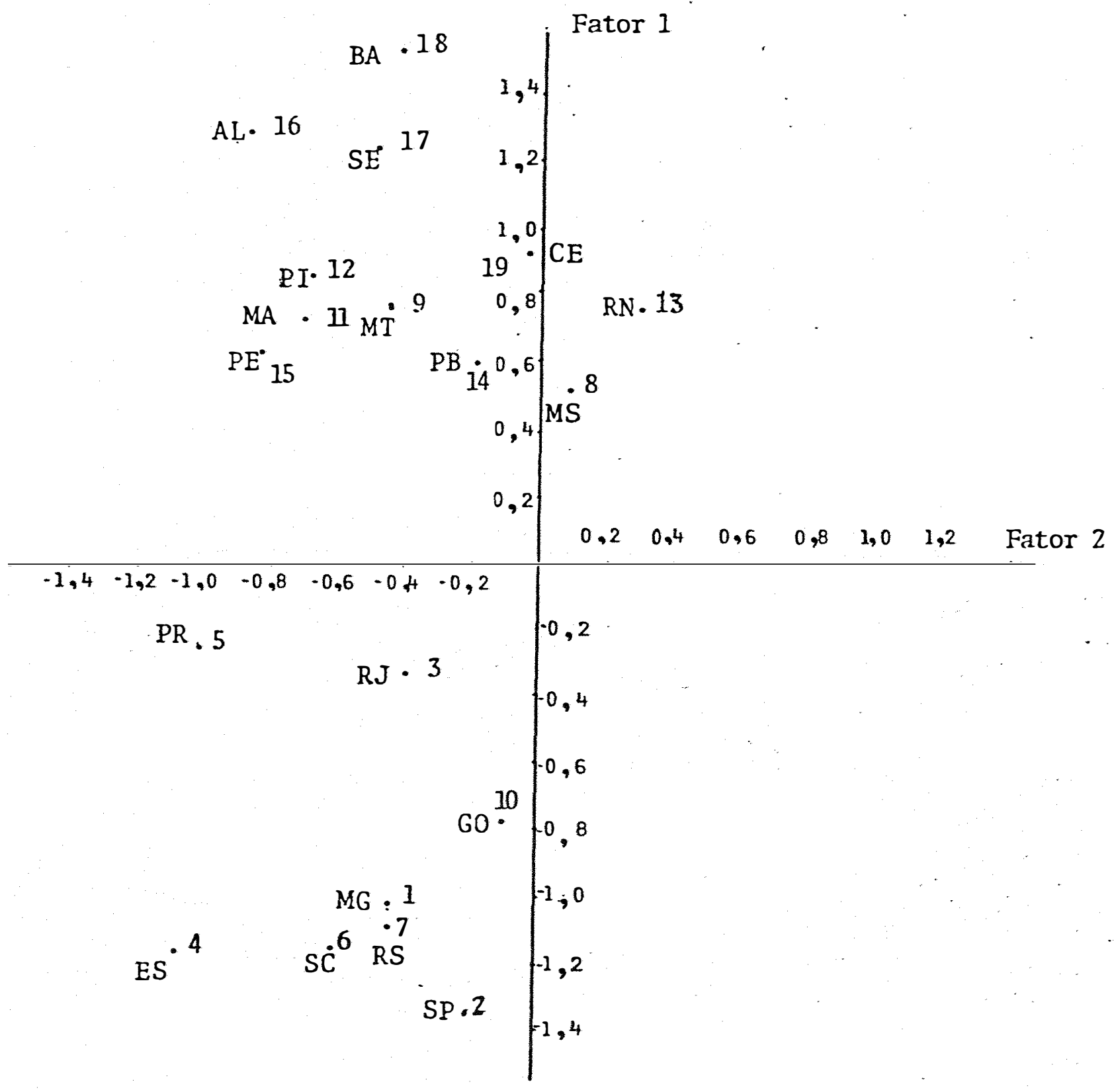


Examine-se as diferenças entre culturas atra vés da configuração da distribuição de pontos. A distinção entre os dois grupos de culturas pode ser efetuada com relativa facilidade.

o feijão é um caso típico em que o fator 1 assume valores positivos e fator 2 valores negativos para quase todos os Estados. O milho com maior dispersão entre valores positivos e negativos do fator 1 concentra quase to dos os pontos na parte negativa do fator 2. 0 arroz apresenta uma posição intermediária com dispersão em relação aos 2.fatores. A soja é um outro caso extremo com todos os valores do fator 1 negativos, em alguns casos fortemente ne gativos. A cana-de-açúcar, por outro lado, apresenta todos os valores do fator 2 positivos (refletindo a alta concentração da área de colheita). A cultura de algodão tem uma posição intermediária com dispersão em relação aos 2 fatores, embora com distribuição de pontos bem distinta da cultura de arroz.

Em relação à análise regional é possível rea lizar comparaçōes com base nos mesmos parâmetros (e caracterizar regiōes em relação às seis culturas). Verifica-se, por exemplo, que o Estado de São Paulo é plotado para todas as culturas nos quadrantes inferiores, ou seja, sempre com valor do fator 1 negativo.

A análise gráfica permite comprovar visualmente as diferenças sistemáticas entre culturas. As Tabelas demonstrativas do valor dos fatores, conjuntamente com - respectivo valor da média aritmética da produtividade em 3 anos consecutivos $(1974,1975$ e 1976) são apresentadas no apêndice 3 . 


\section{ANALISE DOS VALORES DOS FATORES}

Neste capitulo determina-se a relação existente entre os valores dos fatores obtidos e os níveis de produtividade, visando obter confirmação da validade dos indicadores construídos e mostrando que a análise da evolução da produtividade pode substituir parcialmente o estudo da evolução do valor dos fatores, impossibilitado por deficiên cia de informações. A anãlise discriminante utilizando os valores dos vários fatores segundo diferentes alternativas, evidencia as alterações que se obtêm quando se consideram os vários aspectos do sistema produtivo.

\subsection{Relação entre Produtividade e Valores dos Fatores}

$$
\text { Deve-se reafirmar que os diferentes niveis }
$$
de produtividade por ha, indicador mais comum do desenvolvimento técnico de uma determinada cultura, podem não refle tir a maior ou menor modernização. Dadas as diferentes con dições edafológicas, existem fortes limitações em comparações entre diferentes regiões. A comparação entre desenvol vimento técnico nas diferentes culturas é extremamente difí cil, senão impossível, com base em níveis de produtividade. 
A anälise que se conduz envolvendo um conjun to de seis culturas permite comparações entre culturas e en tre regiões, dada a natureza das variáveis utilizadas e na medida em que se caracteriza o sistema produtivo de uma for ma muito mais completa do que com um único indicador como a produtividade por hectare.

0 modelo econométrico utilizado é: $Y=\alpha+$ $\beta X_{1}+\beta X_{2}+\beta X_{3}+\beta X_{4}$ onde a variáve1 dependente (Y) é a produti vidade média da cultura por Estado (média aritmética dos anos - 1974-75-76, uma vez que todos os dados primários para cálcular os valores dos fatores são retirados do Censo Agropecuário de 1975). As variáveis independentes consistem nos valores dos fatores. O ajustamento foi determina do independentemente para cada cultura, por não ter sentido atribuir à variável $\mathrm{Y}$ os valores de diferentes produtivida des para culturas distintas. O número de observações por cultura limita a análise de regressão mültipla e a possibilidade de obter resultados estatisticamente significativos.

$\mathrm{Na}$ Tabela 24 resume-se os resultados obtidos nos ajustamentos para as diferentes culturas. Verifica-se que os coeficientes de determinação são bastante elevados. Mesmo os menores valores obtidos para arroz e feijão são ainda razoáveis considerando-se que se trata de ajustamentos para determinação de produtividade.

Os fatores 1 e 2 são os que apresentam o maior numero de coeficientes significativos nos vários ajus tamentos. Os coeficientes do fator I são significativos para algodão, cana-de-açücar e milho. Os coeficientes do fator 2 são significativos para cana-de-açūcar e arroz. Para a cultura de arroz o fator mais significativo (estatistica- 


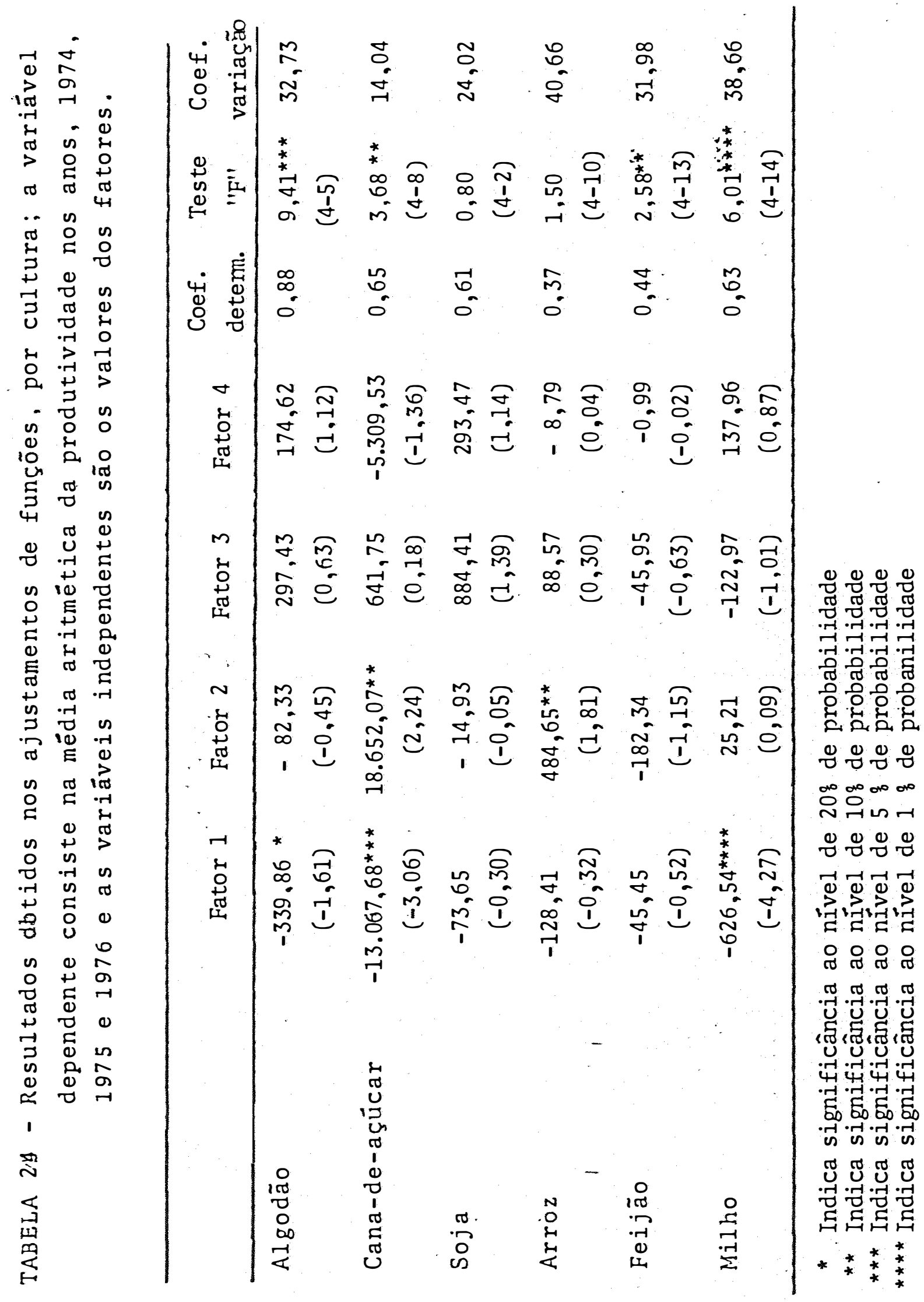


mente de maior significância) é exatamente o fator 2 que se associa a nível de concentração da ärea de colheita. Desta forma a concentração da área de colhèita parece ser elemen to importante na "determinação" do nível de produtividade para cana-de-açücar e arroz.

O fator 3, fator de "auto-consumo" não apresentou nenhum coeficiente significativo.

O fator 4 que representa "tipo de produtor", mais precisamente produção por Parceiro e Ocupante, tambëm não apresenta qualquer coeficiente estatisticamente significativo.

Pelo valor do teste "F", verifica-se que os ajustamentos em relação à produtividade não foram significa tivos para as culturas de soja e arroz.

Uma das causas do fraco ajustamento pode ser a pequena variação da variável dependente, pois não se pode pretender explicar variaçōes quando estas quase não ocor rem. Observe-se a Tabela 25 , em que se apresenta os valores do desvio padrão da variável dependente (produtividade) divididos pela média respectiva de cada cultura e os respecti vos coeficientes de determinação obtidos nos diversos ajustamentos.

Verifica-se que dois dos melhores ajustamentos correspondem às culturas que possuem maior variação relativa (a1godão e milho). Note-se, entretanto, que no caso da cana-de-açücar o coeficiente de determinação é relativamente alto, embora apresente a menor variação relativa da produtividade entre Estados. Para a cultura da soja, com 
pequena variação da produtividade e um coeficiente de deter minação relativamente elevado, dispomos do menor número. dé observaçōes (em número de 7 ), o que restringe qualquer análise estatistica.

TABELA 25,-Valores do desvio padrão da variável dependente: (produtividade) divididos pela média respectiva de cada cultura e os respectivos coeficientes de determinação obtidos nos diversos ajustamentos.

Cultura

$$
S_{Y / \bar{Y}}
$$

Coef. deter.

$\begin{array}{lll}\text { Algodão } & 0,7125 & 0,88 \\ \text { Cana-de-açücar } & 0,1932 & 0,65 \\ \text { Soja } & 0,2232 & 0,61 \\ \text { Arroz } & 0,4345 & 0,37 \\ \text { Feijão } & 0,3746 & 0,44 \\ \text { Milho } & 0,5621 & 0,63\end{array}$

Em termos globais conclui-se que o ajustamento foi satisfatório permitindo testar, ainda que de forma incompleta, os indicadores construídos a partir da análi se fatorial. 
5.2. Anälise Discriminante a Partir dos Valores dos Fato res

Com a construção de novas variāveis foi possivel utilizar o mesmo tratamento analitico anterior. Dispondo do valor estimado dos fatores que caracterizam os diferentes aspectos do sistema produtivo foi possivel proceder-se à anālise discriminante considerando todos os fatores, somente os dois primeiros fatores e exclusivamente o primeiro fator. Optou-se igualmente pela pré-classificação segundo os grupos de culturas consideradas, de forma a obter um ajustamento que classifica posteriormente todas as observaçōes, detectando as necessārias alteraçōes na classi ficação original. Os resultados obtidos listados por Estado e por Cultura incluem o valor da função e a respectiva classificação (omite-se a apresentação das respectivas probabilidades de classificação em cada um dos dois grupos con siderados).

Verifica-se, por exemplo, que o milho se inclui no grupo de culturas modernizadas, grupo B, em São Pau 10 e Goiás quando se considera a análise discriminante com 4 fatores; em todos os estados da região Sudeste e Sul. e também em Goiás quando se considera somente o fator 1 (tecnificação). Lembrando que a anālise discriminante foi realizada considerando todos os fatores, portanto todo o siste ma produtivo; fatores 1 e 2 , nível de tecnificação e de con centração e somente o fator 1 , só tecnificação, a interpretação das ạlterações na classificação é de fácil efetivação. 
TABELA 26 - Valor da função discriminante e respectiva clas sificação: 1. incluindo todos os fatores: 2 . in cluindo os 2 primeiros fatores; 3 . incluindo sō mente os valores do fator 1. Inclui-se no $\mathrm{fi}=$ nal as estimativas dos parametros dos 3 casos.

\begin{tabular}{|c|c|c|c|c|c|c|}
\hline \multirow[t]{2}{*}{ Cultura/Estado } & \multicolumn{6}{|c|}{ Valor da funçāo disc. e classificação } \\
\hline & 1 & & 2 & & 3 & \\
\hline 01 Milho/Minas Gerais & 0,23 & A & $-0,84$ & B & $-1,21$ & B \\
\hline 02 Milho/São Paulo & $-2,14$ & B & $-1,80$ & B & $-1,61$ & B \\
\hline 03 Milho/Rio de Janeiro & 1,83 & A & 0,19 & A & $-0,39$ & B \\
\hline 04 Milho/Esp. Santo & 2,17 & A & 0,05 & A & $-1,39$ & B \\
\hline 05 Milho/Paranā & 2,43 & A & 1,44 & A & $-0,28$ & B \\
\hline 06 Milho/Sta.Catarina & 2,48 & A & $-0,80$ & B & $-1,40$ & B \\
\hline 07 Milho/Rio Gde. Sul & 3,16 & A & $-0,96$ & B & $-1,30$ & B \\
\hline 08 Milho/Mato G.Sul & 2,01 & A & 0,70 & A & 0,61 & A \\
\hline 09 Milho/Mato Grosso & 4,06 & A & 2,04 & A & 0,93 & A \\
\hline 10 Milho/Goiās & $-1,38$ & B & $-1,05$ & B & $-0,92$ & B \\
\hline 11 Milho/Maranhão & 4,56 & A & 2,46 & A & 0,90 & A \\
\hline 12 Milho/Piaui & 5,25 & A & 2,61 & A & 1,05 & A \\
\hline 13 Milho/R.Gde.Norte & 2,84 & $A$ & 0,69 & A & 0,91 & A \\
\hline 14 Milho/Paraíba & 3,63 & A & 1,56 & A & 1,12 & A \\
\hline 15 Milho/Pernambuco & 2,96 & A & 2,52 & A & 0,79 & A \\
\hline 16 Milho/Alagoas & 3,21 & A & 3,62 & A & 1,56 & A \\
\hline 17 Milho/Sergipe & 2,42 & A & 2,84 & A & 1,47 & A \\
\hline 18 Milho/Bahia & 4,01 & A & 3,27 & A & 1,86 & A \\
\hline 19 Milho/Ceará & 3,54 & A & 1,33 & A & 0,75 & A \\
\hline 20 Arroz/Minas Gerais & $-1,34$ & $\mathrm{~B}$ & $-0,54$ & B & $-0,05$ & A \\
\hline 21 Arroz/São Paulo & $-1,92$ & B & $-0,94$ & B & $-0,93$ & B \\
\hline 22 Arroz/Rio de Janeiro & $-1,07$ & B & $-0,81$ & B & $-0,99$ & B \\
\hline 23 Arroz/Esp. Santo & 1,58 & A & 2,21 & A & 0,33 & A \\
\hline
\end{tabular}


.115.

\begin{tabular}{|c|c|c|c|c|c|c|}
\hline Cultura/Estado & Valo & dos & fatores $e$ & \multicolumn{3}{|c|}{ classificação } \\
\hline 24 Arroz/Paranā & 0,78 & A & 1,11 & A & 0,55 & A \\
\hline 25 Arroz/Sta Catarina & $-1,33$ & B & $-0,99$ & $\mathrm{~B}$ & 0,01 & A \\
\hline 26 Arroz/R.Gde Sul & $-5,28$ & $\mathrm{~B}$ & $-3,56$ & $\mathrm{~B}$ & $-0,85$ & B \\
\hline 27 Arroz/Mt Gr. Sul & $-3,66$ & B & $-2,07$ & B & $-0,41$ & B \\
\hline 28 Arroz/Mato Grosso & 0,74 & A & 1,97 & $A$ & 0,82 & A \\
\hline 29 Arroz/Goiās & $-1,47$ & B & 0,14 & $A$ & 0,00 & A \\
\hline 30 Arroz/Mlaranhão & 4,05 & A & 3,32 & $A$ & 0,70 & A \\
\hline 31 Arroz/Piauí & 4,82 & A & 2,64 & A & 0,84 & A \\
\hline 32 Arroz/Sergipe & $-3,92$ & B & $-2,44$ & B & $-0,28$ & B \\
\hline 33 Arroz/Bahia & 1,84 & A & 1,48 & $A$ & 0,40 & A \\
\hline 34 Arroz/Cearā & 2,65 & $A$ & 1,35 & A & 0,79 & A \\
\hline 35 Feijāo/Minas Gerais & 1,18 & $A$ & 1,44 & A & 0,97 & A \\
\hline 36 Feijāo/São Paulo & $-0,80$ & B & 0,48 & $A$ & $-0,21$ & B \\
\hline 37 Feijão/R. Janeiro & 1,70 & $A$ & 1,12 & A & 0,28 & $A$ \\
\hline 38 Feijāo/Esp. Santo & 2,27 & A & 1,89 & A & 0,35 & A \\
\hline 39 Feijāo/Paranā & 2,89 & $A$ & 3,40 & A. & 1,05 & $-A$ \\
\hline 40 Feijāo/Sta Catarina & 2,63 & A & 3,08 & $A$ & 1,38 & A \\
\hline 41 Feijāo/Mt.Gr. Sul & 2,41 & A & 2,19 & $A$ & 0,60 & A \\
\hline 42 Feijāo/Mato Grosso & 3,82 & A & 3,76 & A & 1,21 & A \\
\hline 43 Feijāo/Goiās & 2,34 & $A$ & 3,15 & A & 1,09 & A \\
\hline 44 Feijāo/Maranhāo & 4,60 & A & $2,0.0$ & $\hat{A}$ & 0,97 & A \\
\hline 45 Feijāo/Piauí & 4,41 & A & 1,70 & A & 0,92 & A \\
\hline 46 Feijāo/R.Grde Norte & 3,23 & A & 0,30 & A & 0,73 & A \\
\hline
\end{tabular}




$\begin{array}{lllllll}47 \text { Feijāo/Paraỉba } & 3,70 & \text { A } & 1,44 & \text { A } & 0,94 & \text { A } \\ 48 \text { Feijāo/Pernambuco } & \text { 2,63 } & \text { A } & 2,35 & \text { A } & 0,95 & \text { A } \\ \text { 49 Feijāo/Alagoas } & \text { 2,77 } & \text { A } & 3,78 & \text { A } & 1,49 & \text { A } \\ \text { 50 Feijāo/Sergipe } & \text { 2,83 } & \text { A } & 2,34 & \text { A } & 1,25 & \text { A } \\ 51 \text { Feijāo/Bahia } & \text { 2,71 } & \text { A } & 3,13 & \text { A } & 1,69 & \text { A } \\ \text { 52 Feijāo/Cearä . } & \text { 2,20 } & \text { A } & -0,97 & \text { B } & -0,37 & \text { B }\end{array}$

$\begin{array}{lllllll}53 \text { Soja/Minas Gerais } & -4,44 & \text { B } & -2,69 & \text { B } & -1,70 & \text { B } \\ 54 \text { Soja/Sāo Paulo } & -3,53 & \text { B } & -2,79 & \text { B } & -2,66 & \text { B } \\ 55 \text { Soja/Paranä. } & -3,62 & \text { B } & -2,63 & \text { B } & -1,77 & \text { B } \\ 56 \text { Soja/Sta Catarina } & -0,22 & \text { A } & 0,76 & \text { A } & -0,35 & \text { B } \\ 57 \text { Soja/R.Gde. Sul } & -3,38 & \text { B } & -2,48 & \text { B } & -1,32 & \text { B } \\ 58 \text { Soja/Mt.Grosso Sul } & -4,13 & \text { B } & -2,76 & \text { B } & -1,00 & \text { B } \\ 59 \text { Soja/Goiās } & -3,21 & \text { B } & -1,84 & \text { B } & -2,71 & \text { B }\end{array}$

$\begin{array}{lllllll}60 \text { Algodāo/Minas Gerais } & -3,75 & \mathrm{~B} & -2,05 & \mathrm{~B} & -1,87 & \mathrm{~B} \\ 61 \text { Algodāo/Sāo Paulo } & -3,46 & \mathrm{~B} & -3,05 & \mathrm{~B} & -2,69 & \mathrm{~B} \\ 62 \text { Algodāo/Paranā } & -2,36 & \mathrm{~B} & -1,86 & \mathrm{~B} & -2,71 & \mathrm{~B} \\ 63 \text { Algodāo Mt. Sul } & -2,43 & \mathrm{~B} & -1,09 & \mathrm{~B} & -1,98 & \mathrm{~B} \\ 64 \text { Algodão/Goiās } & -5,09 & \mathrm{~B} & -4,50 & \mathrm{~B} & -2,07 & \mathrm{~B} \\ 65 \text { Algodāo/R.Grde.Norte } & -1,48 & \mathrm{~B} & 0,21 & \mathrm{~A} & -0,02 & \mathrm{~A} \\ 66 \text { Algodāo Paraîba } & -0,39 & \mathrm{~A} & 1,33 & \mathrm{~A} & 0,26 & \mathrm{~A} \\ 67 \text { Algodāo/Pernambuco } & 0,96 & \mathrm{~A} & 2,38 & \mathrm{~A} & 0,19 & \mathrm{~A} \\ 68 \text { Algodão/Bahia } & -0,46 & \mathrm{~A} & 1,45 & \mathrm{~A} & 0,05 & \mathrm{~A} \\ 69 \text { Algodāo/Cearā } & -1,20 & \mathrm{~B} & 0,10 & \mathrm{~A} & -0,16 & \mathrm{~B}\end{array}$


Cul tura/Estado

Valor dos fatores e classificação

\begin{tabular}{|c|c|c|c|c|c|c|c|}
\hline 70 & Cana/Minas Gerais & $-3,31$ & B & $-2,86$ & B & 0,30 & A \\
\hline 71 & Cana/São Paulo & $-3,82$ & B & $-2,60$ & B & 0,53 & A \\
\hline 72 & Cana/Rio Janeiro & $-3,10$ & B & $-1,70$ & B & 1,05 & A \\
\hline 73 & Cana/Esp.Santo & $-5,11$ & B & $-3,90$ & B & $-0,74$ & B \\
\hline 74 & Cana/Paraná & $-5,65$ & B & $-4,06$ & B & 0,11 & A \\
\hline 75 & Cana/Mato Grosso & $-3,56$ & B & $-3,26$ & B & 0,08 & A \\
\hline 76 & Cana/R.Grde.Norte & $-4,35$ & $B$ & $-3,15$ & B & 0,49 & A \\
\hline 77 & Cana/Paraíba & $-3,85$ & B & $-2,47$ & B & 0,53 & A \\
\hline 78 & Cana/Pernambuco & $-4,77$ & B & $-3,42$ & B & $-0,20$ & B \\
\hline 79 & Cana/Alagoas & $-3,85$ & B & $-2,74$ & B & $-0,36$ & B \\
\hline 80 & Cana/Sergipe & $-5,27$ & B & $-3,86$ & B & $-0,34$ & B \\
\hline 81 & Cana/Bahia & $-1,29$ & B & $-1,82$ & B & 1,17 & A \\
\hline 82 & Cana/Ceará & 0,06 & A & $-1,94$ & B & 0,22 & A \\
\hline
\end{tabular}

Estimativa dos Parâmetros

$\begin{array}{lcrl}\text { Fator } 1 & 1,83 & 1,59 & 1,19, \\ \text { Fator } 2 & -2,11 & -1,75 & \\ \text { Fator } 3- & 1,48 & & \\ \text { Fator } 4 & 0,39 & \end{array}$


6 - COMPORTAMENTO DE PREÇOS

Até o momento identificou-se as diferenças entre dois grupos de culturas em relação a três aspectos (nível de utilização de insumos modernos, estrutura de produção e de comercialização). Entretanto, a análise efetuada não permite responder a questionamentos sobre aspectos evolutivos. A partir da análise fatorial, construiram-se novas variáveis que mostxaram um razoável ajustamento com os diferentes níveis da produtividade.

No Apêndice 1 apresenta-se uma breve revisão histórica de comportamento da produtividade que, com todas as limitações inerentes, é ainda um bom indicador do estágio de modernização de uma determinada cultura. Se aceitar mos que "produtividade" é uma "proxi" para ção de uma maior ou menor "modernização", verificamos que a modernização ocorre nos últimos anos essencialmente para um único grupo de culturas (algodão, cana e soja). Com estes resultados parece não existir dūvidas de que tem ocorri do um processo de modernização díspar entre culturas e que as diferenças sistemäticas constatadas entre culturas em 1975 tem vindo a se acentuar ao longo do tempo. 
.119.

A análise de conjuntura mundial, em relação aos diferentes níveis de produtividade, de forma a caracterizar a posição relativa do Brasil para cada cultura e também, ainda que de forma grosseira, procurando determinar as possibilidades de maior participação no comércio internacional, é apresentada no apêndice 2. Nesta secção utiliza-se o mercado mundial como padrão comparativo procurando formar uma idéia da evolução relativa da eficiência econômica da produção no Brasil, em relação ao conjunto da comunidade internacional, através da evolução da relação de preços internos com os preços do mercado mundial. Desta for ma procura-se determinar a ocorrência ou não de comportamen to díspar nos preços dos produtos.

As Tabelas 27 e 28 apresentam as relações en tre preços recebidos pelos agricultores de São Paulo e preços médios internacionais (Fob) de 1948 a 1977. Devemos alertar para as limitações deste tipo de cálculo que não con sidera, por exemplo, a dimensão do mercado internacional, 1 i mitação importante para o feijão. Não se leva em considera ção, também, as imperfeições do mercado (cotas de exportação-importação, programas especiais de crédito como o PL480 , etc.). O exercício que se segue, tentando estabelecer as relações entre aquela razão de preços e a evolução da produtividade no Brasil não procura comprovações empiricas e exatas, mas a formulação de novas hipóteses e questionamentos. Se essa relação foi negativa, isto é, maiores produti vidades corresponderem a menores valores para a relação de preços, teremos indicações da importância que a moderniza ção da agricultura pode ter para a sociedade. 
TABELA 27 - Razão entre Preços Médios Recebidos pelos Agri cultores e Preços Médios Internacionais, em Cr\$, $1948 / 65$.

\begin{tabular}{lcccccc}
\hline & Arroz & Feijāo & Milho & $\begin{array}{c}\text { Cana-de } \\
\text { açücar }\end{array}$ & Algodāo & Soja \\
\hline 1948 & 1,72 & - & 0,74 & 0,62 & 0,75 & 0,77 \\
1949 & 2,13 & - & 1,08 & 0,74 & 0,80 & 1,05 \\
1950 & 1,71 & 0,74 & 0,86 & 0,70 & 0,85 & 1,31 \\
1951 & 1,47 & 0,64 & 0,92 & 0,69 & 1,00 & 1,15 \\
1952 & 2,35 & 1,55 & 1,17 & 0,78 & 0,89 & 1,37 \\
1953 & 3,59 & 2,37 & 1,59 & 0,78 & 0,75 & 1,49 \\
1954 & 3,06 & 2,18 & 1,02 & 0,74 & 0,82 & 1,08 \\
1955 & 2,74 & 1,55 & 1,41 & 0,58 & 0,80 & 1,23 \\
1956 & 2,69 & 1,57 & 1,29 & 0,77 & 0,82 & 1,08 \\
1957 & 2,59 & 1,61 & 1,24 & 0,52 & 0,93 & 1,27 \\
1958 & 2,28 & 1,36 & 0,99 & 0,45 & 0,74 & 1,02 \\
1959 & 1,58 & 0,92 & 0,93 & 0,45 & 0,77 & 1,04 \\
1960 & 1,65 & 0,66 & 0,68 & 0,47 & 0,66 & 0,95 \\
1961 & 1,40 & 0,58 & 0,99 & 0,38 & 0,70 & 0,79 \\
1962 & 2,50 & 1,01 & 0,97 & 0,42 & 0,67 & 0,90 \\
1963 & 2,67 & 1,11 & 0,70 & 0,53 & 0,70 & 0,81 \\
1964 & 1,73 & 0,68 & 0,87 & 0,50 & 0,66 & 0,84 \\
1965 & 0,94 & 0,52 & 0,58 & 0,61 & 0,64 & 0,66
\end{tabular}

Para preços recebidos pelos agricultores de São Paulo, da dos do Inst. de Economia Agrícola. Para preços internació nais'médios, dados do Anuário do Comércio da FAO. As taxas de câmbio de arroz, milho e soja, Knight. Para os demais, Von Doellinger, C. et al. Para os coeficientes técnicos de transformação - informaçōes da Comissão de Financiamento da Produção e da Bolsa de Cereais de São Paulo e Borin. In: Homem de Mello, (1981). 
TABEla 28 - Razão entre os Preços Médios Recebidos pelos Agricultores e Preços Médios Internacionais em $\mathrm{Cr} \$, 1966 / 77$

\begin{tabular}{lllllll}
\hline & Arroz & Feijão & Milho & $\begin{array}{c}\text { Cana-de } \\
\text { açúcar }\end{array}$ & Algodāo & Soja \\
\hline 1966 & 1,79 & 1,48 & 0,62 & 0,47 & 0,61 & 0,85 \\
1967 & 1,67 & 0,78 & 0,79 & 0,45 & 0,66 & 0,71 \\
1968 & 1,36 & 0,84 & 0,62 & 0,43 & 0,65 & 0,79 \\
1969 & 1,31 & 1,80 & 0,74 & 0,45 & 0,64 & 0,85 \\
1970 & 1,26 & 1,04 & 0,73 & 0,41 & 0,70 & 0,89 \\
1971 & 2,36 & 1,05 & 0,71 & 0,38 & 0,76 & 0,88 \\
1972 & 2,28 & 1,22 & 0,83 & 0,35 & 0,71 & 0,71 \\
1973 & 1,41 & 2,09 & 0,83 & 0,31 & 0,87 & 0,81 \\
1974 & 1,16 & 0,93 & 0,63 & 0,21 & 0,79 & 0,72 \\
1975 & 1,62 & 1,30 & 0,72 & 0,20 & 0,77 & 0,73 \\
1976 & 1,24 & 2,17 & 0,75 & 0,34 & 1,24 & 0,76 \\
1977 & 1,32 & 1,46 & 0,76 & $0,47$. & 0,81 & 0,67 \\
$\cdots \ldots \ldots \ldots$ & $\ldots$ & $\ldots$ & $\ldots \ldots$ & & & \\
\hline
\end{tabular}

Para os preços recebidos pelos agricultores, média para São Paulo listadas pela Fundação Getúlio Vargas. Para os preços internacionais, Anuário do Comércio da FAO, preço médio dos países exportadores. Para a taxa de câmbio (única para to dos os produtos), Conjuntura Econômica. Para a soja, o preço recebido refere-se aos preços vigentes em S.Paulo durante 1972/77. Fundação Getúlio Vargas. Foram usados os mesmos coeficientes técnicos da tabela anterior. In : Homem de Mello, (1981). 
A soja é um produto cujo indice de relação de preços é superior à unidade até ao final da década de 50 , período em que se verificava um decréscimo nos indices de produtividade. A relação de preços passa a ser. inferior "à unidade e decresce até 1965/67, período em que se inverte a tendência decrescente dos níveis de produtividade (é necessário considerar que os índices das Tabelas 27 e 28 são diretamente comparáveis). De 1967 a 1970 verifica-se uma ten dência ao aumento do valor da relação de preços conjuntamen te com grandes decréscimos da produtividade. A partir de 1970 novamente a relaçāo inversa, decréscimo no indice de relação de preços e aumento da produtividade.

Para o algodão verifica-se a partir de 1957 uma tendência decrescente na relação de preços que se mantém até no final da década de 60 , refletindo a melhoria nos níveis de produtividade. A partir de 1970 até 1979 o índice de preços tem tendência a aumentar atingindo em 1976 va lor superior à unidade, apesar da produtividade continuar aumentando.

A cana-de-açũcar è uma cultura que se tem ca racterizado quase que continuamente por acréscimos de produ tividade. A observação da evoluçāo do índice de relaçāo de preços paṛece refletir esse comportamento mostrando uma diminuição do seu valor quase contínua.

O milho apresenta no conjunto para o Brasil acréscimos na sua produtividade a partir de 1957 exatamente ano a partir do qual o indice de relaçāo de preços passa de super or a inferior à unidade. A tendéncia decrescente man tém-s até aos anos de 65/68. A partir do início da década de se enta ocorrem variaçōes com tendência a novos aumentos do 3 ice de relação de preços. 
Ind.Pr. $\quad$ CULTURA DE SOJA

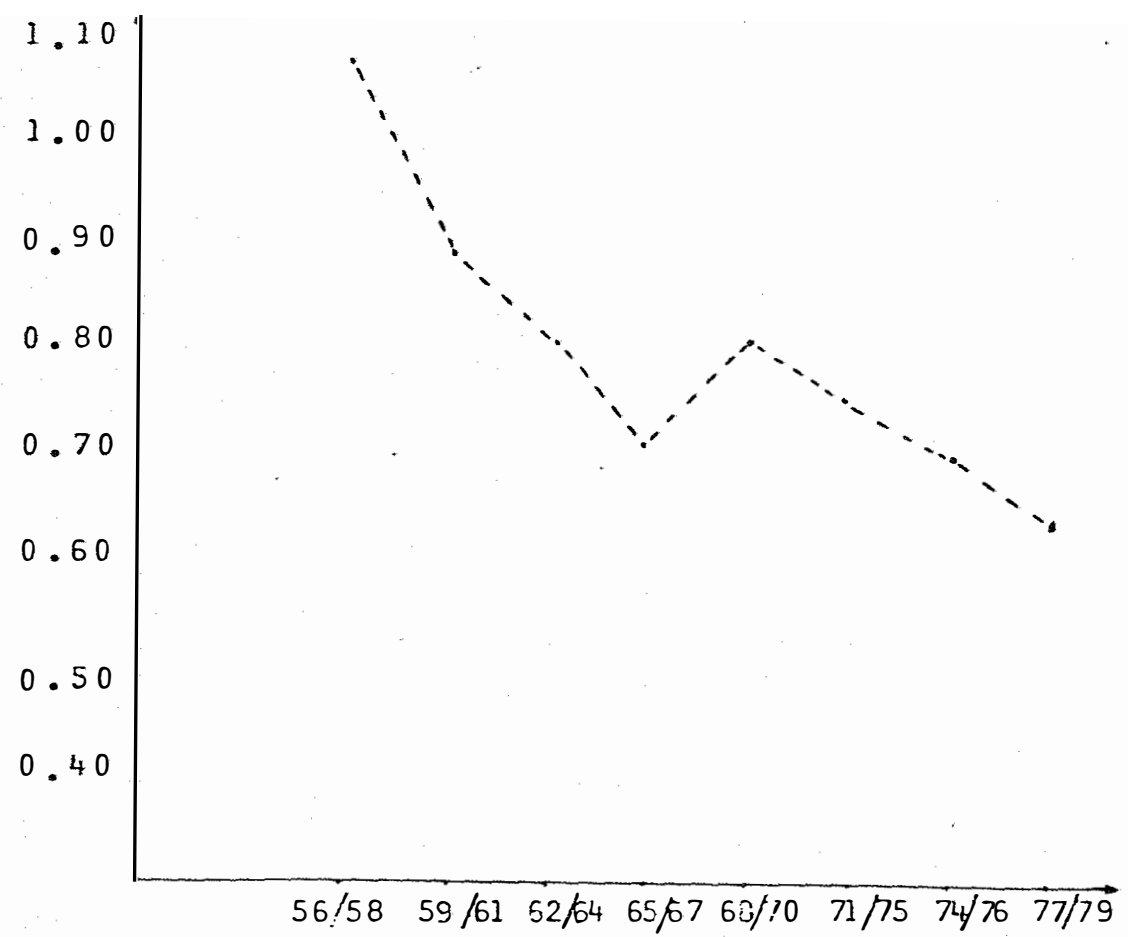

GRAFICO 7. - Razāo entre preços médios segundo as Tabelas 27 e 28 para a cultura da soja.

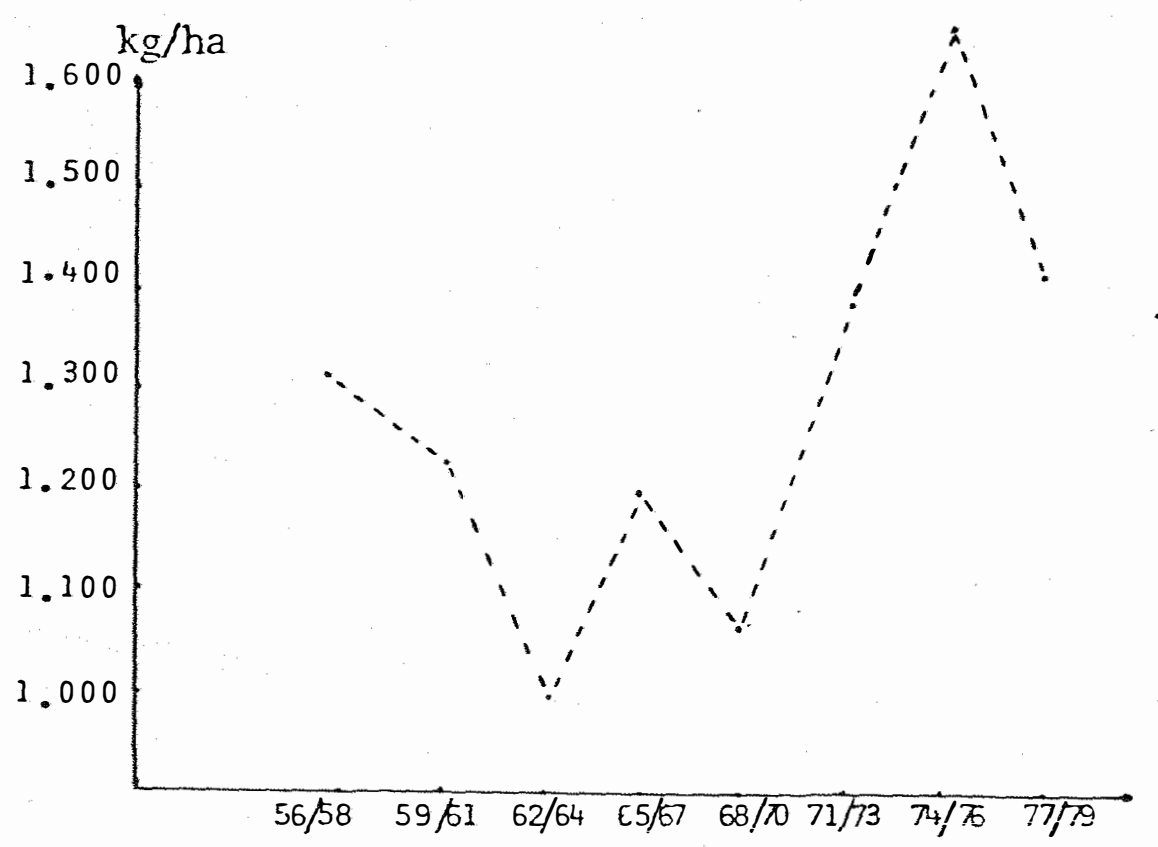

GRAFICO 8.- Evolução da produtividade da soja.

FONTE de dados básicos: Fundaçāo Instituto Brasileiro" de Geografia e Estatística (FIBGE), Anuário Estatístico (Vários números). 
Ind.Pr.

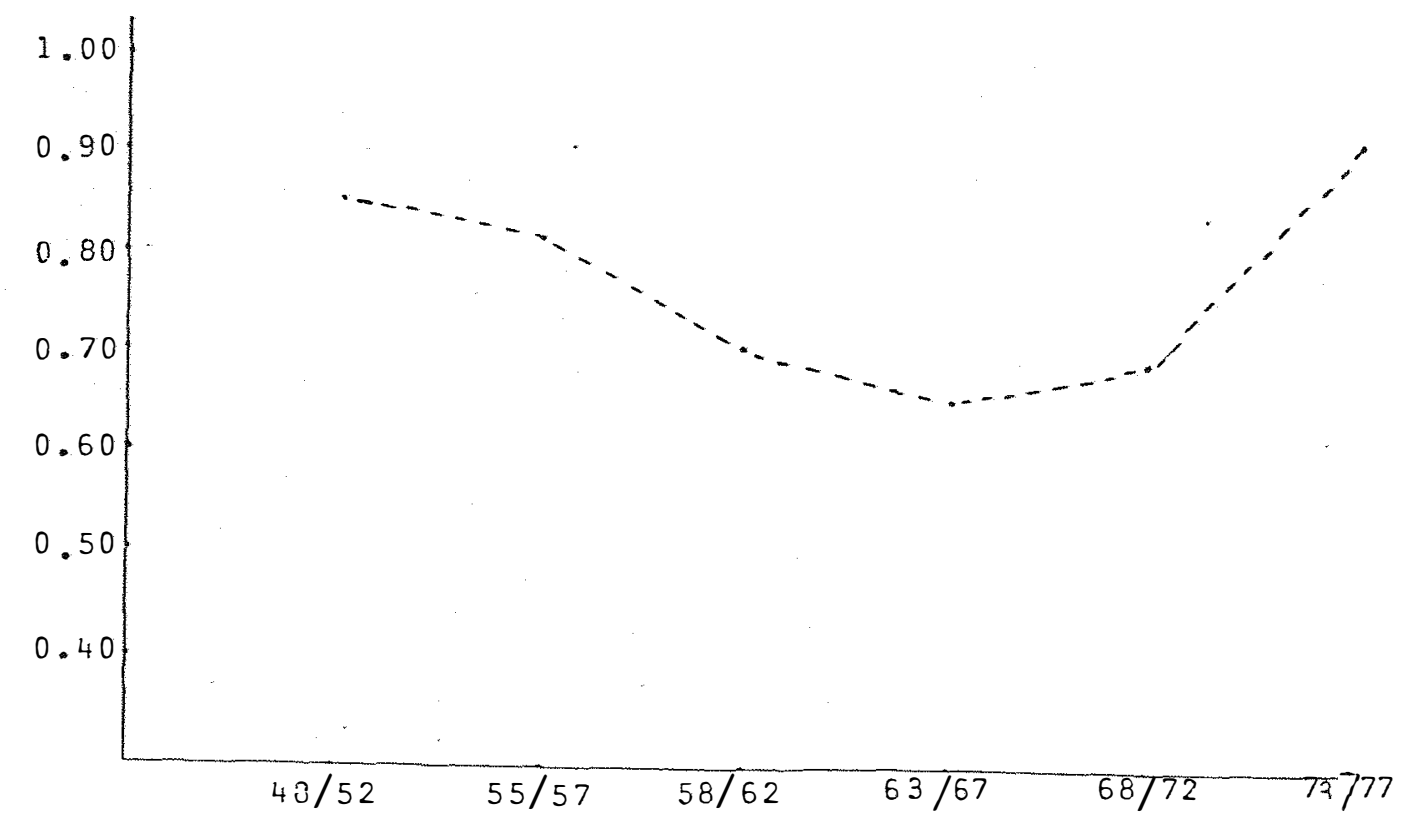

GRĀFICO 9 - Razão entre preços médios segundo as Tabelas 27 e 28 pára a cultura de algodão.

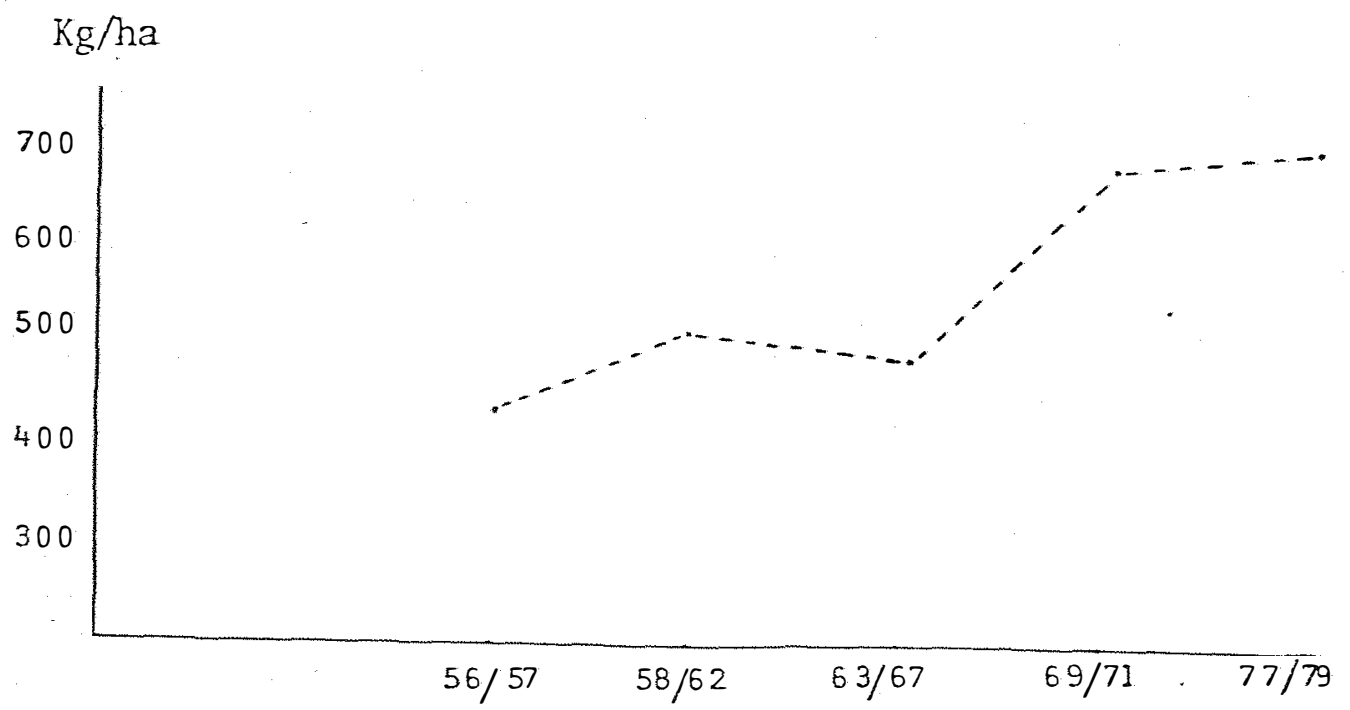

GRAFICO \0 - Evolução da produtividade do algodão.

FORTE de dados Básicos : Fundaçāo Instituto Brasileiro de Geografia e Estatística (FIBGE), Anuário Estatistico (värios números). Para 1969/71 e 1977/79, Anuário Estatístico da FAO. 


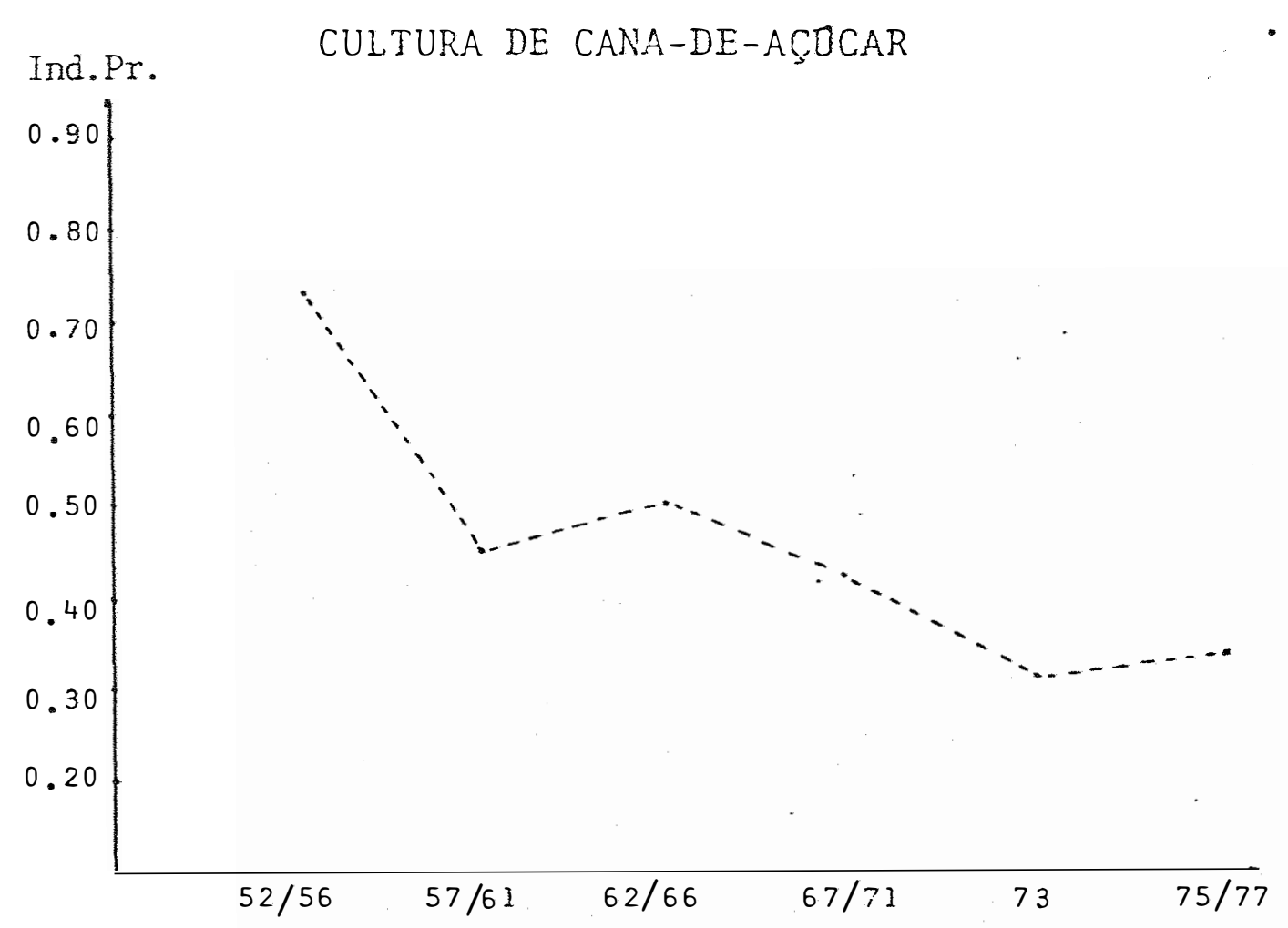

GRÁFICO 11 - Razão entre preços mëdios segundo as Tabelas 27 e 28 para a cultura da cana-de-açücar.

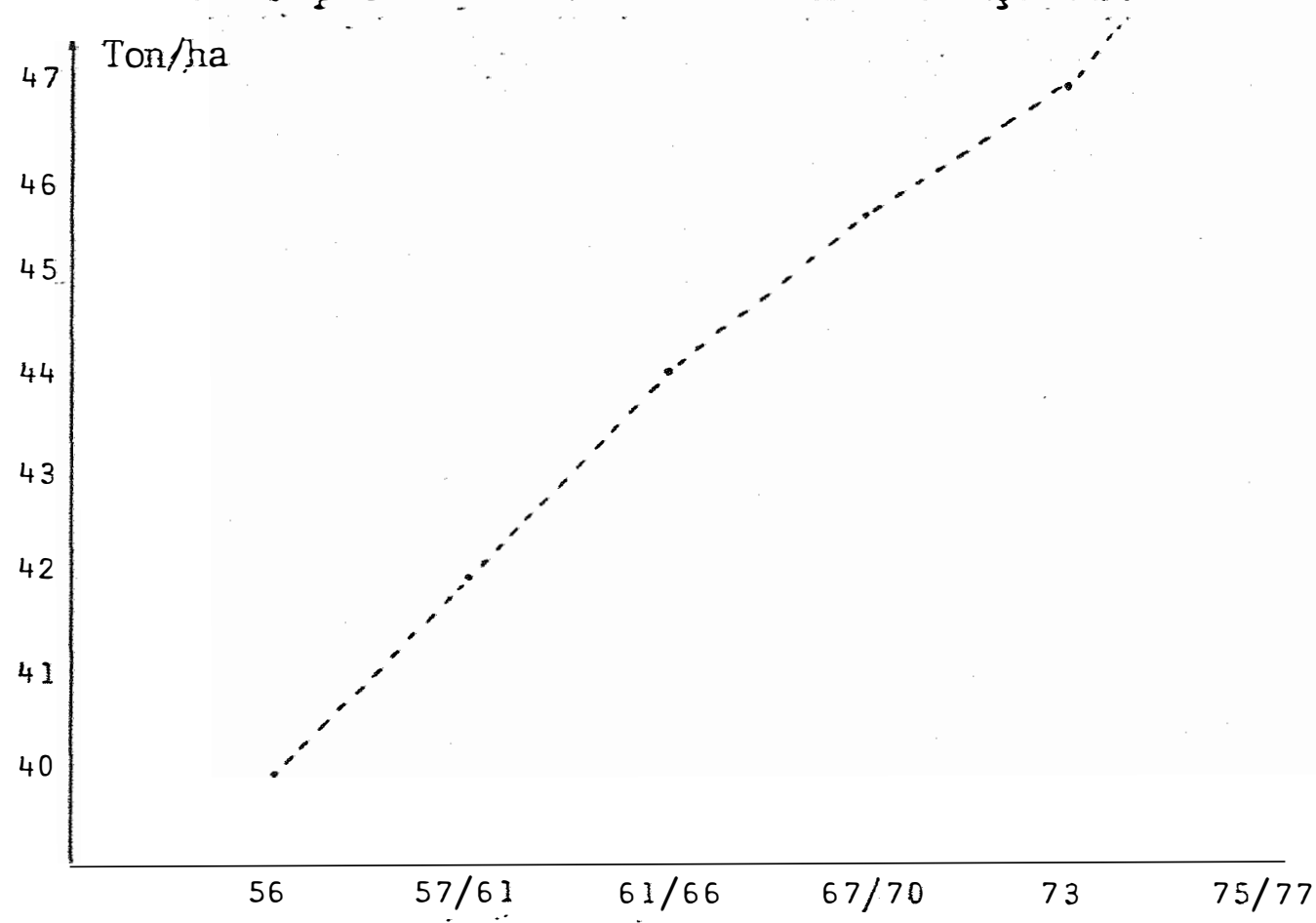

GRÁFICO 12 - Evolução da produtividade da cana-de-açúcar. FONTE de dados básicos : Fundação Instituto Brasileiro de Geografia e Estatística (FIBGE), Anuário Estatísti co (vários números). 


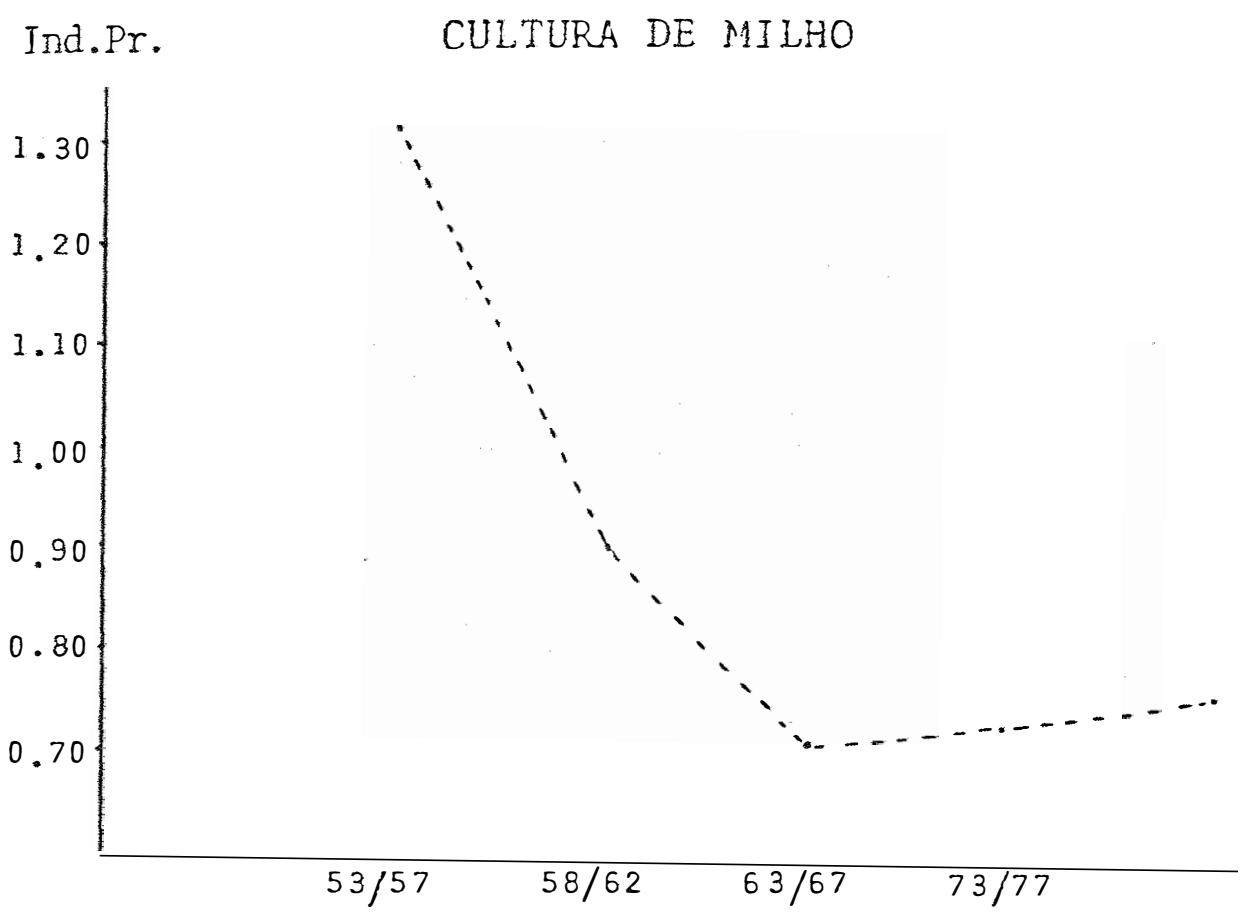

GRĀFICO 13 - Razão entre préços médios segundo as Tabelas 27 e 28 para a "cultura do milho".

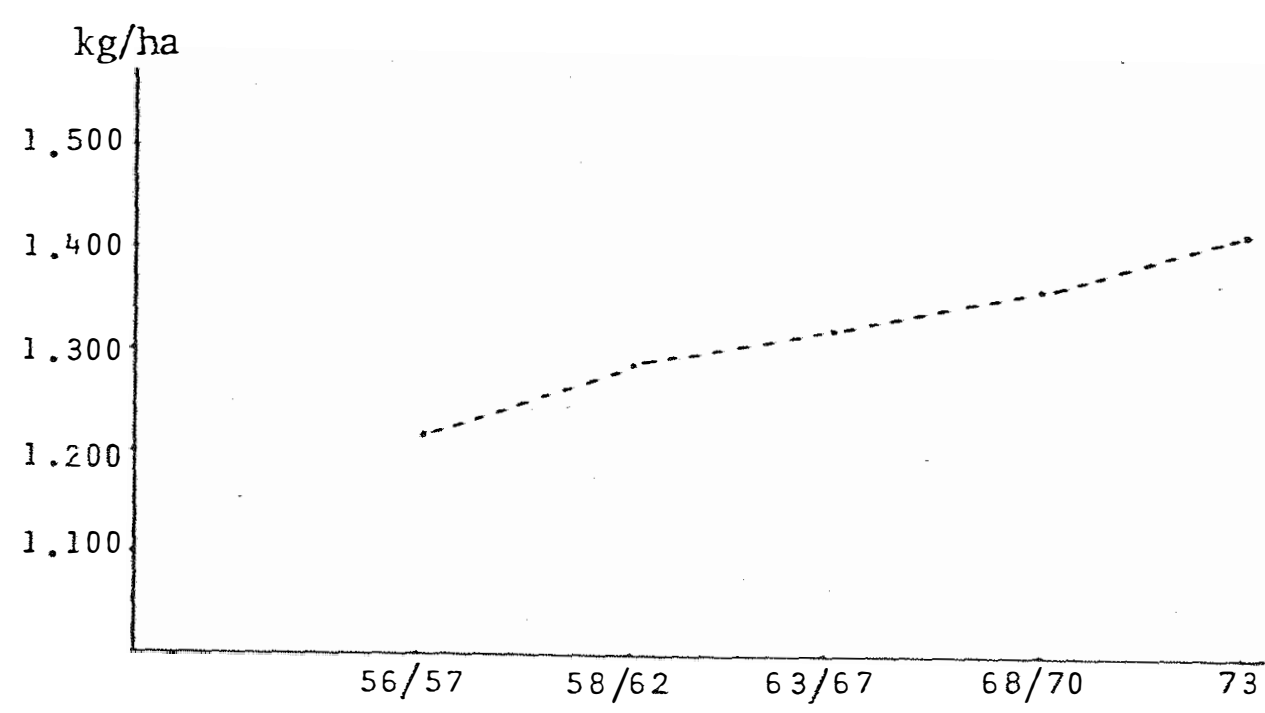

GRÁFICO 14 - Evolução da prọdutividade do milho.

FONTE de dados básicos: Fundaçāo Instituto Brasileiro de Geografia e Estatística (FIBGE), Anuärio Estatísti co (rários números). 
Para o arroz e feijão a maior característica do indice de relação de preços é a sua enorme variação, por vezes de níveis muito inferiores à unidade para níveis bem superiores, de um ano para o outro. Esta situação reflete a enorme instabilidade de preços e quantidades tanto no mer cado interno como no mercado externo.

Através da anālise de regressão linear simples determina-se a relação entre indice de relação de preços e produtividade. Para o conjunto de culturas analisa das graficamente os ajustamentos significativos (teste "F") ao nível de 5 de significância determinaram uma relação ne gativa, à exceção da cultura de algodão. Para esta cultura, quando se realiza a separação em dois períodos, 1956 - 1965 e 1966 - 1977 (segundo os dois conjuntos de relações de pre ços nāo diretamente comparáveis), o ajustamento foi signifí cativo nos dois períodos determinando uma relação negativa no primeiro período è positiva no segundo período. A relação positiva, isto é, maiores níveis de produtividade cor respondendo a maiores preços internos em relação aos internacionais é justificável dada a contração do mercado internacional a partir do início da década de 70. 0 Brasil, que tinha tradição no mercado externo, no início da déçada de 70 metade da produção destinava-se à exportação, deixou de ter participação efetiva nas transaçōes internacionais (ver apêndice 2). A própria produção em termos absolutos tem vindo a diminuir.

A cultura de soja apresentou ajustamento sig nificativo (ao nível de $5 \xi$ de significância) exclusivamente para o período de 1966 - 1977 determinando também relação negativa entre as variāveis.

A cultura de arroz, que apresenta quase sem- 
pre indices de relação de preços superiores à unidade, não mostra qualquer relação significativa entre esses indices e produtividade. Para o feijão, contudo, determinou-se relação significativa e tambēm negativa para o período de 1966 a 1977. Os maiores coeficientes de correlação em termos a solutos para ajustamentos significativos foram:

$\begin{array}{ll}\text { Algodão: } & -0,62\left(1^{\circ} \text { per.) }\right. \\ \text { Cana-de-açücar: } & -0,48 \\ \text { Soja : } & -0,61\left(2^{\circ} \text { per, }\right) \\ \text { Milho: } & -0,51 \\ \text { Feijão: } & -0,69\left(2^{\circ} \text { per.) }\right.\end{array}$

Vimos que são exatamente os produtos tipicamente alimentares que apresentam maior ineficiência na produção em relação à comunidade internacional. Identificou-se a relação existente entre o mesmo indice e as variações de produtividade. Os níveis de correlação obtidos, conside rando-se o enorme elenco de variáveis importantes na determinação de preços no mercado internacional e no mercado interno, são muito significativos. Parece plausivel atentar para a relação entre nível de produtividade, eficiência eco nômica, nível de preços internos versus internacionais e concluir que os indices superiores à unidade para determina dos produtos parecem estar associados a uma menor "modernizaçāo". 
1 - DISTRIBUIÇAO GEOGRAFICA E CREDITO RURAL

Evidenciou-se as diferenças sistemāticas entre culturas, mais precisamente entre dois grupos de culturas de características distintas. O critério utilizado con sistiu na escolha de um conjunto em que se demarcam as seguintes características: produtos que sofrem processo de in dustrialização ou de exportação e produtos típicos de alimentação básica. Argumenta-se que essas características são fatores importantes a nível macro-econômico no processo de modernização da agricultura.

Verificou-se que o grupo de culturas de alimentação básica possui um "nível de modernização" inferior alèm de diferir também em relação à estrutura de produção e de comercialização. No conjunto de fatores considerados im portantes a nível macro-econômico incluem-se tambëm a distribuição geográfica, disponibilidade de tecnologia e o grau de acesso às políticas agrícolas. Sem determinar rela çōes de causalidade verifica-se que esses fatores estão relacionados. Assim, de acordo com as hipóteses iniciais, es tuda-se a distribuição geogrāfica da produção e o grau de acesso às políticas agrícolas, essenciálmente distribuição 
do crédito, procurando identificar padrões de comportamento distinto entre os dois grupos de culturas diferenciados.

\subsection{Distribuição geogrä́fica}

A distribuiçāo geogrāfica da produçāo tem importância na disponibilidade de um determinado produto ao longo do ano. Em países como o Brasil, de dimensões continentais e com variabilidade climática, é possível obter menores flutuações de preços no mercado interno e produzir na entre-safra de muitos países.

Os aspectos mencionados mostram as possiveis vantagens de uma maior dispersāo da produçāo. O Brasil ain da nāo se mostrou em condições de tirar partido desses aspectos positivos. Nas condições atuais a maior dispersāo da produção parece ter efeitos maléficos no desenvolvimento e modernização da agricultura pelas dificuldades que cria no desenvolvimento tecnológico e obtenção de escala de produçāo e de comercializaçāo mais adequada, em suma, dificuldade de "internalizar" os "excedentes" gerados e suas conse quências no estímulo à pesquísa como na própria utilização da tecnologia disponível.

A concentraçāo da ārea de colheita è outro aspecto a considerar na distribuiçẵo geográfica. Para determinar a concentraçāo de ärea de colheita, calculou-se ín dices de Gini e Theil estimados, segundo HOFFMANN (1979) con siderando desigualdade dentro dos estratos, pressupondo que a distribuiçāo dentro do estrato tem funçāo de densidade lí near e, no último estrato aberto é direita, funçāo de Pareto com dois parâmetros. 
A Tabela 29 apresenta os indices de Gini cal culados por Estado e por cultura cujos valores foram utilizados conjuntamente com os indices de Theil nas análises an teriores.

As diferenças entre Estados são evidentes, mas de maior significado ao presente estudo são as diferenças sistemáticas entre culturas. A cana-de-açūcar: evidencia-se por ser a cultura de maior concentração. Algodão e soja apresentam na generalidade indices superiores às cultu ras de milho e feijão, indiscutivelmente, culturas com menor concentração da área de colheita. 0 arroz é uma cultura que apresenta grande variação, em algumas regiōes com indices elevados, da mesma forma que, em alguns Estados, tem produção altamente modernizada e, em outras regiões, é utilizada no desbravamento de novas äreas.

A Tabela 30 apresenta os indices de concentração da área de colheita no Brasil, confirmando-se os comentários realizados.

Ficou evidente que os indices de concentração de área de colheita para todas as culturas variam muito entre Estados em parte como consequência da própria estrutu ra fundiária. As diferenças entre culturas se mantêm, com algumas exceções, de forma sistemätica. Para São Paulo,por exemplo, à exceção do caso da cana-de-açūcar, todas as culturas apresentam indices de concentração muito próximos. E possivel que a maior igualdade entre culturas em relação aos niveis de concentração da área de coḷeita seja reflexo da maior igualdade do nível de modernização. 


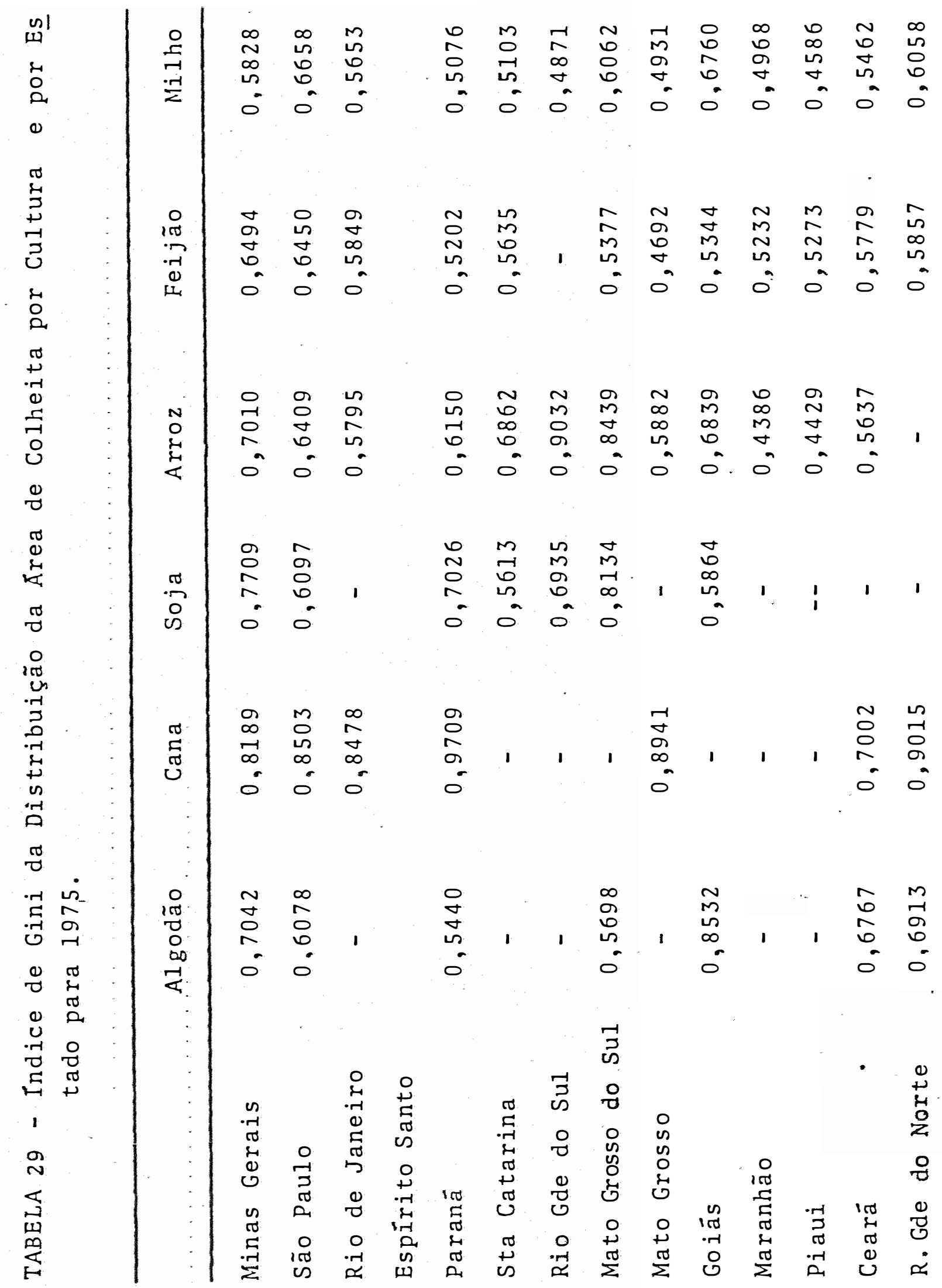




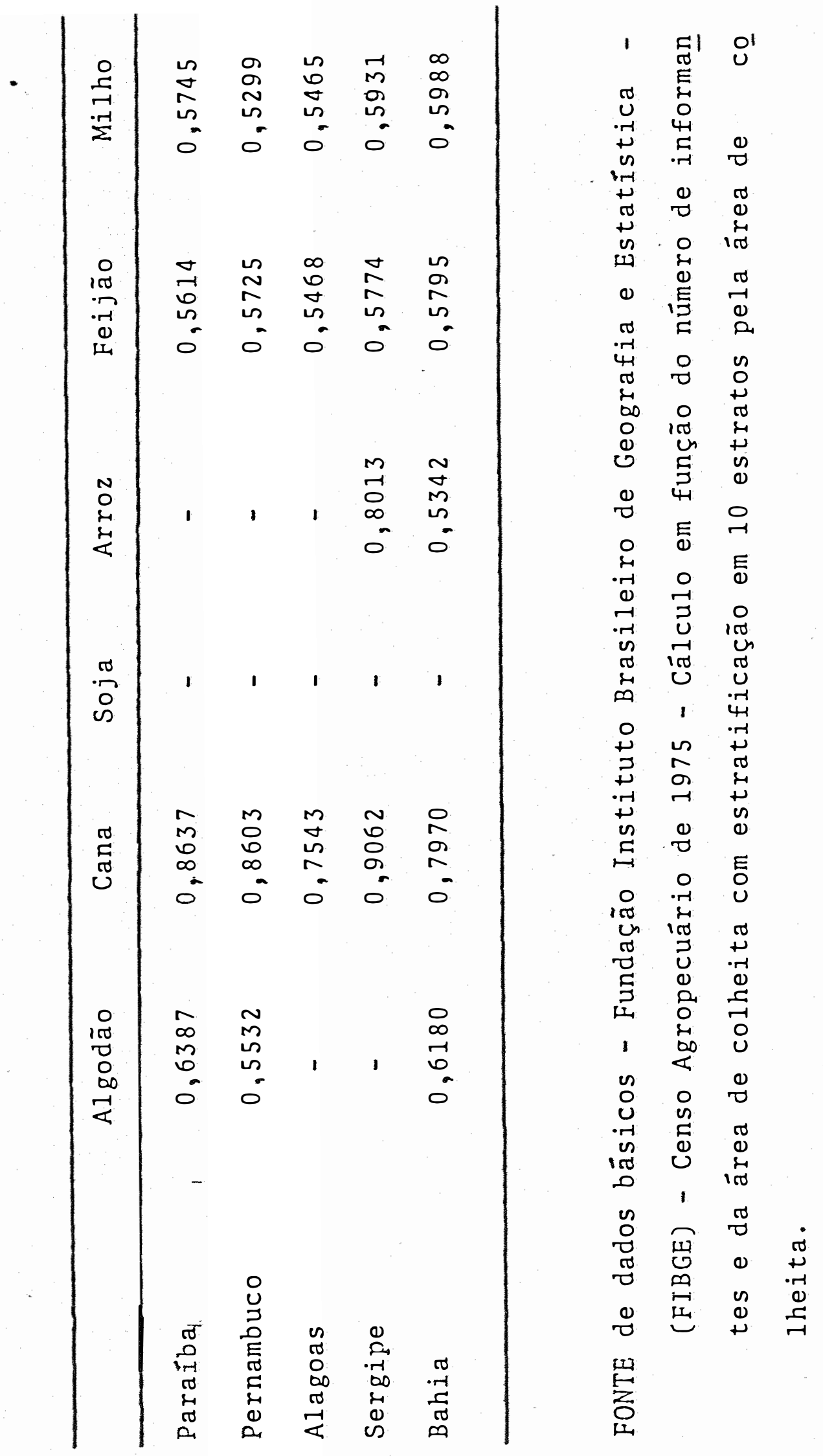

.133. 
TABELA 30 - Indices de Gini da Distribuição da Area de Colheita para o Brasil - 1975.

Cultura

Indice de Gini

Indice de Theil

Algodão

0,7133

0,7111

Cana

0,9287

0,9580

Soja

0,7096

0,7231

Arroz

0,7162

0,7874

Feijão

0,6005

0,5330

Milho

0,6022

0,5556

FONTE de dados básicos: Fundação Instituto Brasileiro de Geografia e Estatística (FIBGE) - Censo Agropecuário 1975 .

A anālise ela evolução dos níveis de concentração em termos de área de colheita não foi possível. Cons truiu-se um outro indice de concentração, calculado a partir da estratificação em grupos de ārea total (15 estratos, sendo o ủitimo aberto à direita) e número de estabelecimento segundo uma determinada atividade econômica. A Tabela 31 apresenta os resultados obtidos para O Brasil em 1970 :e 1975 . 
TABELA 31 - Indices de Concentração da Distribuição de Estabelecimentos Segundo a Atividade Econōmica

Cultura

Indice de Gini

Indice de Gini 1970 1975

Algodão

0,7501

0,7684

Cana

0,8410

0,8333

Soja

0,5342

0,6593

Arroz

0,8630

0,8790

Feijão

0,7436

0,7526

Milho

0,6843

0,7153

FONTE de dados básicos : Fundação Instituto Brasileiro de Geografia e Estatística (FIBGE) - Censo Agropecuário de 1970 e 1975 .

A evolução no tempo mostra existir uma ligeira tendência ao aumento do nível de concentração dos estabelecimentos à exceção daqueles que produzem cana-de-açūcar em que ocorre uma pequena diminuição na concentração. As culturas de soja e do milho apresentaram os maiores acréscimos dos indices de concentração entre 1970 e 1975 I/. Contudo,

If A maior alteração para a soja em termos de concentração reflete as profundas modificações na produção de soja a partir de 1970 com a enorme expansão da produção e da própria produtividade. 
a soja é ainda a cultura, tanto em 1970 como em 1975 que apresenta a menor concentração de ārea dos estabelecimentos na sua produção.

A distribuição regional da produção apresenta também peculiaridades e desuniformidade entre culturas e, até mesmo, entre os dois grupos de culturas. Algỏdão: , cana e soja são culturas em que a maior parte de sua produção se concentra em determinadas regiōes; as culturas de ar roz, feijão e milho possuem : maior disseminação de sua produção por todo o território nacional. A Tabela 32 apre senta a distribuição da produção por região e por Estado em termos de quantidade produzida e ārea de produção. Os grāficos circulares construídos a partir dessa conjunto de dados, ao apresentarem em ordem decrescente de valor percentual. (sentido horārio), as quantidades produzidas por Estado, são bem elucidativos da distribuição geográfica da produção.

Em relação à ärea de ocupação, o milho $\vec{e}$ a cultura que ocupa a maior ārea seguindo-se o arroz e a soja com áreas equivalentes, o feijão, a cana-de-açúcar e o a go dão em ordem decrescente. As diferenças de produtividade entre regiões são evidentes (compare-se a percentagem de produção com a percentagem de área). 


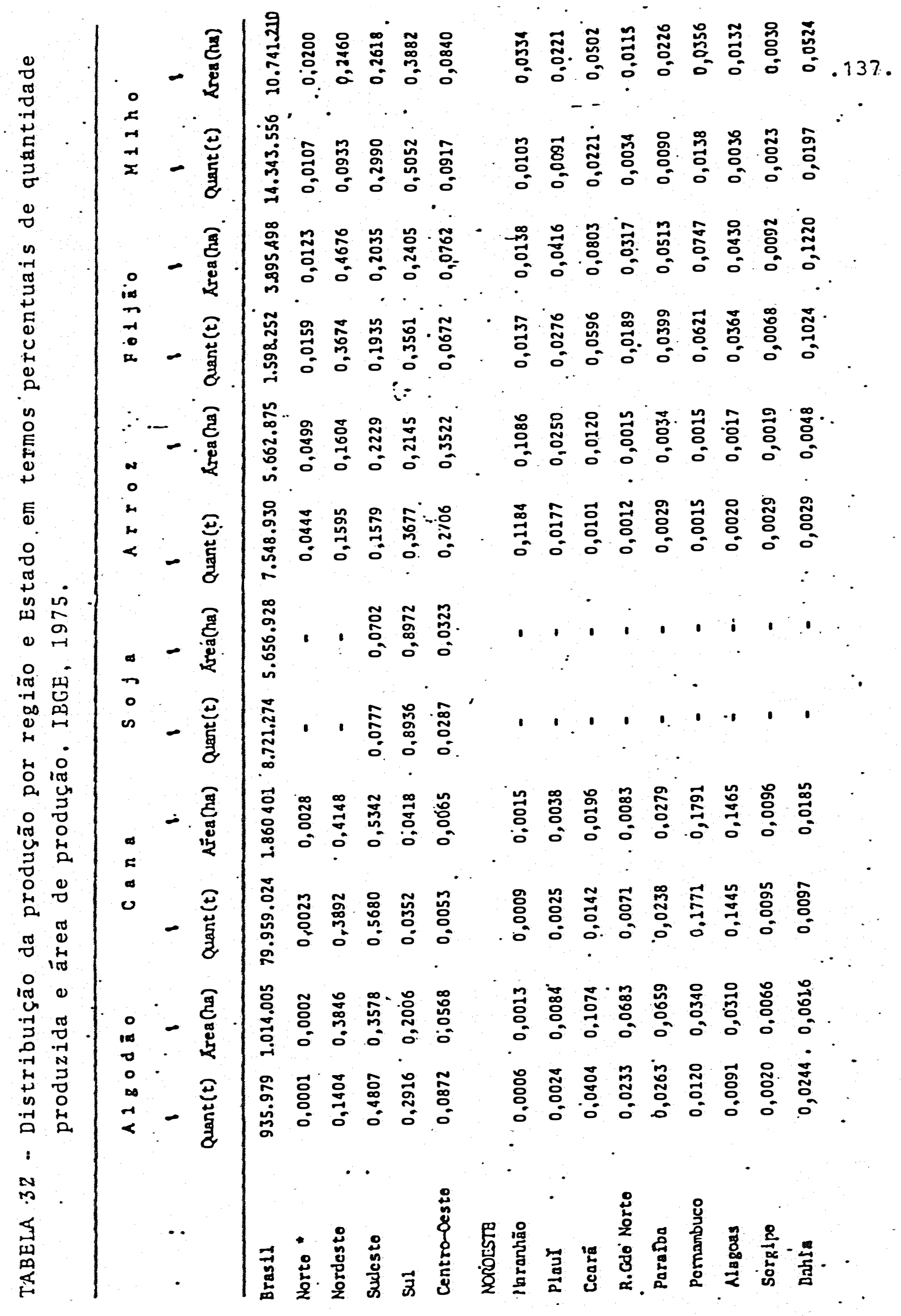




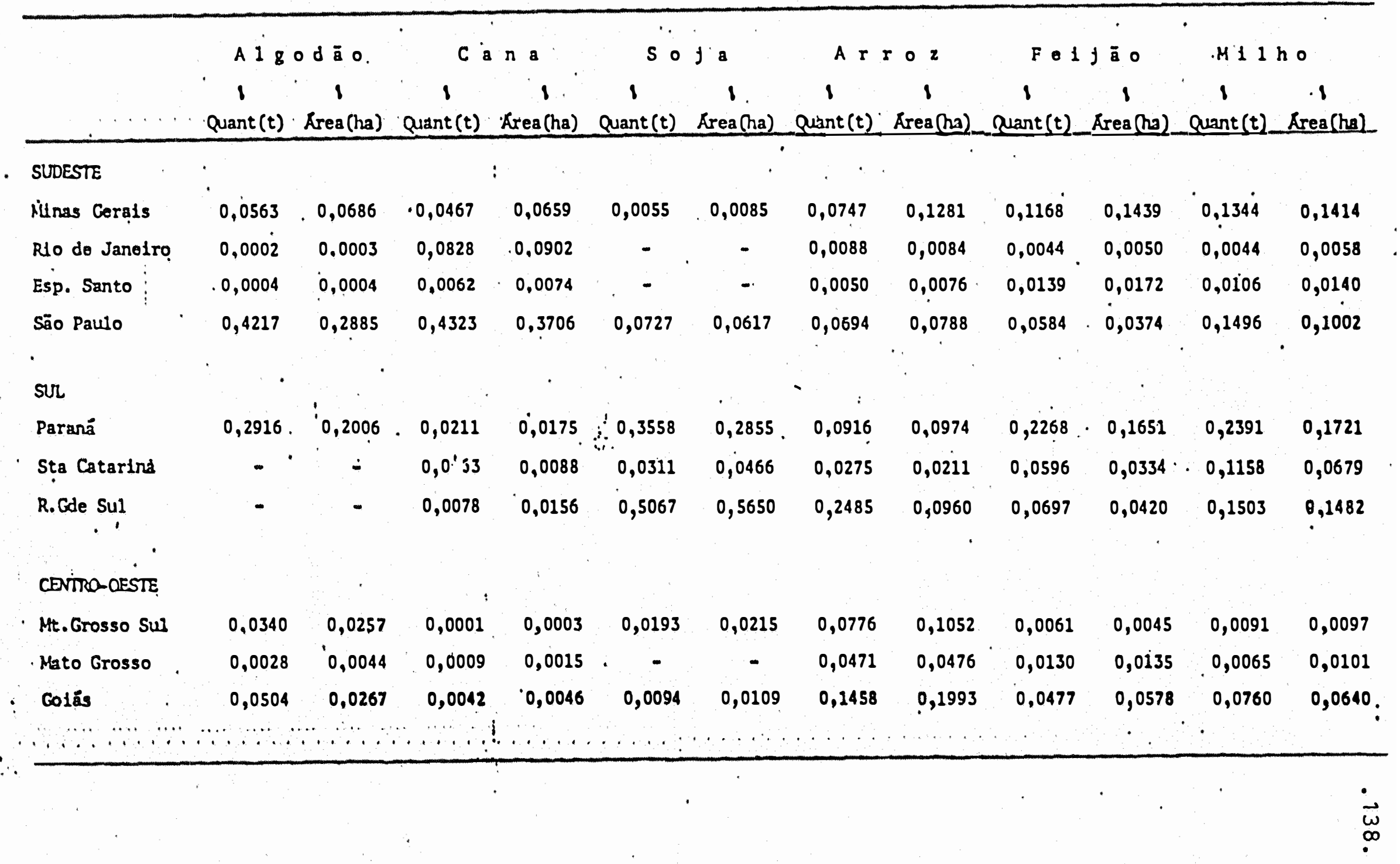


TABELA 33 - Gräficos circulares, mostrando a distribuiçāo por Estado da quantidade produzida em ordem de-. crescente de valor percentual, segundo a Tabela 32 .

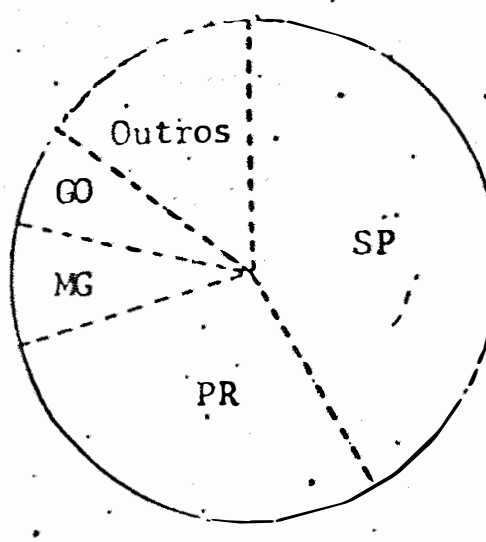

AlOODAO

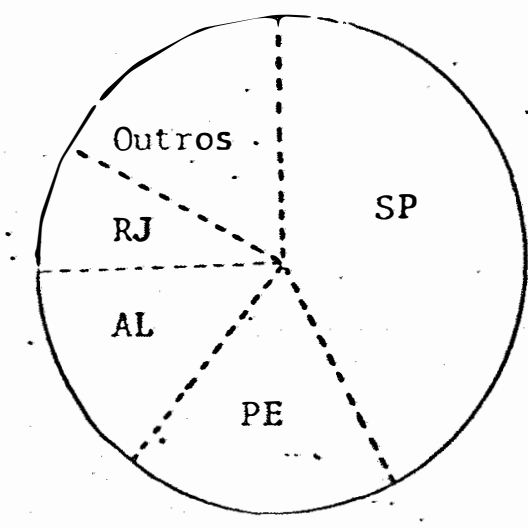

CANA-DE-AÇOCAR

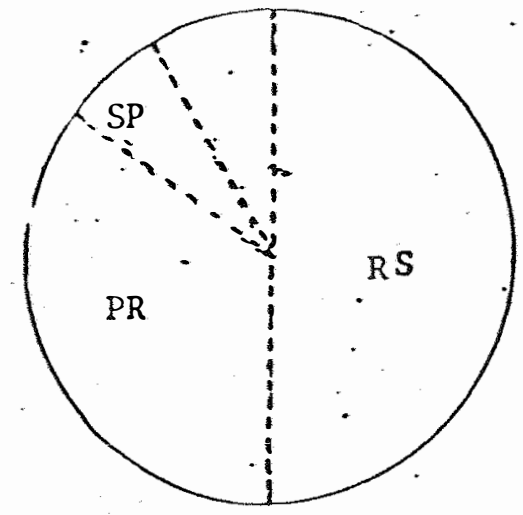

SaJA

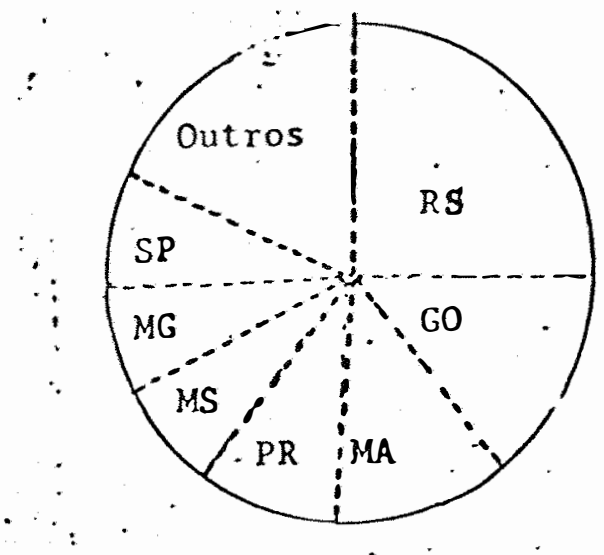

ARROZ

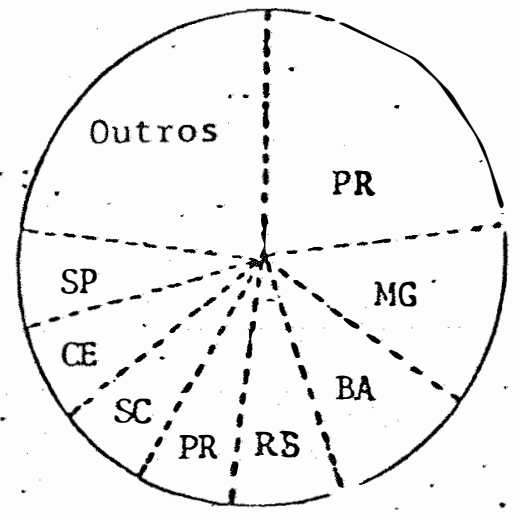

FEI JĀO

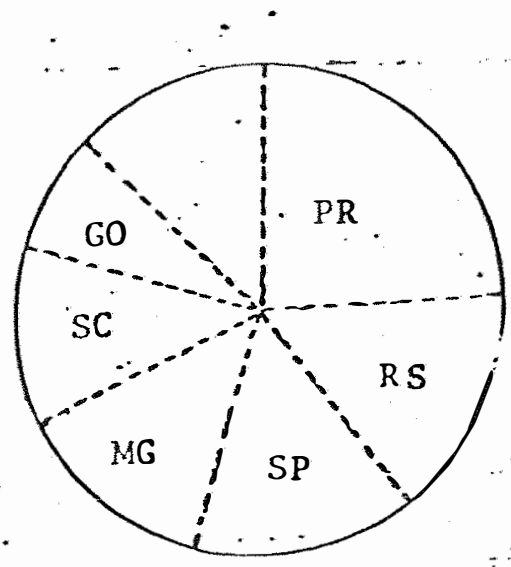

MILHO 


\subsection{Crédito Rural}

Mostrou-se que a distribuição geogräfica, a concentração da ärea de colheita e a concentração de ārea dos estabelecimentos que produzem os diferentes produtos são aspectos distintos entre as culturas. Alguns comentários sobre a distribuição do crédito, indices de concentra ção e distribuição regional, só por si, permitem concluir, dadas as evidências anteriores, que o acesso ao crédito não é idêntico para todas as culturas.

GUEDES PINTO (1980, p. 138) analisa a concen tração do crédito com base em classes de valor dos empréstí mos concedidos (27 estratos para 1969 e 34 para os demais anos), trabalhando com dados do Banco do Brasil, que respon de por aproximadamente três quartos dos financiamentos à agricultura e pecuária. Apresenta a parcela de crédito que é recebida pelo conjunto dos $50 \%$ menores contratos (valor inferior à mediana) e pelos $10 \%, 5 \xi$ e $1 \xi$ maiores " (Tabela 34).

Entre 1969 e 1979 hä um aumento do indice de Gini, o conjunto dos $50 \%$ menores contratos ( $\left.50^{-}\right)$diminui sua participação no montante global de crédito de 7,48 para 5,28 , enquanto que a participação do conjunto dos $1 q$ maiores contratos $\left(1^{+}\right)$aumenta de $25,7 \%$ para $38,5 \%$. Enotório, entretanto, nos últimos dois anos, 1978 e 1979, a diminuição do valor do índice de Gini.

A anâlise da Tabela 35 mostra mais evidências da desigualdade da distribuição de crédito. Enquanto para estratos de ärea inferiores a 10 ha o valor da produção é de $14,76 \%$ e a percentagem do crédito obtido de $3,18 \%$, para o estrado superior a produção é de $1,31:$ com un crédi- 
TABELA 34.- Indice de Gini da distribuição do crēdito para a agricultura concedido pelo Banco do Brasil de acordo com o valor dos contratos; porcentagem do valor correspondente aos 508 dos contratos com valor inferior à mediana, aos 108, 58 e 18 com valor superior a $90^{\circ}, 95+$ e $99^{\circ}$ percen til respectivamente.

\begin{tabular}{|c|c|c|c|c|c|c|}
\hline Ano & & $\begin{array}{l}\text { Indice } \\
\text { de Gini }\end{array}$ & $50^{-}(\%)$ & $10^{+}(q)$ & $5^{+}(8)$ & $1^{+}\left(\begin{array}{l}o \\
0\end{array}\right)$ \\
\hline 1969 & & 0,731 & 7,4 & 65,0 & 51,2 & 25,7 \\
\hline 1972 & & 0,782 & 5,4 & 70,5 & 57,2 & 31,6 \\
\hline 1973 & & 0,787 & 5,3 & 71,0 & 58,9 & 36,0 \\
\hline 1974 & & 0,787 & 5,4 & 71,0 & 58,8 & 35,6 \\
\hline 1975 & . & 0,808 & 4,5 & 73,0 & 60,8 & 38,2 \\
\hline 1977 & & 0,815 & 4,2 & 73,9 & 62,3 & 39,8 \\
\hline 1978 & & 0,808 & 4,7 & 73,8 & 62,1 & 39,1 \\
\hline 1979 & & 0,798 & 5,2 & 72,8 & 61,4 & 38,5 \\
\hline$\cdots \cdots$ & & $\cdots \cdots$ & & & - & \\
\hline
\end{tabular}

FONTE de dados primários - Banco do Brasil

In GUEDES PINTO $(1980, p .138)$ 
.142 .

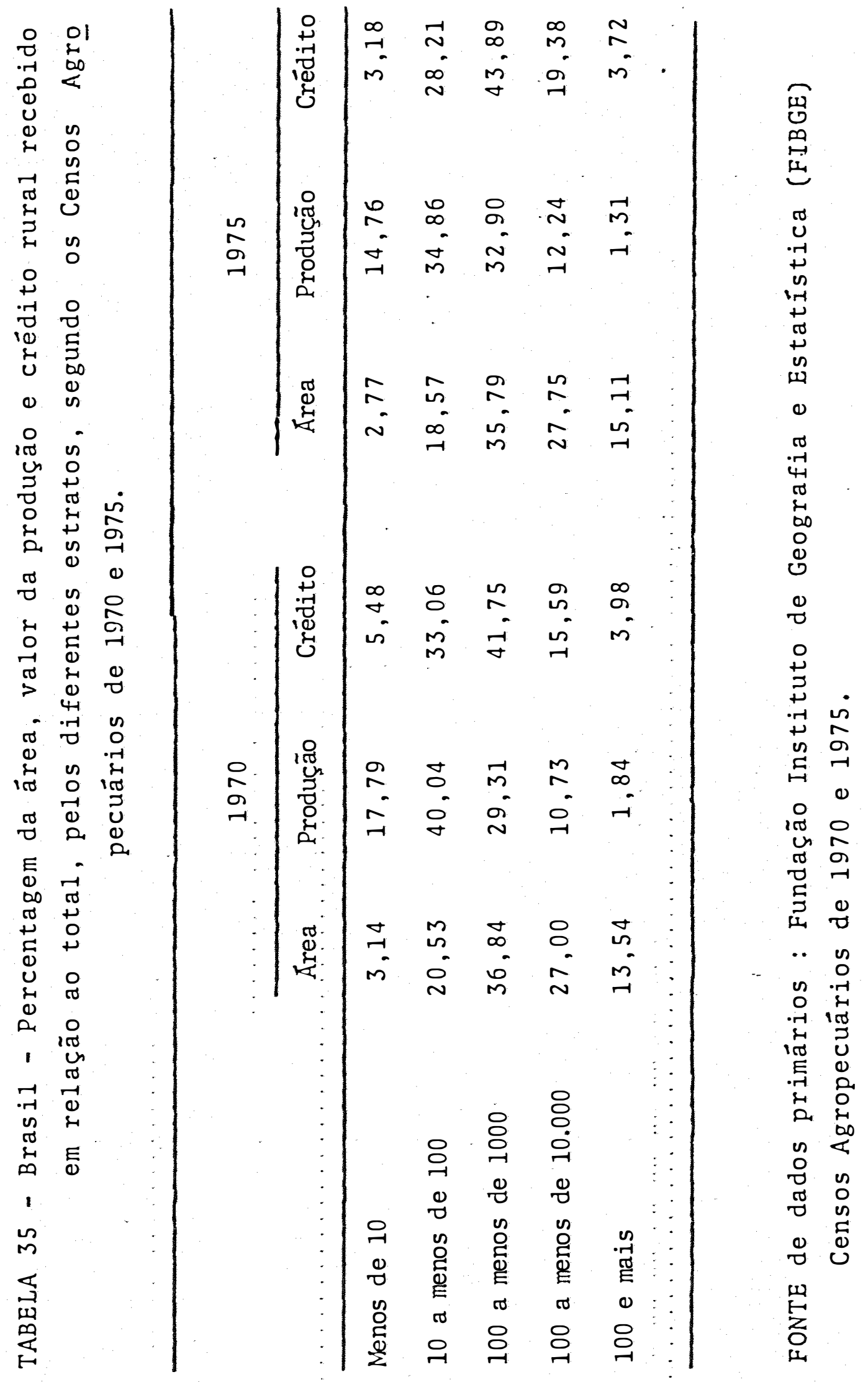


to correspondente de $3,72 \%$.

As Tabelas 36 e 37 mostram a distribuição por região da porcentagem de estabelecimentos, área, prơdução, valor do crédito e ainda a porcentagem dos estabelecimentos com empreśtimos no total dos estabelecimentos regionais, para 1970 e 1975. Os principais aspectos a realçar são:

1) Baixa porcentagem de estabelecimentos com acesso ao cr̈édito de forma mais acentuada na região Norte e Nordeste.

2) A porcentagem do valor dos empréstimos por região parece relacionar-se mais à percentagem do valor da produção do que à porcentagem de área.

3) As regiões Sudeste e Centro-Oeste (região Sul, só em 1970) recebem parcela de crédito superior à parcea no produto agrícola, enquanto para as regiões Norte e Nordeste ocorre o inverso.

A comparação entre 1970 e 1975 mostra que "a porcentagem do número de estabelecimentos cresceu para as regiōes Norte, Nordeste e Centro-Oeste. Em percentagem de ắrea as regiões Norte e Centro-Oeste aumentam a sua partici pação no total enquanto em produção o aumento na participação ocorre para o Centro.Oeste e Sul. A melhoria no acesso ao crédito ocorreu para todas as regiões à exceção da região Norte. A parcela de crédito entre regiões altera-se ligeiramente. A região Sul deixa de receber parcela superior à parcela de produção. A região Sudeste diminui a sua participação, agora com valores próximos da participação na produção. A região Norte diminui também, enquanto o Centro -Oeste aumenta de forma muito evidente. 


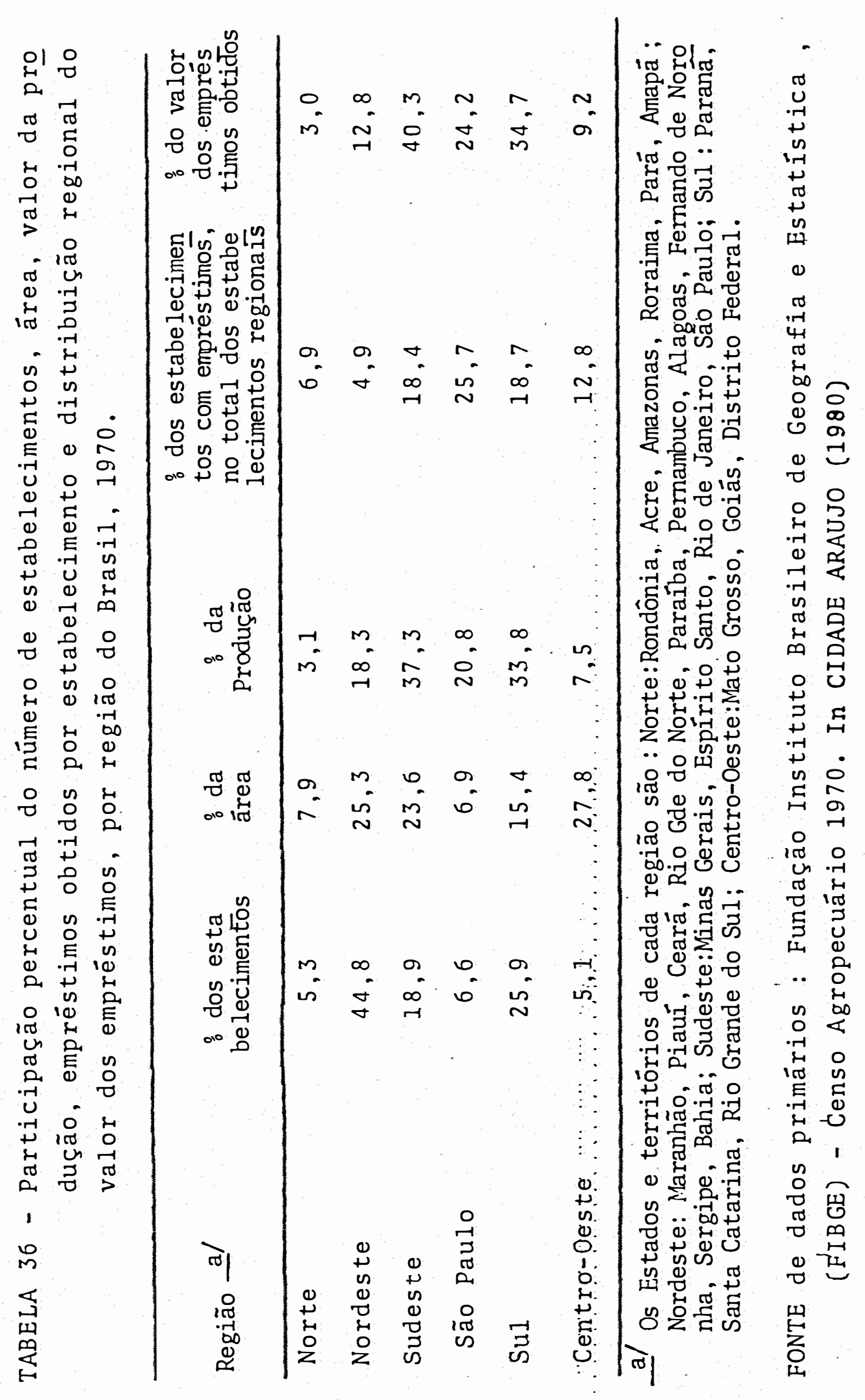


.145

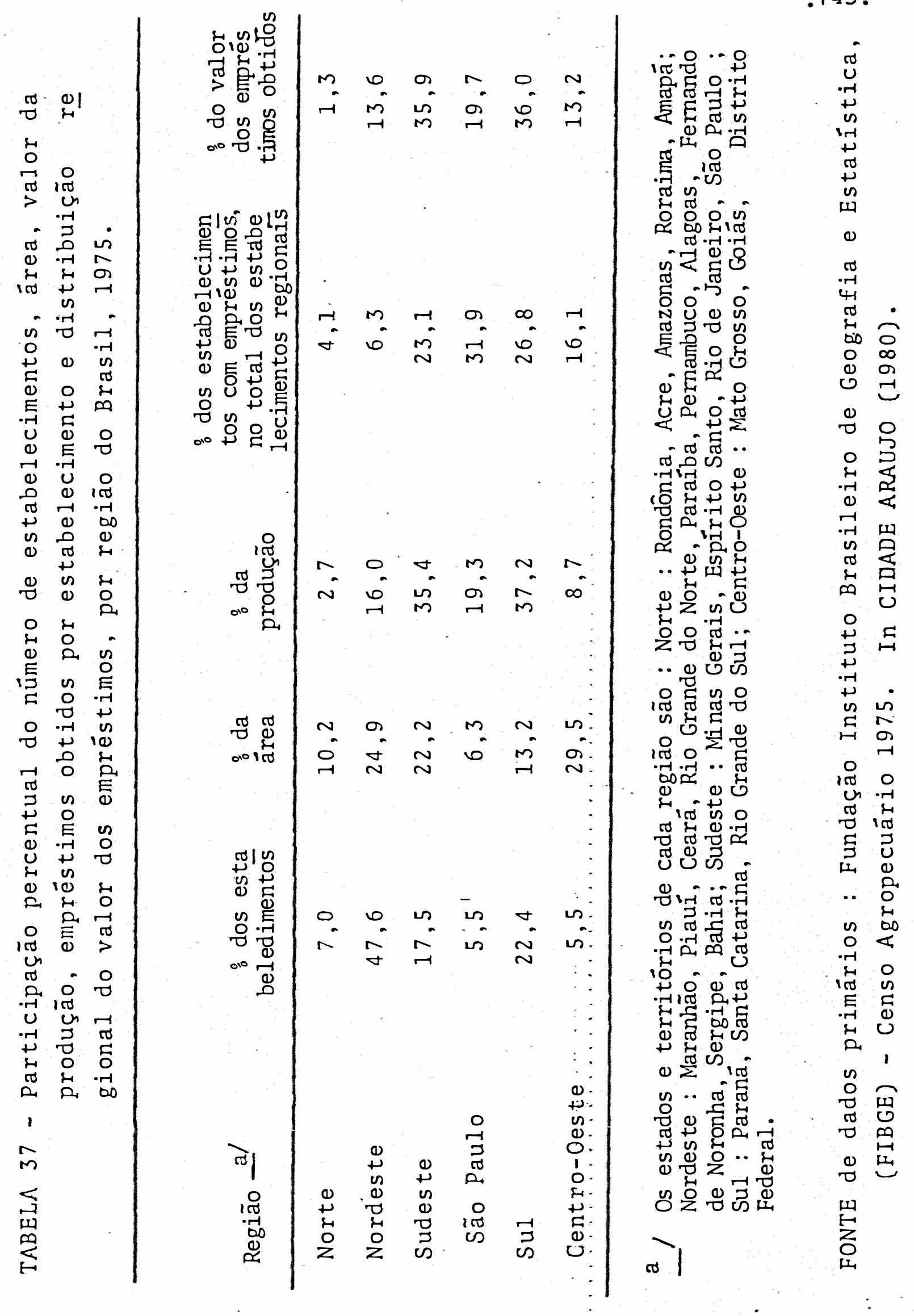


Neste momento dispomos de informação sobre a concentração de crédito e de sua distribuição regional. 0 aspecto principal do capítulo é, contudo, o levantamento de informações por cultura.

As Tabelas 38 e 39 mostram a distribuição do crédito de custeio e de comercialização em número de contratos e valor (nominal). Essas informações permitem calcu lar para 1975 a relação entre o crédito concedido e o valor da produção (Tabela 40). Além dessas relações outra forma de destacar a desigualdade entre culturas em relação ao acesso ao crédito é o cálculo do valor médio do contrato também calculado para 1975 a partir das mesmas. informaçōes.

As colunas 1,2 e 3 da Tabela 40 sāo extre mamente interessantes e auto-elucidativas. E de conhecimen to comum que talvez a principal politica econômica de que o governo tem lançado mão em relação ao setor agrícola é exatamente a política de crédito agrícola. o crédito altamente subsidiado tem sido a principal forma de apoio ao setor e rapidamente se compreende que os produtos com alta relação crédito/produção são altamente subsidiados.

No que se refere à relação crédito de custeio e valor da produção, o algodão é o produto mais benefí ciado, seguindo-se a soja, cana-de-açúcar e arroz, com valo res bem próximos. 0 milho e o feijão estão no extremo oposto. Quanto ao crédito de comercialização, a mesma sequência é válida (para a cana-de-açúcar e feijão o crédito de comercialização não tem significado), embora o arroz,que tinha valores próximos, na coluna 1 , à soja tem valores na coluna 2 bem inferiores. 
TABELA 38 - Distribuição de crédito de custeio entre culturas.

\begin{tabular}{|c|c|c|c|c|c|c|}
\hline \multirow[t]{2}{*}{ Culturas } & \multicolumn{3}{|c|}{ NP contratos } & \multicolumn{3}{|c|}{ Valor $(\mathrm{Cr} \$ 1.000 .000)$} \\
\hline & 1975 & 1976 & 1977 & 1975 & 1976 & 1977 \\
\hline Algodão & 69496 & 79853 & 86905 & 1443 & 3076 & 4949 \\
\hline Arroz & 120934 & 88674 & 77713 & 5377 & $\therefore 7047$ & 10332 \\
\hline Cana-de-açücar & 22844 & 22839 & 19025 & 3282 & 4553 & 5645 \\
\hline Feijão & 32889 & 47008 & 83034 & 431 & 872 & 182 \\
\hline Milho & 157238 & 164401 & 140579 & 3292 & 4738 & 5205 \\
\hline Soja & 69577 & 73226 & 71528 & 5325 & 9018 & 13042 \\
\hline
\end{tabular}

TABELA 39 - Distribuição de crédito de comercialização entre culturas.

Culturas

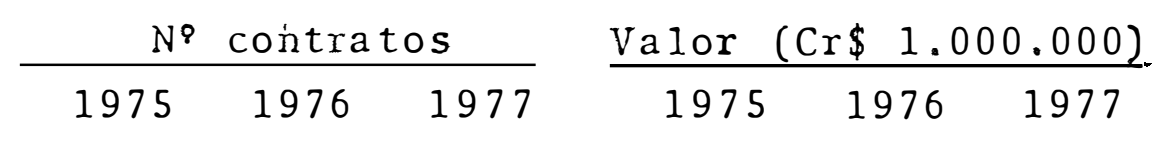

$\begin{array}{lrrrrrr}\text { Algodão } & 10311 & 9212 & 13708 & 2204 & 3050 & 6036 \\ \text { Arroz } & 12034 & 22481 & 12132 & 1724 & 3859 & 3621 \\ \text { Milho } & 14503 & 14667 & 18601 & 1033 & 2037 & 2348 \\ \text { Soja } & 20795 & 16146 & 23314 & 6014 & 7823 & 11833\end{array}$

FONTE de dados bāsicos : Fundação Instituto Brasileiro de Geografia e Estatística (FIBGE) - Anuärio Estatístico (vãrios números). 
TABElA 40 - Relações entre valor de crédito, valor da pro dução e valor médio do contrato de custeio.

\begin{tabular}{|c|c|c|c|}
\hline Culturas & Coluna 1 & Coluna 2 & Coluna 3 \\
\hline Algodão & 0,6265 & 0,9567 & 20765 \\
\hline Arroz & 0,4562 & 0,1463 & $44 \quad 461$ \\
\hline Cana-de-açūcar & 0,4617 & - & 143656 \\
\hline Feijão & 0,1048 & - & 13103 \\
\hline Milho & 0,3294 & 0,1033 & 20937 \\
\hline Soja & 0,4664 & 0,5267 & $76 \quad 531$ \\
\hline
\end{tabular}

Coluna 1 - Relação entre o valor do crédito de custeio con cedido e o valor da produção para 1975.

Coluna 2 - Relação entre o valor do crédito de comerciali zação concedido e o valor da produção para 1975.

- Coluna 3 - Valor médio do contrato de custeio para 1975.

FONTE de dados básicos - Fundação Instituto Brasileiro de Geografia e Estatística (FIBGE) - Anuário Estatís tico (vărios números). 
$\mathrm{Na}$ anảlise da coluna 3 verificamos que maior valor médio do contrato de custeio ocorre para a cultura de cana-de-açúcár, seguindo-se a soja, arroz, milho, algodão e feijão em ordem decrescente de valor. o valor mé dio do contrato para algodão com valores semelhantes ao valor médio para milho pode parecer incoerente com os resulta dos apresentados nas outras colunas da Tabela 40. Devemos considerar que o valor médio do contrato deve refletir a di mensão da exploração e que o número de estabelecimentos com acesso ao crédito é percentualmente pequeno e provavelmente distinto entre estabelecimentos que produzem os diferentes produtos.

CIDADE ARAOJO (1981) calcula a distribuição percentual de crédito de custeio agrícola no Brasil, segundo grupos de produtos, alocando os produtos de exportação e industrialização (algodão, amendoim, cacau, café, cana-de-a çúcar e soja) num grupo, produtos de mercado interno em outro grupo (arroz, feijão, mandioca, milho e trigo). Obteve os seguintes resultados para 1978:

a) Produtos de exportação e matérias-primas industriais dis pöem de $47, \exists 7 \%$ do valor total do crédito de custeio (94.938,2 milhöes de cruzeiros de 1978).

b) Produtos de mercado interno detiveram $34,14 \%$ do crédito de custeio.

Estes resultados são congruentes com as análises anteriores. O ponto principal da análise, a relação entre crédito concedido e o valor da produção, fornece uma idéia do subsídio implícito em cada produto, aspecto conclu sivo de desigualdade entre culturas. Desta forma não existe qualquer dúvida na afirmação de que na produção dos dife rentes produtos o acesso ao crédilto é distinto e, portanto, 
os subsídios são também diferentes. Este resultado é coerente com todos os outros cálculos e outra coisa não se poderia esperar depois que se considerou a concentração e dis tribuição regional tanto das culturas como do crëdito rural. 
Através da análise discriminante foi possí vel constatar a existência de diferenças sistemáticas entre culturas em relação a três aspectos : nível tecnológico (utilização de insumos "modernos"), estrutura de produção e processo de comercialização. O estudo da localização e concentração geográfica mostrou que existe uma tendência, para o grupo de culturas consideradas "modernas", de uma maior concentração regional de sua produção, além de possuírem maior importância em regiōes reconhecidamente mais desenvolvidas. Ao se estudar a distribuição de crédi to, que reflete o grau de acesso às políticas agrícolas, ve rificou-se existir, em geral, o mesmo comportamento distinto entre culturas. Através da anālise fatorial conseguiu-se um maior detalhamento das relaçōes entre as variáveis e uma "tipologia" de cada cultura por Estado considerando os diferentes aspectos do sistema produtivo isoladamente. Obteve-se vários indices susceptíveis de utilização na caracterização e identificação do maior ou menor desenvolvimento técnico e económico de cada cultura e da própria agricultura a nivel regional. 
A partir dos resultados obtidos, na impossibilidade de dispor do mesmo conjunto de informaçōes em sērie temporal, procurou-se determinar a relação entre as variāveis disponíveis e um indice que, de alguma forma, repre sentasse diferentes níveis de "modernização" e permitisse estudo de sua evolução no tempo. O indice escolhido, produ tividade por ha, com todas as limitaçōes inerentes, a nivel agregado pode ser considerado um bom indicador. A anālise do comportamento da produtividade por ha (apêndice 1) ao longo das ültimas décadas leva-nos a considerar que os resultados encontrados para 1975 (diferenças entre culturas) têm, provavelmente, vindo a agravar-se ao longo do tempo.

Considerando o processo de desenvolvimento em direção à "maturidade econômica"ll identificamos a exis tência de "dualismo" entre culturas. A modernização da lagricultura tem ocorrido de forma mais intensa em direção a produtos que possuem determinadas características (são em grande parte, exportados ou industrializados). Argumenta-se que essas características são fatores importantes no processo de modernização conjuntamente (a nível macroeconômico) com outros fatores relacionados entre si, na medida em que influem no processo de geração e alocação de exceden tes e, portanto, no processo de modernização e de acumulação.

Dispomos de informação e evidências para afirmar que culturas alimentares são, em geral, menos tecnificadas e modernizadas. Argumenta-se também que o processo de modernização de culturas alimentares ocorre em ültimo lu

17 "Maturidade econômica" - mesmo conceito utilizado por RANIS e FEI. 
gar. Consideremos algumas indicaçōes nesse sentido. Em São Paulo, estado com agricultura razoavelmente desenvolvida, encontramos maior igualdade de condições entre culturas e em todas as classificações. No outro extremo estão alguns Estados do Nordeste, em que a maior parte das classifi caçoeśobtidas através da análise discriminante, são também homogêneas no sentido inverso, isto é, culturas classificadas como "não modernas". Em outros Estados encontramos uma posição intermediāria,com culturas classificadas em ambos os grupos. Analisando, por exemplo, os valores do fator 1 (atraso técnico) por Estado, verificamos que em São Paulo todas as culturas têm valores negativos (quanto mais negativo o fator maior onível de tecnificação) enquanto que na Bahia todos os valores do fator 1 são positivos e no Paraná ocorrem tanto valores positivos como negativos.

Os modelos "dualistas", comentados inicialmente para países em desenvolvimento, acabam tendo o seu paralelo dentro da própria agricultura em função do tipo de cultura, com um setor moderno e empresarial e um setor tradicional ou de subsistência. A afirmativa de que estaria ocorrendo uma realocação de recursos da agricultura em favor de produtos de exportação, dadas as características de mercado desses produtos, parece muito limitada. E necessário considerar o processo de modernização e o avanço do sís tema empresarial no campo, assim como o processo de acumula ção da sociedade e de alocação do excedentes gerados. Nes:te sentido convém lembrar que o setor agrícola é considerado de extrema importância na geração de excedentes transferíveis a outros setores e que a mudança técnica é um fator determinante de excedentes de produção e de capital. A for ma como este excedente é transferido e os processos que per mitem a sua "realização" e "internalização" no próprio se- 
tor de, pelo menos parcela significativa desse excedente, determinam o comportamento diferenciado do setor em relação às várias culturas. Em determinados casos verifica-se a impossibilidade de "realização de excedentes potenciais" por falta de mecanismos capazes de promover a sua "realização" e indispensável "mobilização". PAIVA (1971, p. 204) apercebe-se desse imobilismo quando critica John Mellor que afirma que o aumento da produtividade e da produção do setor agríiola cria os próprios aumentos de renda e de de manda de produtos agrícolas. Considera este raciocínio semelhante ao da lei de Say: "Evidentemente se o aumento da produção agrícola criasse a sua própria demanda, não haveria necessidade de ocorrer a transferência de recursos da agricultura para o setor não Agrícola". A tendência, entretanto, é de colocar a agricultura com um papel pouco dinâa mico e na total dependência do setor não agrícola. Devemos lembrar que é exatamente no setor agrícola que se encontra a maior pobreza como é, também, o setor de menor renda per capita. Sabe-se que a baixas rendas correspondem altas elas ticidades renda no consumo de alimentos. Por outro lado, existem condiçōes de "realizar excedentes potenciais" ¿e "mobilizá-los" de forma a sair do círculo vicioso (não se gera renda porque não há mercado mas não hã mercado porque não se gera renda).

A exportação e industrialização do produtoagrícola são formas de viabilizar a "realização de exceden: tes potenciais" na agricultura, na medida em que promovem tanto a sua "mobilização" como a própria capacidade de "internalizar" no própria setor parte dos excedentes econômi cos gerados na produção. A exportação, quando possível, de 
ve ser encarada em termos marginais 1 (espera-se o aumento do consumo interno, de forma que não se aplica o mesmo raciocínio, tipo "mecanismo de auto-controle", ao mercado externol. A industrialização do produto agrícola altera as condições de mercado desse produto, com um papel importante na mobilização de fatores, nomeadamente,mão-de-obra. Na medida em que incorpora mais trabalho e capital ao produto, aumenta as possibilidades de capitalização, além de exer cer influência na expansão do espírito empresarial ao próprio agricultor.

Entende-se agora porque estes dois processos são cruciais na modernização do setor. Temos a conviç̧ão de que (a nível macro-econômico), onde existir produção para exportação ou para a indústria, invariavelmente, esta serā mais "modernizada" e eficiente comparativamente a outras culturas. A transferência de recursos da agricultura a outros setores é um processo que faz parte do próprio desenvolvimento econômico. Os instrumentos de política utilj zados tentam muitas vezes acelerar este processo, podendo desempenhar tanto um papel importante no desenvolvimento co mo introduzir graves distorsões:

$1 /$ - Em termos marginais (no mercado mundial) no mesmo sentido da crítica de NICHOLLS (1973, p. 43) a PAIVA; ajustamentos agrícolas sendo feitos marginalmente e não por todos os agricultores de uma única vez, são de tal ordem que preocupações com produção que invariavelmente supere a demanda efetiva são em grande parte, impro cedentes. 
Verificou-se no cálculo de relaçōes de preços internos e internacionais que produtos como arroz e feijão apresentam frequentemente relações de preços superiores à unidade o que leva a questionamentos sobre a taxa ção do consumidor interno e não do produtor via preços. Ar gumenta-se que essa ocorrência é devida, por um lado, à for ma como se tem procurado acelerar a transferência de recursos e por outro lado fruto do desenvolvimento econômico com uma certa dualidade na agricultura e modernização distinta entre produtos. A transcrição de Adam Smith $\underline{l} \vec{e}$ ex tremamente interessante à luz da presente discussão: "A grande subida de preço do porco como da criação na Grã-Bretanha tem sido frequentemente atribuída à diminuição do número dos pequenos agricultores, acontecimento que, na maior parte da Europa, tem precedido imediatamente o progresso dos melhoramentos e do cultivo, mas que contribui talvez simultanemante para fazer subir o preço desses artigos mais : e mais depressa do que teriam subido de outra maneira. Assim como a mais pobre das familias pode frequeritemente manter um cão ou um gato sem incorrer em despesas suplementares, também os mais pequenos agricultores podem geralmente manter alguns bicos ou uma porca e alguns porcos com uma despe sa minima $(\ldots$.$) . Quando o número desses pequenos agricul-$ tores diminui, a quantidade de animais criados com pouca ou nenhuma despesa diminui também em grande medida, pelo. que seu preço deve ter subido mais cedo e mais depressa do que teria subido de outra maneira":-

I7 - ADAM SMITH, An Inquiry into the Nature and Causes of the Wealth of Nations. 
Não se discute, por ser amplamente reconhecido 1/. o fato da política agrícola ter sido orientada para o abastecimento do mercado interno adotando medidas com perspectiva de curto prazo e com objetivo de obter preços dos alimentos tão baixos quanto possível. E simples a conclusão de que dadas as características e papel da agricultura no desenvolvimento (reservatório de mão-de-obra com produçāo de alimentos) se tem procurado realizar tranferência de recursos através de preços do produto. A medida que se processa o desenvolvimento econômico ocorre absorção de mão-de-obra da agricultura e a quantidade de alimentos produzidos com caráter residual pode diminuir em relação às necessidades da sociedade. Por outro lado observa-se que näo ocorre praticamente nenhuma melhoria na eficiência econômica (não ocorre modernização) na produção destes produtos e, portanto, é bastante provável que se observe tendência a una subida do preço desses produtos, senão em termos internos, relativamente à produção em outros países. Em determina das regiões torna-se então viāvel a produção comercial. Neste momento espera-se que se processe o aumento da tecnificação da produção,aumentem os incentivos ao desenvol vimento de tecnologia e se obtenha então, uma maior eficiên cia econômica que proporcione tendência a menores preços do produto.

$1 /$ - MOREIRA e CASTRO (1977, p. 181) afirmam: "E ponto pacífico que, entre abastecimento interno a preços controlados ou a expansão da produção pelo incentivo de preços livres, as autoridades, optam, quase sempre, pela primeira alternativa, fácil e indolor a curto pra zo, porém de efeitos maléficos a longo prazo, porque afeta a rentabilidade e a taxa de capitalização do se tor". 
.158 .

Acreditamos que a modernização da produção de produtos de alimentação básica ocorre quando a economia se encontra perto do pleno funcionamento de mercado, ou seja, da maturidade econômica. Enquanto houver condiçōes de obter produção com uso de recursos residuais a tendência é extrair excedentes da agricultura via preço, manten do-se a produção em níveis adequados ao abastecimento interno.

Os resultados encontrados para a relação de preços internos e internacionais não permitem negar a taxação do consumidor (preços internos de produtos alimentares superiores aos preços internacionais) mas a justificativa dessa ocorrência pode estar em parte na própria existência de políticas do tipo "alimentação barata", que åolongo do tempo inibem o maior avanço do processo de modernização da agricultura .

Mostrou-se as atuais diferenças em todos os niveis do sistema produtivo em um grupo de culturas que se pretende representativo. Encontramos argumentação (COELHO, 1979) que justifica um tratamento diferencial do setor público à agricultura pelo fato de possuir entre outras as se guintes características:

1) Maior risco e incerteza no processo produtivo.

2) Estrutura competitiva na agricultura frente a outros se tores menos competitivos.

3) Inelasticidade preço e renda da demanda por produtos agrícolas.

Com a caracterização do grupo de culturas e $\underline{s}$ 
tudadas são evidentes as diferenças entre culturas quanto a estes aspectos e muitos outros. Não pretendemos argumen-

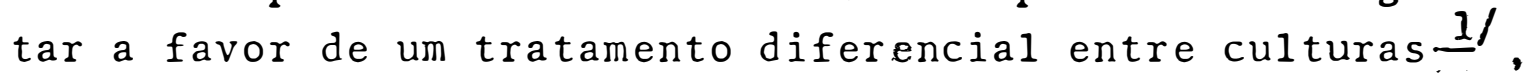
mas sim a favor de uma maior identificação da possibilidade de "realizar e mobilizar excedentes potenciais", processos que requerem muitas vezes forte intervenção governamental.

A transferência de recursos da agricultura a outros setores é quase um processo "automático" no desenvolvimento, sendo de muito maior importância a "realização de excedentes potenciais" do que uma excessiva preocupação em acelerar a transferência.

Justificou-se as formas através das quais a industrialização e a exportação podem promover o processo mencionado ao mesmo tempo que são também responsáveis por uma mais rápida modernização. No contínuo esforço de moder nização da agricultura é essencial que se considere as características do produto (industrializável ou exportável principalmente) e na medida do possível se tire partido des sas mesmas características ou se reconheça a maior dificuldade de modernização que, quando se justifique, deverá merecer maior atenção das autoridades responsáveis.

$\mathrm{Na}$ atualidade assistimos ao desenvolvimento da necessidade de novas contribuiçōes do setor agrícola no que diz respeito à área energética. HOMEM DE MELO e FONSECA (1981) demonstraram que a agricultura deverá desempenhar

1/ - Na literatura citada, existe menção à necessidade de intervenção governamental na geração de tecnologia da. das determinadas características dos produtos (bens püblicos ou com efeitos externos significativos). 
um papel importante na solução da crise energética. Além da substituição da gasolina pelo álcool já encaminhado, outras formas alternativas para substituição do Diesel (através de álcool aditivado e/ou hidratado e através de óleos vegetais), além de programas de florestas energéticas com vistas à substituição parcial do óleo combustível, exercerão novas pressões no setor agrícola.

Muitas críticas poderão ser elaboradas, mas um dos aspectos positivos dos programas energéticos com base na agricultura é a promoçāo da industrialização do produ to agrícola dando condições de "realizar e mobilizar" excedentes potenciais.

No conjunto de produtos estudados deseja-se chamar a atenção para a cultura do milho. No apêndice 2 verifica-se que o Brasil tem perdido oportunidades no comércio internacional principalmente em relação ao milho, em que de exportador passa a importador de relativa importância no mercado mundial. Por outro lado, o milho é um produ to que se caracterizou por fazer parte do grupo de culturas "não modernizadas". E, contudo, o produto que ocupa a maior área da agricultura no Brasil, com alta capacidade de adaptação às mais diversas condições e que possui condiçōes, defendidas como importantes no processo de modernização, de ser um produto de exportação ou até mesmo susceptível de industrialização (alēm de ter várias alternativas de utilização, fator também importante na diminuição dos riscos da produção).

Em resumo, o milho possui todas as condições para sofrer um processo de modernização rápido: E uma cultura que se classificou como não moderna, possuindo todas 
as características desse grupo de culturas, salvo em algumas regiões de maior desenvolvimento. Verifica-se que a ex portação de milho é possível com o mercado mundial em expansão e perspectivas positivas a longo prazo. Considerando diferentes níveis de produtividade a SUPLAN (1975) realizou comparações de custos entre Brasil e E.U.A. identificando a competitividade da produção no Brasil antes da comercializa ção e incidência de carga tributāria. No caso da soja também se evidencia a deficiência de infra-estrutura de comercialização (comparativo de custos) embora as cooperativas te nham vindo a assumir um papel de importância na comercialização, melhorando a sua eficiência. Para a soja verifica-se que os altos cultos de comercialização não tem sido impeditivos de uma maior participação direta e indireta "na pauta das exportações, dadas as características do sistema produtivo, o que já não ocorre para o milho.

0 milho apresenta todas as condições para uma maior participação do comércio externo. 0 arroz poderá obter também, uma participação efetiva na pauta de exportações. Neste sentido faz-se necessārio a intervenção governamental organizando a produção e principalmente a comer cialização a nível internacional.

Conscientes da necessidade de incrementar as exportações, é inaceitável desprezar oportunidades reais existentes (no conjunto de culturas estudadas principalmente o milho e também o arroz com maiores restrições), na cer teza de se obter efeitos altamente positivos na modernização do setor. Contrariamente ao que comumente se pensa, o incentivo à exportação de produtos alimentares poderá resul tar no curto prazo em problemas para o consumidor interno 
.162 .

mas certamente proporcionarā uma maior eficiência econômica na sua produção e, no longo prazo, condições positivas para o próprio consumidor. 
ACCARINI, J.H., (1978). Preços de Produtos Agrícolas no Bra sil. Estudos Econômicos, 3:3) :69- $104 \mathrm{p}$.

ANTUNIASSI, M.H.R., (1976). Multiplicidade Tecnológica na Agricultura do Estado de São Paulo. In : Agricultura Bra sileira, Curso de Extensão Universitāria, Botucatu, 50$68 \mathrm{p}$.

ARAOJO, F.F.C.de, (1981). Análise da Política de Crédito à Agricultura Brasileira. Piracicaba, ESALQ/USP, $225 \mathrm{p} \cdot($ Te se de Livre Docência).

ARAOJO, P.F.C. de e G.E. SCHUH (Coord.), (1975). Desenvolvi mento da Agricultura. São Paulo, Livararia Pioneira Edito ra, 192 p. (série Estudos Econômicos 1).

AYER, H.W. e G.E. SCHUH, (1972). Social Rates of Return and Others Aspects of Agricultural Research: The Case of Cotton Research in São Paulo, Brasil. American Journal of Agricultural Economics, 54 (4); 557 - 69 . 
BARAN, P.A., (1972). A Economia Política do Desenvolvimento, 3a ediçāo, Rio de Janeiro, Zahar Editores, 399 p.

BRASIL, Fundaçāo Instituto Brasileiro de Geografia e Esta tística, Censos Agropecuários de 1970 e 1975.

BRASIL, Fundação Instituto Brasileiro de Geografia e Esta tística, Anuário Estatístico - vários números.

COELHO, C.N. de A. (1979). A Política de Preços Mínimos den tro de uma Perspectiva de Desenvolvimento Económico. Se cretaria do Planejamento - CFP, Coleção Análise e Pesqui sa, $12,138 \mathrm{p}$.

DElgado, G.C., (1979). Modelo de Desenvolvimento Agrícola Brasileiro. Revista de Economia Rural - Agricultura e Inflaçāo. Brasília, 17 (1) : $107-132$.

FAO, PRODUCTION YEARBOOK, (1977 e 1979). Food and Ágriculture Organization of the United kations. Rome, Vo?.31 e vol. 33 .

FAO, TRADE YEARBOOK, (1977 e 1979). Food and Agriculture Organization of the United Nations. Rome, vol. 31 e vol. 33.

GRILICHES, 2. (1957). Hybrid Corn : An Exploration in the Economics of Technological Clange. Econometrica. 25 (4): $501-522$.

GUEDES PINTO, L.C. (1980). Notas sobre Política Agrícola e Crédito Rural. Campinas (versão preliminar), $343 \mathrm{p}$.

GUIMARAES, A.P. (1979). A Crise Agräria. Rio de Janeiro,Edí 
tora Paz e Terra S.A., 362 p.

GURVITCH, G., (1971). Dialética e Sociologia. Lisboa, publi caçōes D. Quixote, $341 \mathrm{p}$.

HARMAN, H.H. (1976). Modern Factor Analysis, 3: edição. Chị cago. The University of Chicago Press, 487 p.

HAYMI, Y. e V.W. RUTTAN, (1971). Agriculture Development :

An International Perspective. Londres. The John Hopkins Press, $367 \mathrm{p}$.

HOFFMANN, R. (1979). Estimação da Desigualdade dentro de Estratos no Cálculo do Indice de Gini e da Redundância. Pesquisa e Planejamento Econômico. Rio de Janeiro, $\underline{9}$ (3): 719 a 738 .

HOMEM DE MELO, F.B., (1978). Agricultura Brasileira : Incer teza è Disponibilidade de Tecnologia. São Paulo, USP, 142 p. (Tese de Livre Docência).

HOMEM DE MELO, F.B., (1981). Política Comercial, Tecnologia e Preços dos Alimentos no Brasil. Estudos Econômicos, 11 (2) : $132-142$.

HOMEM DE MELHO, F.B. e E.G. da FONSECA, (1981). PROALCOOL, Energia e Transportes. São Paulo. Estudos Econômicos FIPE / Pioneira, $163 \mathrm{p}$.

HONEK, T.P., (1974). Some Economic Aspects of Agricultural Regulation and Stabilization. Americam Journal of Agricultural Economics, 56(5) : 1113 - 1124 . 
IBM, (1967). 1130 Statistical System (1130-CA-06 X) User '. s Manual, Segunda Edição. White Plains, N.Y., IBM; Technical Publications Department, 31 - $71 \mathrm{p}$.

JOHNSTON, B.F. e J.W. MELLOR, (1961). The Role of Agriculture in Economic Development. The Americam Economic Review, 51 (4) : $566-593$.

LEWIS, W.A., 1954. Economic Development with Unlimited Supplies of Labour. Manchester School, 22 : $139-91$. In AGARWALA, A.N. e S.P. SING (1970) (Coord.). A Economia do Subdesenvolvimento. Rio de Janeiro, Forense, 406$456 \mathrm{p}$.

LOPES, M. de R. e G.E. SCHUH, (1979). A Mobilização de Recursos da Agricultura : Uma análise de Política para o Brasil. Secretaria de Planejamento. CFP. Coleção Análise e Pesquisa, 8, $105 \mathrm{p}$.

MENDONÇA DE BARROS, J.R. e D.H. GRAHAM, (1978). A Agricultu ra Brasileira e o Problema da Produção de Alimentos. Se minário sobre a Economia da Tecnologia. São Paulo, IPE Secretaria da Cultura. Ciência e Tecnologia.

MOREIRA, R.M. e P.R. de CASTRO, (1977). A Agricultura de Exportação In: CARNEIRO, D.D., (Coord.). Brasil : Dỉle mas da Política Econômica, Rio de Janeiro, Editora Campus Ltda, $177-192 \mathrm{p}$.

MORRISON, D.F., (1976). Multivariate Statistical Methods, 2. edição. United States of America, Mc Graw Hill, Inc. $415 \mathrm{p}$. 
NICHOLLS, W.H., (1963). An Agricultural Surplus as a Factor in Economic Development. The Journal of Political Economy, $\underline{71}(1): 1$ - 29. Tradução publicada In : ARAOJO, P.F. de e G.E. SCHUH (Coord.), (1975). Desenvolvimento da Agricultura. São Paulo, Livraria Pioneira Editora, 338 p. (série Estudos Econômicos 1).

NICHOLLS, W.H., (1973). Paiva e o Dualismo Tecnológico na Agricultura : Um Comentário. Pesquisa e Planejamento Eco nômico. Rio de Janeiro, 3 (1) : 15 - 50 .

PAIVA, R.M. (1971). Modernização e Dualismo Tecnológico na Agricultura. Pesquisa e Planejamento Econômico. Rio de Janeiro, 1 (2) : $171-234$.

PAIVA, R.M., (1979). A Agricultura no Desenvolvimento Econô mico. Suas limitaçōes como Fator Dinâmico. Rio de Janeiro, IPEA/INPES. Monografia n' 38, $204 \mathrm{p}$.

PASTORE, A.C., E.R.A. ALVES E J.A.B. RIZZIERI, (1974).

Inovação Induzida e Limites à Modernização na Agricultura Brasileira. Mimeo. IPE.

PASTORE, A.C., (1971). A oferta de Produtos Agrícolas no Brasil. Estudos Econômicos. São Paulo, 1(3) : 35 - 69 .

PASTORE, J., G.L. DIAS e M.C. de CASTRO, (1976). Condicionantes: da Produtividade Agrícola no Brasil. Estudos Econômicos, São Paulo, 6 (3) : $147 \div 181$.

PATRICK, G.E., (1975). Fontes de Crescimento da Agricultura Brasileira : 0 Setor de Culturas. In : Tecnologia e Desenvolvimento Agrícola. Rio de Janeiro, IPEA/INPES, Monografia $17,89-110 \mathrm{p}$. 
PEREIRA DE QUEIRÓZ, M.I., (1972). Modernização da Agricultụ ra no Brasil. Pesquisa no Estado de São Paulo.

In: Cooperativismo e Nordeste. Recife, 7 (3) : 9 - 29.

RANIS, G. e J.C. FEI, (1966). Agrarianismo, Dualismo e Desenvolvimento Econômico. Em I. Adelman e E. Thorbecke (editores). The Theory and Design of Economic Development, John Hopkins Press, 3 - 41 p. - Tradução publicada In : ARAUJO, P.F.C. de e G.E. SCHUH (Coord.). (1975). Desenvolvimento da Agricultura. São Paulo, Livraria Pioneira Editora, 3 - 38 p. (Série Estudos Agrícolas 1).

RUTTAN, V.W., (1975). Teorias de Crescimento em Estágios, Modelos em Economia Dualista e Política de Desenvolvimento Agrícola. In : ARAOJO, P.F.C. de e G.E. SCHUH (Coord.), (1975). Desenvolvimento da Agricultura. São Paulo, Li vraria Pioneira Editora, 153 - 172 p. (série Estudos Agrí colas 1).

RUTTAN, V.W., (1973). Induced Technical and Institucional Technology, Polices and Adjustment, 15th International Conference of Agriculture Economics. Change and the Future of Agriculture. University of Oxford, $41 \mathrm{p}$.

SANCHES DA FONSECA, M.A., (1976). Retorno Social aos Investimentos em Pesquisa na Cultura do Café. Piracicaba, ESALQ/USP, 149 p. (Tese de Mestrado).

SCHUH, G.E., (1973). Modernização e Dualismo Tecnológico na Agricultura : Alguns Comentários. Pesquisa e Planejamento Econômico. Rio de Janeiro, 3 (1) : 51 - 94 . 
SCHULTZ, T.W., (1965). A Transformação da Agricultura Tradi cional. Rio de Janeiro, Editora Zahar, 207 p.

SMITH, ADAM, (1976). An Inquiry into the Nature and Causes of the Wealth of Nations. Tradução de Conceição Jardim Maria do Carmo Cary e Eduardo Lucio Nogueira. 2. Edição, São Paulo, Abril Cultural, 1979. (Coleção "Os Pensadores").

SUPLAN, (1974). Subsídios aos Planos Anuais de Produção e Abastecimento. Soja. Brasilia, Subsecretaria de Planeja mento e Orçamento. Ministério da Agricultura, $52 \mathrm{p}$.

SUPLAN, (1975). Subsídios aos Planos Anuais de Produção e Abastecimento. Algodão. Brasilia, Subsecretaria e Planejamento e Orçamento, Ministério da Agricultura, $57 \mathrm{p}$.

SUPLAN, (1975). Subsídios aos Planos Anuais de Produção e Abastecimento. Arroz. Brasilia, Subsecretaria de Planejamento e Orçamento. Ministério da Agricultura, 56 p.

SUPLAN, (1975). Subsídios aos Planos Anuais de Produção e Abastecimento. Feijão. Brasilia, Subsecretaria de Planejamento e Orçamento. Ministério da Agricultura, 69 p.

SUPLAN, (1975). Subsídios aos Planos Anuais de Produção e Abastecimento. Milho. Brasilia, Subsecretaria de Planejamento e Orçamento. Ministério da Agricultura, $47 \mathrm{p}$.

VERA FIlHo, F. e H. TOLlini, (1979). Processo Tecnológico e Desenvolvimento Agricola. In : VEIGA, A. (Coord.). Ensaios sobre Política Agrícola Brasileira. São Paulo, Secretaria da Agricultura, $87-136$ p. 
.170.

ZOCKUM, M.H.G.P., (1980). A expansão da Soja no Brasil. Alguns Aspectos da Produção. São Paulo, Ensaios Econômicos $04,245 \mathrm{p}$. 
.171.

A PENDICE I 


\section{PRODUTIVIDADE}

Este aspecto da caracterização das culturas fornece indicaçōes muito importantes principalmente quando pretendemos obter uma série histórica recente do comporta mento da agricultura e da própria modernização do setor. A análise realizada entre culturas foi essencialmente estáti ca no tempo por não ser possível dispor de dados que per mitissem a construção da mesma'estrutura de variáveis pa ra diferentes anos.

A produtividade, indicador mais usual para determinar o estágio de desenvolvimento em uma determinada cultura, mostra-se o indicador mais adequado, para só por si, mostrar qual a evolução no tempo, em termos de moder nização da produção de uma determinada cultura. Se essa análise é feita em termos agregados, ou para uma determi nada região e condição edafológica, esse indicador, produ tividade, responde razoavelmente bem à questão de qual tem sido o desenvolvimento ou modernização.

\subsection{Soja}

De origem oriental, a soja (Glycine max.) é 
uma leguminosa anual cujos grāos apresentam elevado teor proteico, sendo o único vegetal cuja proteína contém os onze aminoácidos essenciais ao organismo humano.

Segundo a SUPLAN (1974) as mais antigas cita çōes e experimentos de soja no Brasil referem-se aos traba lhos de Gustavo D'utra em 1882 e, em Sāo Paulo, por Daffert em 1982. No Rio Grande do Sul, a primeira introduçāo pare ce ter ocorrido em 1915 e a sua difusāo entre agricultores ocorreu em 1931 no município de Santa Rosa.

A observaçāo do Gräfico " 8 no capítulo 6 per mite verificar que é uma cultura com produtividade crescen te a partir da década de 70. A queda do nível de produtí vidade nos últimos anos, reflete, provavelmente, a expan sāo da soja em áreas menos adequadas à cultura.

As referências à cultura de soja, são feitas muitas vezes citando o complexo soja constituído pela in teraçāo entre a agricultura e indústria que vem assumindo no Brasil um papel de enorme importância. O excelente de sempenho da soja é citado por ZockUM (1980) como um exem plo da resposta da produçāo agrícola e industrial aos es tímulos da demanda por fontes proteicas vegetais e por uma das mais baratas formas de obtençāo de gordura comestível.

\subsection{Algodão}

PASTORE et alii (1976) interrelacionaram o desempenho da produtividade do algodāo com o desempenho da pesquisa agrícola. Referem que para o Nordeste os esfor ços de pesquisa se caracterizaram pela timidez ou descon tinuidade com ênfase quase exclusiva no aumento do compri mento de fibra, alēm do desconhecimento sobre fisiologia e 
patologia do álgodoeiro nordestino. o resultado deste pro cedimento tem sido uma diminuiçāo dos níveis de produtiví dade.

No Estado de Sāo Paulo observa-se um espeta cular desempenho mostrando os resultados positivos de uma intensa atividade de pesquisa e da ótima interação com os agricultores refletindo a própria estrutura empresarial da produção. A cotonicultura tornou-se uma atividade com ren tabilidade altamente associada a elevados investimentos em insumos modernos, exigindo sofisticaçāo empresarial e elí minando os agricultores marginais de baixa produtividade. As altas taxas de retorno da pesquisa agrícola para o al godāo de acordo com Ayer e Schuh (1972) foram das mais ele vadas em todo o mundo.

Para o Brasil de forma agregada, verifica-se uma ligeira tendência ascencional nos níveis de produtí vidade (Gráfico 10) •

\section{3 cana-de-açūcar}

0 Gräfico 12 construído no capítulo 6 de for ma agregada para o Brasil mostra a tendência constante de aumento de níveis de produtividade. Os altos níveis de pro dutividade e sua evolução estão, sem dúvida, relacionados à condiçāo de matéria-prima industrial. A própria indús tria passou a pressionar fortemente tanto o agricultor co mo o próprio sistema de pesquisa, dadas as condiçōes de realizaçāo de "excedentes potenciais" e a possibilidade de internalizar os benefícios da inovaçāo técnica pelos usi neiros e fazendeiros.

A própria indústria passou a participar no 
desenvolvimento técnico. A cooperativa - Copersucar, desem penha hoje, além de um papel de difusāo de informações de técnicas disponíveis, atividades de desenvolvimento de pés quisa própria: A nível governamental a criação do Programa Nacional de Melhoramento da Cana-de-açúcar (PLANALSUCAR) em 1971 pelo IAA, tem, também, promovido maior dinamismo na moderniz ação.

Conclui-se que as très culturas analisadas (soja, algodão e cana-de-açúcar) se caracterizam por uma tendência ao aumento dos níveis produtivos.

\section{$1: 4$ Arroz}

0 arroz foi inicialmente um produto de ex portação quando introduzido no Brasil no século XVIII. Veio a tornar-se um produto básico na alimentação e a sua disseminação na agricultura foi considerável evitando im portações do produto que em 1910 eram de 70 : do consumo.

E cultivado na maior parte do território na cional em sequeiro. Em termos gerais sabe-se que quanto às condiçōes edafológicas encontra condiçōes favoráveis em "todo o território brasileiro". E considerado uma cultura "pioneira" na abertura de novas äreas cedendo lugar à so ja, milho, algodão ou pastagens após os primeiros anos de plantio.

Ao considerarmos o trabalho de PASTORE et alii (1976) fica evidente que a produtividade do arroz pa ra o Brasil, Nordeste e São Paulo no período de 33/70 tem apresentado tendência ao declínio, embora as variações se jam de dimensão bem significativa, refletindo as adversi 
dades climáticas, efeito de esgotamento de áreas de cultí vo nāo devidamente conservadas, do ataque de pragas e doen ças como da prōpria degeneração das variedades cultivadas. Estes resultados sugerem a deficiência da pesquisa agríco 1a. A evoluçāo da produtividade no Rio Grande do Sul tem apresentado tendência altamente significativa de melhoria dos niveis de produtividade, consequência de um sistema de produçāo "empresarial" de altos custos e alta rentabilida de, com menores variações da produção (irṛigação) e maior interaçāo com atividades de pesquisa que permitiram a ob tençāo de tais resultados.

\subsection{Feijāo}

O feijāo é uma cultura muito antiga no Bra sil. O comportamento da produtividade para o Brasil, Nor deste e São Paulo, de acordo com PASTORE et alii (1976) pa ra o período de $33 / 75$, tem sido declinante. Para Sāo Paulo verifica-se a partir da década de 60 um aumento da produ tividade que deve ser consequência do aumento da produçāo em termos empresariais, maiores investimentos e uso de "in sumos modernos", dado o maior desenvolvimento do Estado e proximidade de grandes centros consumidores.

\subsection{Milho}

$E$ uma planta que se adapta preferencialmente às regiōes quentes intertropicais mas de adaptaçāo fácil a outras condiçōes dada a grande diversidade de "formas" que apresenta.

A evolução da produtividade do milho em con junto para todo o Brasil nāo tem sofrido grandes altera çōes com estagnação ou uma ligeira tendência à melhoria 
dos níveis produtivos (de $1.400 \mathrm{~kg} / \mathrm{ha}$ a $1.500 \mathrm{~kg} / \mathrm{ha}$ ) nos últimos 20 anos. No Nordeste tem ocorrido um declínio qua se contínuo da produtividade. Para São Paulo ocorre o in verso com grandes aumentos da produtividade.

Se para arroz e feijão o desenvolvimento da pesquisa tem sido de grande instabilidade, para o milho a literatura confirma que a pesquisa tem apresentado não só continuidade como grande dinamismo e resultados positivos. As firmas privadas têm assumido inclusive um papel impor tante na produção de sementes e desenvolvimento tecnoló gico. As condições atuais da cultura do milho mostram que nem sempre existe uma relação direta entre disponibilidade de tecnologia e aumentos de produtividade. Para o milho pa rece ter existido um esforço deliberado no sentido de maior disponibilidade tecnológica que não tem surtido os resul tados esperados. 
.178.

$A P E N D I C E \quad 2$ 


\section{CONJUNTURA MUNDIAL}

A insersão da discussão em termos internacio nais vai permitir, além da caracterização de um outro as pecto de cada produto, comparar níveis de produtividade (evo lução mais recente do seu comportamento) e dispor de algu mas indicaçōes sobre a possibilidade de maior participação do Brasil no mercado mundial. A análise será realizada por produto individualmente com uma breve análise de conjunto no final do capítulo.

\subsection{Soja}

Verifica-se que a produção de soja entre 1970 e 1979 duplicou em termos mundiais. O Brasil quase decupli cou a sua produção, ocupando atualmente posição de desta que na produção desta leguminosa. A comparação da produ tividade obtida no Brasil e em outros paises conduz à con , clusão de que o Brasil, atingindo em alguns anos níveis próximos dos $1.800 \mathrm{~kg} / \mathrm{ha}$, está bem. próximo dos níveis de produtividade obtidos nos E,U.A. e de outros países com ní veis elevados de produtividade. 
0 volume comercializado em grão internacio nalmente situa-se em torno de 25 a 30 \& de volume produzi do. As maiores importaçōes ocorrem na Europa e na Asia e as maiores exportaçōes têm origem no continente americano. O principal exportador são os E.U.A. com quase $100 \&$ da exportação da América do Norte e Central. Na América do Sul, o Brasil detinha em 1975 quase $100 \&$ das exportaçōes, participaçāo que tem vindo a diminuir observando-se acrés cimos da exportação na Argentina nos ültimos anos.

TABELA 41 - Cultura de Soja. Rendimento mëdio por continente e de alguns países de maior releváncia.

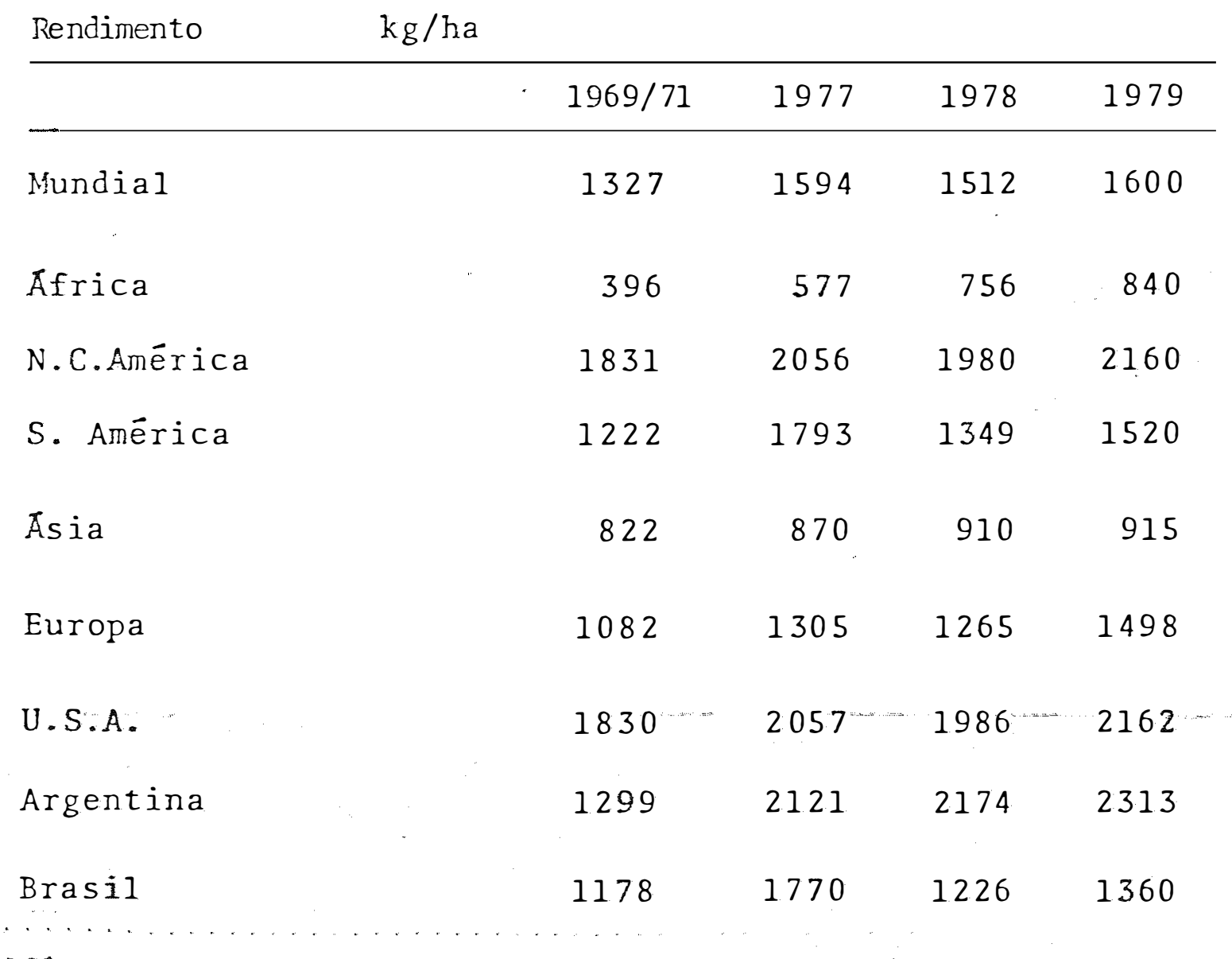

FONTE de dados básicos : Anuário Estatístico - Production Yearbook - FAO 
TABELA 42-- Produção de soja por continente e de alguns países de maior relevância.

Produção $1.000 \mathrm{MT}$

\begin{tabular}{|c|c|c|c|c|}
\hline$\ldots \ldots$ & $1969 / 71$ & 1977 & 1978 & 1979 \\
\hline Mundial & 46747 & $78 \quad 460$ & 80532 & 94207 \\
\hline Africa & 75 & 145 & 206 & 241 \\
\hline N. C. Amërica & 31683 & 48995 & 51750 & 63088 \\
\hline S. América & 1751 & 14437 & 12592 & 14456 \\
\hline Āsia & 12594 & 13888 & 14809 & $15 \cdot 047$ \\
\hline Europa & 117 & 399 & 465 & 672 \\
\hline U.S.A & 31174 & 47949 & 50899 & 61715 \\
\hline Argentina & 39 & 1400 & 2500 & 3700 \\
\hline Brasil & 1547 & 12513 & 9535 & 9959 \\
\hline
\end{tabular}

FONTE de dados básicos : Anuário Estatístico - Production Yearbook - FAO 
.182 .

TABELA 43 - Soja em grão, Importações por continente e de alguns países de maior relevância.

Importaçōes $1.000 \mathrm{TM}$

\begin{tabular}{|c|c|c|c|c|c|}
\hline & 1975 & 1976 & 1977 & 1978 & 1979 \\
\hline Mundial & 16314 & 19972 & 19621 & 23303 & 26009 \\
\hline Africa & 9 & 18 & 72 & 67 & 65 \\
\hline N. C. América & 442 & 815 & 894 & 1087 & 938 \\
\hline S. América & 69 & 43 & 47 & 201 & 325 \\
\hline Ásia & 4733 & 5273 & 5427 & 6343 & 7037 \\
\hline Europa & 10695 & 12063 & 11776 & 14683 & 15879 \\
\hline Canadá & 385 & 397 & 318 & 324 & 351 \\
\hline México & 22 & $348^{*}$ & 520 & 681 & 519 \\
\hline U.S.A. & - & 3 & - & - & - \\
\hline Venezuela & 48 & 37 & 25 & 73 & 42 \\
\hline Brasil & - & - & - & 89 & 213 \\
\hline Paraguai & - & - & - & - & - \\
\hline Argentina & - & - & 120 & 2640 & $1000 *$ \\
\hline
\end{tabular}

* Dados não oficiais.

FONTE de dados básicos - Anuário Estatístico - Trade Yearbook, Vol. 31 e 33 - FAO 
TABELA A - Soja em grāo. Exportaçōes.

Exportaçōes - 1.000 TM

\begin{tabular}{|c|c|c|c|c|c|}
\hline & 1975 & 1976 & 1977 & 1978 & 1979 \\
\hline Mundial & 16459 & 19753 & 20004 & 24054 & 25471 \\
\hline Africa & 5 & 3 & 7 & 1 & 6 \\
\hline N. C. América & 12506 & 15357 & 16234 & 20793 & 20951 \\
\hline S. América & 3435 & 3934 & 3441 & $\cdot 2840$ & 3798 \\
\hline Ás ia & 387 & 228 & 169 & 175 & 331 \\
\hline Europa & 121 & 198 & 152 & 243 & 383 \\
\hline Canadà & 9 & 2 & 38 & 83 & 47 \\
\hline México & - & - & - & - & - \\
\hline U. S. A. & 12496 & 15332 & 16196 & 20710 & 20905 \\
\hline Brasil & 3333 & 3639 & 2587 & 658 & 638 \\
\hline Paraguai & 102 & 208 & 241 & 192 & 347 \\
\hline Argentina & - & 78 & 613 & 1983 & 2810 \\
\hline \multicolumn{6}{|l|}{$=$} \\
\hline $\begin{array}{r}\text { FONTE de dados } \\
\text { Yearbook }\end{array}$ & $\begin{array}{l}\operatorname{sicos}- \\
\text { Vol. } 31\end{array}$ & $\begin{array}{l}\text { Anuārio } \\
\text { e } 33-1\end{array}$ & statístico & - & Trade \\
\hline
\end{tabular}




\subsection{Algodão}

A produção mundial do algodão cresceu de 1970 a 1979 cerca de 15 a 208 , os maiores aumentos. Ocor rendo nos E.U.A. e na U.S.S.R. A América do Sul manteve a proximadamente a sua produção, o Brasil apresentando produ ção decrescente. O Brasil é também um dos maiores produto res mundiais depois dos 4 mais destacados U.S.S.R., U.S.A., China e India.

Os rendimentos para o Brasil entre 1970 e 1979 mantiveram-se estáveis embora com um dos níveis mais baixos em todo o mundo superando apenas alguns resultados obtidos na India e em alguns países da Africa.

O volume comercializado em 1979, em termos internacionais, diminui para aproximadamente $50:$ do volu me comercializado em 1975. O Brasil com tradição no merca do exportador (no início da década de $70,50 \&$ da demanda total do algodão brasileiro correspondia a exportaçōes) de xou de ter participação significativa nas transações in ternacionais 1 ! A perspectiva de aumento da demanda exter na não é, de forma alguma, de grande expansão nos próximos anos.

1/ O mercado internacional de algodão diminuiu drastica mente dada a crise internacional e a competição por outras fibras, principalmente produtos sintéticos. 
TABELA 45 - Algodão em Caroço - Seed Cotton. Rendimento mé dio por continente e em alguns países de maior relevância.

Rendimento $\mathrm{kg} / \mathrm{ha}$

\begin{tabular}{|c|c|c|c|c|c|c|c|c|}
\hline & 1969 & $9-71$ & & 1977 & & 1978 & & 1979 \\
\hline Mundo & & 067 & 1 & 220 & 1 & 171 & 1 & 251 \\
\hline Africa & & 791 & & 737 & & 785 & & 775 \\
\hline N.C. América & 1 & 431 & 1 & 662 & 1 & 411 & 1 & 705 \\
\hline S. América & & 815 & & 909 & & 881 & & 774 \\
\hline Ásia & & 840 & 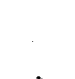 & 905 & & 917 & & 961 \\
\hline U.S.S.R. & 2 & 445 & 2 & 927 & 2 & 798 & 2 & 964 \\
\hline México & 2 & 108 & 2 & 852 & 2 & 579 & 2 & 323 \\
\hline U.S.A. & 1 & 303 & 1 & 516 & 1 & 246 & 1 & 619 \\
\hline Argentina & & 906 & 1 & 008 & 1 & 176 & & 699 \\
\hline Brasil & & 691 & & 746 & & 692 & & 678 \\
\hline Espanha & 1 & 456 & 1 & 769 & 2 & 256 & 2 & 380 \\
\hline Grécia & 2 & 333 & 2 & 088 & 2. & 576 & 2 & 070 \\
\hline China & 1 & 245 & 1 & 394 & 1 & 398 & 1 & 505 \\
\hline India & & 424 & & 464 & & 512 & & 488 \\
\hline Paquistão & & 983 & & 900 & & 743 & 1 & 032 \\
\hline
\end{tabular}

FONTE de dados básicos : Production Yearbook - FAO 
TABELA $4 \dot{6}$ - Algodão em caroço. Produção por continente e em alguns países de maior relevância.

Ṕrodução $1.000 \mathrm{MT}$

\begin{tabular}{|c|c|c|c|c|c|c|c|c|}
\hline & 1969 & $9-71$ & & 1977 & & 1978 & & 1979 \\
\hline Mundo & 34 & 855 & 40 & 252 & 38 & 173 & 41 & 104 \\
\hline Africa & 3 & 794 & 3 & 036 & 3 & 385 & 3 & 3203 \\
\hline N.C. América & 7 & .545 & 10 & 350 & 8 & 229 & 10 & 338 \\
\hline S. Amērica & 2 & 901 & 3 & 161 & 3 & 059 & 3 & 064 \\
\hline Assia & 13 & 413 & 14 & 316 & 14 & 342 & 14 & 735 \\
\hline U.S.S.R. & 6 & 566 & 8 & 758 & 8 & 499 & 9 & 160 \\
\hline México & & 979 & 1 & 197 & & $895 *$ & & $885^{*}$ \\
\hline U.S.A. & 5 & 967 & 8 & 142 & 6 & 237 & 8 & 496 \\
\hline Argentina & & 370 & & 522 & & 714 & & 466 \\
\hline Brasil & 1 & 828 & 1 & $600 \mathrm{~F}$ & 1 & $400 \mathrm{~F}$ & 1 & 673 \\
\hline Espanha & & 155 & & 138 & & 97 & & 119 \\
\hline Grécia & & 342 & & 382 & & 407 & & 297 * \\
\hline China & 5 & $965 \mathrm{~F}$ & 6 & $148 \mathrm{~F}$ & 6 & $502 \mathrm{~F}$ & 6 & $621 \mathrm{~F}$ \\
\hline India & 3 & $264 \ldots$ & 3 & 624 & 3 & 837 & 3 & $660 F$ \\
\hline Paquistão. & 1 & 786 & 1 & 659 & 1 & 435 & 1 & 951 \\
\hline
\end{tabular}


TABELA 47 - Algodão em Caroço - Seed Cotton. Importações em vários continentes.

Importaçōes - $1.000 \mathrm{MT}$

\begin{tabular}{lrrrrr}
\hline & 1975 & 1976 & 1977 & 1978 & 1979 \\
\hline Mundial & 208 & 278 & 195 & 155 & 109 \\
Africa & 1 & 3 & 13 & - & - \\
N.C. América & 14 & 109 & 41 & 49 & 15 \\
S. América & - & - & - & - & - \\
Asia & 161 & 118 & 107 & 100 & 82 \\
\hline
\end{tabular}

TABELA 48 - Algodão em caroço. Exportações.

Exportaçōes - $1.000 \mathrm{MT}$

\begin{tabular}{lrrrrr}
\hline & 1975 & 1976 & 1977 & 1978 & 1979 \\
\hline Mundial & 253 & 297 & 210 & 162 & 113 \\
Africa & 114 & 75 & 75 & 45 & 33 \\
N. C. América & 33 & 101 & 53 & 47 & 93 \\
S. América & - & - & - & - & - \\
Asia & 42 & 14 & 8 & 23 & 28 \\
\hline
\end{tabular}

FONTE de dados básicos : Anuário Estatístico - Trade Yearbook, Vol 31 e 33 - FAO 


\subsection{Arroz}

Excluindo os países da Ásia, o Brasil é o maior produtor mundial superando E.U.A. e U.S.S.R. Na Asia se concentra 90 da produção mundial e também o maior consumo. A análise de rendimento para o Brasil entre 1969-70 e 79 mostra uma tendência senāo decrescente de ma nutenção dos mesmos níveis de produtividade, que em termos comparados a nível mundial são dos mais baixos (o próprio Continente Africano apresenta médias de rendimento supe riores ao Brasil).

$\mathrm{Na}$ observação do fluxo comercial verifica-se que é na Asia que ocorrem às maiores transações, exporta ções e importações, em relativo equilíbrio. A Europa é um continente nitidamente importador; a América Central e do Norte sāo "exportadores líquidos"; a América do Sul tem um volume exportado superior ao importado em todos os anos analisados, exceto em 1979, ano em que o Brasil importou quantidades significativas. O volume comercializado inter nacionalmente é bastante (pequeno) reduzido e variações na produçāo de países asiáticos resultam em grande instabili dade de preços.

Verifica-se que os E.U.A., excluindo

transações na Asia, sāo o maior exportador, mesmo com uma produçāo menor que a do Brasil e no período de 1969-70 a 1979 quase duplicaram a sua produção. Embora sem grande precisāo, é possível afirmar, que mesmo com um mercado ex terno limitado e não muito promissor há possibilidade de uma política agressiva brasileira de incremento de suas exportações, considerando que a maior produçāo no Brasil se realiza na entre-safra de países de maior expressão na importaçāo (excluindo os países da Ásia). 
.189 .

TABElA 49-Arroz em casca. Rendimento médio em vários continentes e países.

Rendimento $\mathrm{kg} / \mathrm{ha}$

\begin{tabular}{|c|c|c|c|c|c|c|c|c|}
\hline & $196 !$ & $9-71$ & & 1977 & & 1978 & & 1979 \\
\hline Mundial & & 320 & 2 & 559 & 2 & 662 & 2 & 615 \\
\hline Áfica & 1 & 830 & 1 & 792 & 1 & 786 & 1 & 827 \\
\hline N.C. América & 3 & 740 & 3 & 777 & 4 & 118 & 4 & 046 \\
\hline S. América & 1 & 655 & 1 & 823 & 1 & 702 & 1 & 827 \\
\hline Āsia & 2 & 338 & 2 & 597 & 2 & 709 & 2 & 646 \\
\hline Europa & 4 & 607 & 3 & 815 & 4 & 641 & 4 & 967 \\
\hline U.S.S.R. & 3 & 573 & 4. & 060 & 3 & 614 & 3 & 934 \\
\hline U.S.A. & 5 & 087 & 4 & 945 & 5 & 026 & 5 & 142 \\
\hline Brasil & 1 & 430 & 1 & 501 & 1 & 305 & 1 & 395 \\
\hline
\end{tabular}

FONTE de dados básicos : Production Yearbook - FAO 
.190.

TABELA 50 - Produção de arroz em värios continentes e palses.

Produçāo em 1.000 MT

\begin{tabular}{|c|c|c|c|c|c|c|c|c|}
\hline & 196 & $9-71$ & & 1977 & & 1978 & & 1979 \\
\hline Mundial & 311 & 506 & 369 & 729 & 386 & 303 & 379 & 814 \\
\hline Africa & 7 & 338 & 7 & 964 & 8 & 322 & 8 & 732 \\
\hline N.C. América & 5 & 350 & 6 & 524 & 7 & 990 & 8 & 121 \\
\hline S. Anérica & $9^{\circ}$ & 500 & 13 & 118 & 11 & 504 & 12 & 401 \\
\hline Assia & 285 & 937 & 337 & 845 & 354 & 029 & 345 & 491 \\
\hline Europa & 1 & 820 & 1 & 505 & 1 & 850 & 1 & 933 \\
\hline U.S.S.R. & 1 & 272 & 2 & 217 & 2 & 096 & 2 & 400 \\
\hline U.S.A. & 3 & 953 & 4 & 501 & 6 & 040 & 6 & 199 \\
\hline Brasil & 6 & 847 & 8 & 994 & 7 & 242 & 7 & 589 \\
\hline
\end{tabular}

FONTE de dados básicos : Production Yearbook - FAO 
.191.

TABELA 51 - Importaçōes de Arroz em Casca - $(1.000$ MT) em vários continentes e países.

\begin{tabular}{|c|c|c|c|c|c|c|c|c|c|c|}
\hline & & 19.7 .5 & & 197.6 & & 19.7 .7$. & & 1978 & & 1979 \\
\hline Mundial & 7 & 538 & 9 & 221 & 10 & 042 & 10 & 264 & 11 & 411 \\
\hline África & & 720 & 1 & 009 & 1 & 742 & 2 & 139 & 1 & 893 \\
\hline N.C. América & & 485 & & 467 & & 447 & & 425 & & 455 \\
\hline S. América & & 169 & & 216 & & 60 & & 45 & & 864 \\
\hline Ás ia & 4 & 716 & 5 & 555 & 5 & 631 & 5 & 346 & 5 & 813 \\
\hline Europa & 1 & 062 & 1 & 537 & 1 & 576 & 1 & 761 & 1 & 626 \\
\hline U. S. A. & & - & & 1 & & 1 & & - & & - \\
\hline Brasil & & 62 & & 17 & & - & & 29 & & 711 \\
\hline Argentina & & - & & - & & - & & - & & - \\
\hline
\end{tabular}

FONTE de dados básicos - Trade Yearbook - FAO 
.192.

TABELA 52 - Exportaçōes de Arroz em Casca - (1.000 MT) em vários continentes e países.

\begin{tabular}{|c|c|c|c|c|c|c|c|c|c|c|}
\hline & & 1975 & & 1976 & & 1977 & & 1978 & & 1979 \\
\hline Mundial & 7 & 755 & 8 & 987 & 10 & 849 & 9 & 837 & 11 & 887 \\
\hline Africa & & 720 & 1 & 009 & 1 & 742 & 2 & 139 & 1 & 893 \\
\hline N.C. América & 2 & 144 & 2 & 116 & 2 & 343 & 2 & 386 & 2 & 362 \\
\hline S. América & & 431 & & 504 & & 962 & & 698 & & 57 \\
\hline As ia & 4 & 253 & 5 & 215 & 6 & 269 & 5 & 463 & 7 & 694 \\
\hline Europa & & 613 & & 659 & & 739 & & 839 & & 873 \\
\hline U.S.A. & 2 & 139 & 2 & 107 & 2 & 287 & 2 & 279 & 2 & 301 \\
\hline Brasil & & 2 & & 76 & & 409 & & 180 & & - \\
\hline Argentina & & 71 & & 87 & & 195 & & 129 & & 37 \\
\hline
\end{tabular}

FONTE de dados básicos - Trade Yearbook - FAO 


\subsection{Feijāo}

- O Brasil detém cerca de 15 a 20 \& da prodú ção mundial de feijão. Recentemente denota-se uma ligeira tendēncia à diminuição da sua produção. Em relação à pro dutividade verifica-se ser muito baixa e inferior inclusi ve à média da América do Sul. Na análise por continente conclui-se que só a América do Sul tem apresentado decrés cimo da produtividade, resultado que reflete principalmen te a queda de produtividade no Brasil.

\section{Invariavelmente quase todos os países} grandes produtores de feijão, são também grandes consumi dores. O volume comercializado internacionalmente $\bar{e}$ muito pouco significativo. O feijão é um produto de baixa elas ticidade renda ou até mesmo negativa, com poucas oportuni dades de grande incremento nas transaçōes internacionais, com tendência em muitos países desenvolvidos à manutenção dos níveis de produção ou até mesmo decréscimo. 0 aumento de produção, se ocorre, é devido a aumentos na produtivida de. 
TABELA 53 - Feijão em Grão. Rendimento médio em vãrios continentes e países.

Rendimento $\mathrm{kg} / \mathrm{ha}$

\begin{tabular}{|c|c|c|c|c|c|c|c|c|}
\hline & 196 & $9-71$ & & 1977 & & 1978 & r & 1979 \\
\hline Mundial & & 522 & & .549 & & 560 & & 580 \\
\hline Africa & & 584 & & 597 & & 603 & & 584 \\
\hline N.C. América & & 718 & & 677 & & 794 & & 875 \\
\hline S. América & & 643 & & 542 & & 519 & & 571 \\
\hline Ásia & & 457 & $\cdot$ & 526 & & 526 & & 536 \\
\hline Europa & & 347 & & 430 & & 467 & & 449 \\
\hline México & & 503 & & 472 & & 595 & & 666 \\
\hline U.S.A. & 1 & 403 & 1 & 455 & $i$ & 441 & 1 & 633 \\
\hline Brasil & & 642 & & 503 & & 477 & & 519 \\
\hline China & & 728 & . & 868 & & 885 & & 929 \\
\hline India & & 283 & & 330 & & 299 & & 289 \\
\hline Bulgāria & & 692 & & 870 & 1 & 352 & 1 & 273 \\
\hline França & 1 & 252 & 1 & 646 & 1 & 664 & 1 & 664 \\
\hline Grécia & 1 & 031 & 1 & 079 & 1 & 162 & 1 & 227 \\
\hline Itảlia & & 875 & 1 & 572 & 1 & 568 & 1 & 700 \\
\hline
\end{tabular}

FONTE de dados básicos: Production Yearbook - FAO 
.195.

TABELA 54 - Produçāo(1.000 MT) de feijão em grão em vãrios continentes e países.

\begin{tabular}{|c|c|c|c|c|c|c|c|c|}
\hline & $196 !$ & $9-71$ & & 1977 & & 1978 & & 1979 \\
\hline Mundial & 12 & 337 & 14 & 055 & 14 & 202 & 14 & 781 \\
\hline Africa & & 108 & 1 & 249 & 1 & 285 & 1 & 259 \\
\hline N. C. América & 2 & 045 & 1 & 855 & 2 & 198 & 2 & 378 \\
\hline S América & 2 & 682 & 2 & 838 & 2 & 736 & 2 & 814 \\
\hline Europa & & 846 & & 686 & & 701 & & 699 \\
\hline México & & 849 & & 770 & & 940 & 1 & 056 \\
\hline U.S.A. & & 790 & & 753 & & 864 & & 937 \\
\hline Brasil & 2 & 366 & & 2290 & 2 & 188 & 2 & 187 \\
\hline China & 2 & $460 \mathrm{~F}$ & & $3459 \mathrm{~F}$ & 3 & $592 \mathrm{~F}$ & 4 & $000 \mathrm{~F}$ \\
\hline India & 2 & 152 & & 2747 & 2 & 464 & 2 & $400 \mathrm{~F}$ \\
\hline Bulgāria & & 76 & & 75 & & 72 & & $70 \mathrm{~F}$ \\
\hline França & & 46 & & 39 & & 36 & & $36 \mathrm{~F}$ \\
\hline Grécia & & 52 & & 41 & & 43 & & $45 \mathrm{~F}$ \\
\hline Itália & & 155 & & 98 & & 94 & & 85 \\
\hline
\end{tabular}

F - Estimativas da FAO.

FONTE de dados básicos : Production Yearbook - FAO 


\subsection{Milho}

A produção mundial situa-se em torno dos 400 milhōes de toneladas. Os E.U.A. detém mais de $50 q$ da produção mundial. O Brasil depois dos E.U.A. é um dos maio res produtores mundiais. Os níveis de produtividade são. contudo, inferiores aos.médios da América do Sul. 0 aumen to de rentabilidade não existiu ou foi praticamente nulo. Os E.U.A. que já em 1969-70 tinham níveis de rentabilidade de 3 a 4 vezez superiores, aumentaram no mesmo período (até 1979) a sua produtividade em cerca de $30 \&$.

As transações internacionais são totalmente dominadas pelos E.U.A. responsāvel por mais de $70 \&$ do volu me transacionado, aumentando a sua participação de forma muito significativa no período de análise. O Brasil em 1975 e 76 exportou quantidades significativas de milho da ordem dos 2 \& das transações mundiais, em 1978 e 79 , inver tendo a situação para ser um importador relativamente importante no mercado internacional. Por outro lado os E.U.A. e a Argentina quase duplicam as suas exportaçōes entre 1975 e 1979.

E notório a expansão do mercado internacio nal de milho entre 1975 e 1979 com grande incremento no volume comercializado. As perspectivas futuras são promis soras no sentido de manutenção de um mercado em expansão . (é um produto com elasticidade - renda positiva.)

A comparação de custos realizado pela SUPLAN entre os E.U.A. (Iowa) e o Brasil (Goiás com produtividade$3.000 \mathrm{~kg} / \mathrm{ha}$ ) mostra a competividade da produção nacional até ao momento da comercialização e incidência da carga triburária a que o produto brasileiro está sujeito. Como no caso da soja, fica evidente a deficiência de infra-és 
TABELA 55 - Milho em Grão. Rendimento médio em vários con tinentes e países.

Rendimento $\mathrm{kg} / \mathrm{ha}$

\begin{tabular}{|c|c|c|c|c|c|c|c|c|}
\hline & 196 & $9-71$ & & 1977 & & 1978 & & 1979 \\
\hline Mundial & 2 & 558 & 2 & 914 & 3 & 083 & 3 & 271 \\
\hline Africa & & 178 & 1 & 283 & 1 & 304 & 1 & 145 \\
\hline N.C. América & 4 & 062 & 4 & 623 & 5 & 137 & 5 & 527 \\
\hline S. América & 1 & 553 & 1 & 853 & 1 & 656 & 1 & 742 \\
\hline Ásia & 1 & 817 & 1 & 756 & 1 & 937 & 2 & 124 \\
\hline Europa & 3 & 366 & 4 & 190 & 4 & 193 & 4 & 609 \\
\hline U.S.S.R. & 2 & 763 & 3 & 266 & 3 & 531 & 3 & 150 \\
\hline Canadá & 5 & 078 & 5 & 795 & 5 & 155 & 5 & 575 \\
\hline México & 1 & 218 & 1 & 357 & 1 & 519 & 1 & 295 \\
\hline U.S.A. & 5 & 164 & 5 & 691 & 6 & 330 & 6 & 865 \\
\hline Argentina & 2 & 247 & 3 & 278 & 3 & 647 & 3 & 107 \\
\hline Brasil & 1 & 365 & 1 & 632 & 1 & 221 & 1 & 442 \\
\hline
\end{tabular}

FONTE de dados básicos : Production Yearbook - FAO 
TABELA 56 - Produção de milho em grão em vários continentes e países.

Produção em $1.000 \mathrm{MT}$

\begin{tabular}{|c|c|c|c|c|c|c|c|c|}
\hline & 1969 & $9-71$ & & 1977 & & 1978 & & 1979 \\
\hline Mundial & 278 & 389 & 346 & 227 & 363 & 927 & 394 & 231 \\
\hline Africa & 21 & 589 & 26 & 206 & 27 & 751 & 23 & 880 \\
\hline N.C. América & 163 & 352 & 179 & 967 & 197 & 508 & 213 & 896 \\
\hline S. América & 25 & 663 & 31 & 232 & 26 & 794 & 29 & 023 \\
\hline Asia & 45 & 896 & 47 & 945 & 54 & 221 & 62 & 350 \\
\hline Europa & 38 & 635 & 49 & 537 & 48 & 390 & 56 & 290 \\
\hline U.S.S.R. & 9 & 933 & 10 & 979 & 8 & 951 & 8 & 400 \\
\hline Canadá & 2 & 487 & 4 & 197 & 4 & 032 & 4 & 963 \\
\hline México & 9 & 025 & 10 & 138 & 10 & 909 & 9 & 255 \\
\hline U.S.A. & 122 & 649 & 163 & 213 & 180 & 008 & 197 & 208 \\
\hline Argentina & 8 & 717 & 8 & 300 & 9 & 700 & 8 & 700 \\
\hline Brasil & 13 & 680 & 19 & 256 & 13 & 533 & 16 & 309 \\
\hline
\end{tabular}

FONTE de dados básicos : Production Yearbook - FAO 
TABELA 57 - Importaçōes - Milho em Grāo - (1.000 MT)

\begin{tabular}{|c|c|c|c|c|c|c|c|c|c|c|}
\hline & & 1975 & & 1976 & & 1977 & & 1978 & & 1979 \\
\hline Mundial & 51 & 620 & 61 & 728 & 55 & 077 & 68 & 653 & 74 & 752 \\
\hline África & 1 & 295 & 1 & 155 & 1 & 555 & 1 & 867 & 1 & 565 \\
\hline N. C. América & 4 & 295 & 2 & 585 & 3 & 153 & 3 & 022 & 2 & 713 \\
\hline S. América & & 443 & & 906 & 1 & 064 & 2 & 128 & 2 & 485 \\
\hline Āsia & 11 & 153 & 13 & 088 & 15 & 075 & 19 & 045 & 22 & 661 \\
\hline Europa & 28 & 884 & 32 & 615 & 30 & 126 & 29 & 529 & 30 & 827 \\
\hline U.S.A. & & 45 & & 46 & & 66 & & 51 & & 34 \\
\hline Argentina & & - & & - & & - & & - & & - \\
\hline Brasil & & 2 & & 1 & & - & & 262 & 1 & 526 \\
\hline
\end{tabular}

FONTE de dados básicos : Trade Yearbook - FAO 
.200 .

TABELA 58 - Milho em Grão - Exportaçōes -(1.000 MT)

\begin{tabular}{|c|c|c|c|c|c|c|c|c|c|c|}
\hline & & 1975 & & 1976 & & 1977 & & 1978 & & 1979 \\
\hline Mundial & 51 & 281 & 61 & 993 & 57 & 487 & 68 & 625 & 76 & 860 \\
\hline Āfrica & 3 & 429 & 2 & 389 & 2 & 047 & 3 & 303 & 2 & 697 \\
\hline N.C. América & 33 & 531 & 44 & 716 & 40 & 587 & 50 & 553 & 59 & 410 \\
\hline S. Amërica & 5 & 077 & 4 & 535 & 6 & 853 & 5 & 924 & 5 & 980 \\
\hline Ás ia & 2 & 598 & 2 & 930 & 2 & 152 & 2 & 434 & 2 & 481 \\
\hline Europa & 6 & 554 & 7 & 294 & 5 & 598 & 6 & 221 & 6 & 045 \\
\hline U.S.A. & 33 & 503 & 44 & 362 & 40 & 481 & 50 & 142 & 59 & 242 \\
\hline Argentina & 3 & 887 & 3 & 080 & 5 & 431 & 5 & 895 & 5 & 959 \\
\hline Brasil & 1 & 148 & 1 & 418 & 1 & 420 & & 14 & & 9 \\
\hline
\end{tabular}

FONTE de dados básicos : Trade Yearbook FAO 
trutura de comercialização. Se para a soja, dada a sua ex portaçāo como produto industrial e estrutura de produção e comercialização, não tem sido um fator impeditivo de aumen to de sua participaçāo direta e indireta na pauta de expor tações, para o milho o mesmo não se poderá afirmar.

Omite-se a anälise em termos internacionais da cultura da cana-de-açūcar, dada a sua importância como matéria-prima industrial.

\subsection{Conclusões}

A breve análise realizada permite verificar que a soja e o milho são produtos de primordial importân cia em relação ao volume de produção, em países industria lizados além de apresentarem um mercado externo em expan são. 0 algodão é um produto de grande expressão tanto em países desenvolvidos como sub-desenvolvidos ou em desen volvimento. 0 mercado externo apresentou contraçāo e, à priori, nāo se pode afirmar que existem possibilidades de grande expansão em futuro próximo. 0 arroz produzido tanto em países desenvolvidos como em desenvolvimento é um produ to de pequena expressāo no mercado internacional. Dada a grande concentraçāo de produção e consumo na Asia qualquer alteração da produção nesta região provoca facilmente gran des alterações de preços no mercado internacional. 0 fe $\underline{i}$ jāo é um produto sem expressāo no mercado externo com as maiores produções em países em desenvolvimento.

E lícito concluir que o Brasil tem perdido oportunidades no mercado externo principalmente no que se refere à cultura do milho. Embora com limitações o arroz deve poder participar da pauta de exportações dadas as 
.202 .

características e ciclo da produçāo brasileira. O feijāo $\bar{e}$ um produto com poucas alternativas de utilização com ten dência a manutenção dos padrōes atuais de produçāo, com maior modernização exclusivamente perto de 'regiōes altamen te urbanizadas. 
.203.

$$
\text { A PEND:I C E } 3
$$


.204 .

Tabela 60 - Valor dos fatores e a respectiva produtividade (média aritmética de très anos, 1974, 1975 e 1976) nas unidades da federação, em que existe informação para alğodão.

\begin{tabular}{|c|c|c|c|c|c|c|}
\hline & $\begin{array}{l}\text { Cultural } \\
\text { Estado }\end{array}$ & Fator 1 & Fator 2 & Fator 3 & Fator 4 & $\begin{array}{c}\text { Produtivi } \\
\text { dade } \\
\mathrm{kg} / \mathrm{ha}\end{array}$ \\
\hline 01 & AL/MG & -1.5708 & -0.2562 & -0.7674 & -0.7129 & 619 \\
\hline 02 & $\mathrm{AL} / \mathrm{SP}$ & -2.2594 & -0.3081 & -0.0256 & 0.1845 & 1375 \\
\hline 03 & $A L / P R$ & -2.2784 & -1.0016 & -0.4114 & 0.8037 & 1504 \\
\hline 04 & $\mathrm{AL} / \mathrm{MS}$ & -1.6663 & -0.8894 & -0.8304 & -0.0467 & 1221 \\
\hline 05 & $\mathrm{AL} / \mathrm{GO}$ & -1.7418 & 0.9905 & -0.1879 & 1.1868 & 1553 \\
\hline 06 & $\mathrm{AL} / \mathrm{RN}$ & -0.0191 & -0.1373 & -1.3804 & 0.7664 & 270 \\
\hline 07 & $\mathrm{AL} / \mathrm{PB}$ & 0.2214 & -0.5603 & -1.4650 & 0.4733 & 325 \\
\hline 08 & $\mathrm{AL} / \mathrm{PE}$ & 0.1611 & -1.2097 & -1.1684 & -0.3998 & 279 \\
\hline 09 & $\mathrm{AL} / \mathrm{BA}$ & 0.0385 & -0.7945 & -1.2963 & -0.7424 & 481 \\
\hline 10 & $\mathrm{AL} / \mathrm{CE}$ & -0.1363 & -0.1795 & -1.0165 & 0.4400 & 222 \\
\hline
\end{tabular}


.205 .

TABELA 61 - Valor dos fatores e a respectiva produtividade (média aritmética de três anos, 1974, 1975 e 1976) nas unidades da federação em que existe informação para cana-de-açũcar.

\begin{tabular}{|c|c|c|c|c|c|c|}
\hline & $\begin{array}{l}\text { Cultura/ } \\
\text { Estado }\end{array}$ & Fator 1 & Fator 2 & Fator 3 & Fator 4 & $\begin{array}{c}\text { Produtivi } \\
\text { dade } \\
\mathrm{kg} / \mathrm{ha}\end{array}$ \\
\hline 01 & CA/MG & 0.2494 & 1.8599 & 0.2934 & -0.7135 & 35596 \\
\hline 02 & $C A R J$ & 0.4471 & 1.8857 & -0.4853 & 0.1355 & 39936 \\
\hline 03 & CAVES & 0.8777 & 1.7635 & -0.4835 & -0.6963 & 31000 \\
\hline 04 & CA/SP & -0.6227 & 1.6633 & -0.1198 & -0.7122 & 58554 \\
\hline 05 & CA $P R$ & 0.0942 & 2.3992 & -0.5026 & -0.0633 & 52404 \\
\hline 06 & $\mathrm{CA} / \mathrm{MT}$ & 0.0642 & 1.9170 & -0.0328 & 1.0350 & 38392 \\
\hline 07 & $\mathrm{CA} / \mathrm{RN}$ & 0.4094 & 2.1705 & -0.2459 & -0.4217 & 56978 \\
\hline 08 & $\mathrm{CA} / \mathrm{PB}$ & 0.4479 & 1.8195 & -0.4851 & -0.3129 & 47041 \\
\hline 09 & $\mathrm{CA} / \mathrm{PE}$ & -0.1709 & 1.7966 & -0.3336 & -0.4550 & 47629 \\
\hline 10 & CA/AL & -0.3013 & 1.2879 & -0.1136 & -1.0618 & 45780 \\
\hline 11 & CA/SE & -0.2896 & 1.9371 & -0.4193 & -0.0842 & 51400 \\
\hline 12 & $\mathrm{CA} / \mathrm{BA}$ & 0.9790 & 1.9235 & 0.7268 & -0.2558 & 40667 \\
\hline 13 & CAVCE & 0.1835 & 1.2757 & 1.6810 & -0.1668 & 35568 \\
\hline
\end{tabular}


.206.

TABELA 62 - Valor dos fatores e a respectiva produtividade (média aritmética de três anos, 1974, 1975 e 1976) nas unidades da federação em que existe informaçāo para soja.

\begin{tabular}{|c|c|c|c|c|c|c|}
\hline & $\begin{array}{c}\text { Cultura/ } \\
\text { Estado }\end{array}$ & Fator 1 & Fator 2 & Fator 3 & Fator 4 & $\begin{array}{c}\text { Produtivi } \\
\text { dade } \\
\mathrm{kg} / \mathrm{ha}\end{array}$ \\
\hline 01 & $\mathrm{SJ} / \mathrm{MG}$ & -1.4286 & 0.2393 & -0.6162 & -1.0378 & 1225 \\
\hline 02 & $\mathrm{SJ} / \mathrm{SP}$ & -2.2335 & -0.4338 & -0.0041 & -0.8570 & 1744 \\
\hline 03 & $\mathrm{SJ} / \mathrm{PR}$ & -1.4832 & 0.1578 & -0.4747 & 0.3344 & 2104 \\
\hline 04 & $\mathrm{SJ} / \mathrm{SC}$ & -0.2945 & -0.7016 & -0.6158 & -0.6365 & 1227 \\
\hline 05 & $\mathrm{SJ} / \mathrm{RS}$ & -1.1048 & 0.4135 & -0.2904 & -0.1265 & 1484 \\
\hline 06 & SJ/MS & -0.8397 & 0.8140 & -1.0159 & 1.5929 & 1379 \\
\hline 07 & $S J / G O$ & -2.2716 & -1.0087 & -0.5585 & -0.8797 & 1233 \\
\hline
\end{tabular}


TABELA 63 - Valor dos fatores e a respectiva produtividade (média aritmética de três anos, 1974, 1975 e 1976) nas unidades da federação em que existe informação para arroz.

\begin{tabular}{|c|c|c|c|c|c|c|}
\hline & $\begin{array}{l}\text { Cultura/ } \\
\text { Estado }\end{array}$ & Fator 1 & Fator 2 & Fator 3 & Fator 4 & $\begin{array}{c}\text { Produtivi } \\
\text { dade } \\
\mathrm{kg} / \mathrm{ha}\end{array}$ \\
\hline 01 & $A R / M G$ & -0.0413 & 0.2704 & -0.1746 & -1.0971 & 1047 \\
\hline 02 & $\mathrm{AR} / \mathrm{SP}$ & -0.7848 & -0.1770 & -0.6087 & 0.1036 & 1204 \\
\hline 03 & $A R / R J$ & -0.8344 & -0.2937 & -0.3573 & 0.9293 & 1657 \\
\hline 04 & AR/ES & 0.2797 & -1.0047 & -0.3898 & -1.2065 & 1380 \\
\hline 05 & $\mathrm{AR} / \mathrm{PR}$ & 0.4634 & -0.2115 & -0.5355 & 0.6985 & 1607 \\
\hline 06 & $\mathrm{AR} / \mathrm{SC}$ & 0.0051 & 0.5706 & 0.0506 & -0.5461 & 2220 \\
\hline 07 & $\mathrm{AR} / \mathrm{RS}$ & -0.7133 & 1.3851 & -0.6977 & -0.0538 & 3490 \\
\hline 08 & $A R / M S$ & -0.3450 & 0.8675 & -1.1486 & 1.2727 & 983 \\
\hline 09 & $\mathrm{AR} / \mathrm{MT}$ & 0.6892 & -0.4978 & -1.1993 & 0.5004 & 1334 \\
\hline 10 & $\mathrm{AR} / \mathrm{GO}$ & 0.0028 & -0.0784 & -1.1836 & 0.2823 & 1009 \\
\hline 11 & AR/MA & 0.5903 & -1.3570 & -0.4059 & 1.7874 & 1405 \\
\hline 12 & $\mathrm{AR} / \mathrm{PI}$ & 0.7091 & -0.8652 & 0.9227 & 0.8474 & 916 \\
\hline 13 & $\mathrm{AR} / \mathrm{SE}$ & $-0: 2 \cdot 347$ & 1.1817 & -0.9812 & 1.1356 & 2224 \\
\hline 14 & $\mathrm{AR} / \mathrm{BA}$ & 0.3326 & -0.5433 & 0.3146 & -0.9777 & 1345 \\
\hline 15 & $\mathrm{AR} / \mathrm{CE}$ & 0.6666 & -0.1637 & 0.7369 & -0.0167 & 1292 \\
\hline
\end{tabular}


TABELA 64 - Valor dos fatores e a respectiva produtividade (média aritmética de três anos, 1974, 1975 e 1976) nas unidades da federação em que existe informação para feijão.

\begin{tabular}{|c|c|c|c|c|c|c|}
\hline & $\begin{array}{l}\text { Cultura/ } \\
\text { Estado }\end{array}$ & Fator 1 & Fätor 2 & Fator 3 & Fator 4 & $\begin{array}{l}\text { Produtivi } \\
\text { dade } \\
\mathrm{kg} / \mathrm{ha}\end{array}$ \\
\hline 01 & $\mathrm{FJ} / \mathrm{MG}$ & 0.8174 & -0.0801 & 0.1181 & -1.6783 & 491 \\
\hline 02 & FJ/SP & -0.1757 & -0.4355 & -0.9131 & -0.1318 & 501 \\
\hline 03 & $\mathrm{FJ} / \mathrm{RJ}$ & 0.2336 & -0.4270 & 0.2131 & 0.1389 & 600 \\
\hline 04 & FJ/ES & 0.2952 & -0.8111 & 0.3621 & -1.3104 & 466 \\
\hline 05 & $\mathrm{FJ} / \mathrm{PR}$ & 0.8828 & -1.1419 & -0.8991 & 0.4825 & 726 \\
\hline 06 & $\mathrm{FJ} / \mathrm{SC}$ & 1.1574 & -0.7099 & -0.5279 & -0.5445 & 759 \\
\hline 07 & $F J / M S$ & 0.5040 & -0.7954 & -0.4679 & 1.2800 & 556 \\
\hline 08 & $\mathrm{FJ} / \mathrm{MT}$ & 1.0192 & -1.2232 & -0.4668 & 0.1641 & 776 \\
\hline 09 & $F J / G O$ & 0.9122 & -0.9723 & -0.8128 & -0.4589 & 494 \\
\hline 10 & $\mathrm{FJ} / \mathrm{MA}$ & 0.8178 & -0.3999 & 0.9340 & 2.2195 & 482 \\
\hline 11 & $\mathrm{FJ} / \mathrm{PI}$ & 0.7737 & -0.2684 & 1.3043 & 1.2715 & 270 \\
\hline 12 & FJ/RN & 0.6157 & 0.3863 & 1.8166 & 0.5824 & 258 \\
\hline 13 & $\mathrm{FJ} / \mathrm{PB}$ & 0.7864 & -0.1097 & 1.3965 & -0.0897 & 256 \\
\hline 14 & $\mathrm{FJ} / \mathrm{PE}$ & 0.7994 & -0.6151 & -0.0870 & -0.0002 & 417 \\
\hline 15 & $\mathrm{FJ} / \mathrm{AL}$ & 1.2497 & -1.0256 & -1.1120 & -0.0989 & 282 \\
\hline 16 & FJ/Ș⿷ & 1.0492 & -0.3871 & 0.1881 & -0.4744 & 287 \\
\hline 17 & FJ/BA & 1.4150 & -0.5010 & -0.1902 & -1.6696 & 504 \\
\hline 18 & FJ/CE & -0.3070 & 0.2772 & 2.1772 & 0.3396 & 258 \\
\hline
\end{tabular}


.209 .

TABELA 65 - Valor dos fatores e a respectiva produtividade (méida aritmética de três anos, 1974, 1975 e 1976) nas unidades da federação em que existe informação para milho.

\begin{tabular}{|c|c|c|c|c|c|c|}
\hline & $\begin{array}{c}\text { Cultura/ } \\
\text { Estado }\end{array}$ & Fator 1 & Fator 2 & Fator 3 & Fator 4 & $\begin{array}{c}\text { Produtivi } \\
\text { dade } \\
\mathrm{kg} / \mathrm{ha}\end{array}$ \\
\hline 01 & $\mathrm{MI} / \mathrm{MG}$ & -1.0188 & -0.4433 & 1.1919 & -1.5027 & 1542 \\
\hline 02 & $\mathrm{MI} / \mathrm{SP}$ & -1.3539 & -0.1982 & 0.0621 & -0.4274 & 2038 \\
\hline 03 & $\mathrm{MI} / \mathrm{RJ}$ & -0.3308 & -0.4080 & 0.9458 & 0.4597 & 1012 \\
\hline 04 & MII/ES & -1.1654 & -1.0833 & 1.6704 & -1.1307 & 1053 \\
\hline 05 & $\mathrm{MI} / \mathrm{PR}$ & -0.2368 & -1.0344 & 0.3418 & 0.4574 & 1957 \\
\hline 06 & $\mathrm{MI} / \mathrm{SC}$ & -1.1714 & -0.6032 & 2.4830 & -0.7920 & 2349 \\
\hline 07 & $M I / R^{S} S^{S}$ & -1.0877 & -0.4404 & 2.9729 & -0.4071 & 1522 \\
\hline 08 & $\mathrm{MI} / \mathrm{MS}$ & 0.5151 & 0.0845 & 0.6289 & 0.7880 & 1354 \\
\hline 09 & $\mathrm{MI} / \mathrm{MT}$ & 0.7844 & -0.4521 & 0.9728 & 0.5782 & 1550 \\
\hline 10 & $\mathrm{MI} / \mathrm{GO}$ & -0.7765 & -0.1019 & -0.1663 & 0.1994 & 1880 \\
\hline 11 & $\mathrm{MI} / \mathrm{MA}$ & 0.7543 & -0.7184 & 0.6364 & 1.8286 & 589 \\
\hline 12 & $\mathrm{MI} / \mathrm{PI}$ & 0.8848 & -0.6892 & 1.2516 & 0.8321 & 530 \\
\hline 13 & $\mathrm{MI} / \mathrm{RN}$ & 0.7608 & 0.2936 & 1.2532 & 0.5449 & 368 \\
\hline 14 & $M I / P B$ & 0.9454 & -0.0357 & 1.3004 & -0.2658 & 520 \\
\hline 15 & $\mathrm{MI} / \mathrm{PE}$ & 0.6669 & -0.8350 & -0.0138 & -0.0127 & 687 \\
\hline 16 & $\mathrm{MI} / \mathrm{AL}$ & 1.3097 & -0.8771 & -0.6880 & -0.0600 & 455 \\
\hline 17 & $\mathrm{MI} / \mathrm{SE}$ & 1.2364 & -0.5010 & -0.5375 & -0.2728 & 650 \\
\hline 18 & $\mathrm{MI} / \mathrm{BA}$ & 1.5632 & -0.4471 & -0.2960 & 1.6232 & 778 \\
\hline 19 & $\mathrm{MI} / \mathrm{CE}$ & 0.6284 & -0.1869 & 1.2247 & 0.4650 & 482 \\
\hline
\end{tabular}

